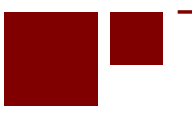

C E N T E R for RETIREMENT RE S E A R C H at BOSTON COLLEGE

\title{
AN EXPERIMENTAL ANALYSIS OF MODIFICATIONS TO THE SURVIVOR BENEFIT INFORMATION WITHIN THE SOCIAL SECURITY STATEMENT
}

\author{
Jeffrey Diebold and Susan Camilleri
}

CRR WP 2017-5

May 2017

\author{
Center for Retirement Research at Boston College \\ Hovey House \\ 140 Commonwealth Avenue \\ Chestnut Hill, MA 02467 \\ Tel: 617-552-1762 Fax: 617-552-0191 \\ http://crr.bc.edu
}

Both authors are with North Carolina State University. Jeffrey Diebold is an assistant professor of public policy in the department of public administration. Susan Camilleri is a Ph.D.

candidate in public administration in the school of public and international affairs. The research reported herein was pursuant to a grant from the U.S. Social Security Administration (SSA) funded as part of the Retirement Research Consortium. The findings and conclusions expressed are solely those of the authors and do not represent the views of SSA, any agency of the federal government, North Carolina State University, or Boston College. Neither the United States Government nor any agency thereof, nor any of their employees, makes any warranty, express or implied, or assumes any legal liability or responsibility for the accuracy, completeness, or usefulness of the contents of this report. Reference herein to any specific commercial product, process or service by trade name, trademark, manufacturer, or otherwise does not necessarily constitute or imply endorsement, recommendation or favoring by the United States Government or any agency thereof.

(C) 2017, Jeffrey Diebold and Susan Camilleri. All rights reserved. Short sections of text, not to exceed two paragraphs, may be quoted without explicit permission provided that full credit, including (C) notice, is given to the source. 


\title{
About the Steven H. Sandell Grant Program
}

This paper received funding from the Steven H. Sandell Grant Program for Junior Scholars in Retirement Research. Established in 1999, the Sandell program's purpose is to promote research on retirement issues by scholars in a wide variety of disciplines, including actuarial science, demography, economics, finance, gerontology, political science, psychology, public administration, public policy, sociology, social work, and statistics. The program is funded through a grant from the Social Security Administration (SSA). For more information on the Sandell program, please visit our website at: http://crr.bc.edu/?p=9570, send e-mail to crr@bc.edu, or call (617) 552-1762.

\section{About the Center for Retirement Research}

The Center for Retirement Research at Boston College, part of a consortium that includes parallel centers at the University of Michigan and the National Bureau of Economic Research, was established in 1998 through a grant from the Social Security Administration. The Center's mission is to produce first-class research and forge a strong link between the academic community and decision-makers in the public and private sectors around an issue of critical importance to the nation's future. To achieve this mission, the Center sponsors a wide variety of research projects, transmits new findings to a broad audience, trains new scholars, and broadens access to valuable data sources.

\author{
Center for Retirement Research at Boston College \\ Hovey House \\ 140 Commonwealth Ave \\ Chestnut Hill, MA 02467 \\ Tel: 617-552-1762 Fax: 617-552-0191 \\ http://crr.bc.edu
}

Affiliated Institutions:

The Brookings Institution

Syracuse University

Urban Institute 


\begin{abstract}
This paper examines the effect of modifications to the survivor benefit information in the Social Security Statement on the benefit knowledge and the expected claiming behavior of married men using an experimental survey of workers from the RAND American Life Panel (ALP). Critical components of this analysis include modifications to the survivor benefit information in the Statement's benefit table and a "special insert" that explains the survivor benefit provisions. The key limitations of this study include the limited generalizability of the results due to the sampling frame (i.e., men) and the self-selection of ALP panel members into the study. Second, a worker's claiming decision is likely the result of a more complicated decision-making process than was allowed for in this experiment. Our study assumes, for example, that married workers evaluate their benefit information and make a decision about when to claim independent of input from their spouse. While the occurrence and scope of such deliberations will vary by household, given the financial implications of this decision for each spouse, the assumption that married workers make this decision unilaterally is somewhat tenuous.
\end{abstract}

The paper found that:

- Providing individuals with comprehensive and complex survivor benefit information improved their awareness and understanding of these provisions.

- When workers are compelled to consider the effect that their claim age has on their survivor benefit, they appear to incorporate this into deciding when to claim. Each modification increased the expected claim ages of respondents by roughly one year relative to the control.

- While it is possible to foster a deeper understanding of the complex interaction among survivor benefit provisions through an informational insert, this level of comprehension does not appear necessary to induce prosocial claiming behavior. Instead, it was sufficient for respondents to merely see that their spouse would receive a lower survivor benefit at lower claim ages.

- The fade-out of the effects of the modifications considered in this analysis was rapid. 
The policy implications of the findings are:

- Respondents in this study were not well informed about the survivor benefit, suggesting that more detailed information may help married workers prepare financially for retirement and the transition into widowhood.

- The finding that workers exposed to survivor benefit information were more likely to adjust their expected claim age suggests that they may not have already factored this information into their expectations and that it has value.

- The rapid fade-out of the improvements in benefit knowledge and expected claiming behavior evident in this study has important practical implications and suggests that workers may benefit most if online information and mailed paper statements were treated as complements as opposed to substitutes. 


\section{Introduction}

Social Security benefits are the largest financial asset for the majority of U.S. households and have long been the largest source of income for elderly households (Poterba, Venti, and Wise, 2013; Social Security Administration, 2016a). This makes the choice about when to claim Social Security benefits one of the most important decisions that retiring workers must make. Not only does this decision help determine the amount of the monthly retirement benefit a worker will receive from Social Security for the rest of their lives, but it can also determine the amount of the "auxiliary benefits” the worker’s spouse is entitled to receive based on the worker's earnings history. For these reasons, the Social Security Statement-a paper document that the Social Security Administration (SSA) periodically mails to workers to explain their benefits to them-is one of, if not the most, important financial documents most workers will receive during their working lives. The central components of this document detail the worker's earnings history and calculate the retirement benefits he or she can expect to receive if claimed at age 62, at the worker's full retirement age (FRA), or at age 70. The Statement also specifies the amounts of the auxiliary benefits the worker's spouse is projected to receive based on the worker's earnings history. However, it communicates considerably less information about these particular benefits to workers. For example, it does not fully explain whether and to what extent the auxiliary benefit amounts are affected by when the worker decides to claim, even though early claiming penalties applied to these benefits can have a significant effect on the total lifetime benefits married couples can expect to receive from Social Security (Sass, Sun, and Webb, 2007).

The absence of detailed auxiliary benefit information is perhaps most notable for the “widow(er)," or "survivor," benefit, which is the most substantial of these benefits in terms of the number of beneficiaries (7.5 million), nearly all of whom are women, and the level of expenditures on both a total and a per-capita basis (Social Security Administration, 2016b). Survivor benefits are paid to the lower-earning surviving spouses of deceased workers who received, or were eligible to receive, a retirement benefit. Like the retirement benefit, the earlier a worker claims between age 62 and age 70, the lower the monthly survivor benefit amount that the worker's spouse can expect to receive in widowhood. In fact, any reduction in the retirement benefit incurred by the worker for claiming before age 70 applies in equal measure to the 
survivor benefit his spouse is entitled to receive in the event of his death. ${ }^{1}$ The results from empirical studies suggest that the provision linking the worker's claim age to his spouse's survivor benefit has important implications for the financial well-being of elderly women in widowhood. Early claiming by the primary earning spouse is associated with a significant reduction in Social Security income in widowhood and a significant increase in the likelihood that his spouse will enter poverty in widowhood (Diebold, Moulton, and Scott, 2016; Sass, Sun, and Webb, 2007).

Most men claim their benefits before their full retirement age - the age when workers become entitled to receive 100 percent of their primary insurance amount —and almost all claim before age 70, when both retirement and survivor benefit amounts are maximized (Johnson, Smith, and Haaga, 2013). As a result, these men receive a reduced retirement benefit, and their spouses can expect to receive a reduced survivor benefit. It is possible that many of these men are not fully aware that the timing of their claiming decision helps determine their spouse's survivor benefit amount or, if they are aware, it may not be a salient consideration for them as they decide when to start receiving their retirement benefit. One plausible explanation for either of these possibilities is that, unlike the retirement benefit, information about the determinants of the survivor benefit are not clearly articulated within the Statement. This is important because the Statement is the primary source of information that workers use, and prefer to use, to learn about their benefits (Greenwald et al., 2010). Empirical studies consistently demonstrate that this document improves workers' knowledge of their retirement benefit, although they vary in terms of the scope and scale of the observed improvements in these outcomes (Mastrobuoni, 2011; Biggs, 2010; Sass, 2015). The results from these studies indicate that the Statement is likely responsible, at least in part, for the near universal understanding among workers that early claiming will result in lower retirement benefit amounts (Brown and Perron, 2011). The Statement emphasizes this particular provision through detailed explanations and by empirically demonstrating its implications for the projected benefit amounts for the worker and for a stylized worker at different claim ages. These efforts are intended to foster awareness about this provision and signal its importance to workers as they consider when to start receiving their

\footnotetext{
${ }^{1}$ The SSA pays survivor benefits to the lower-earning spouse in a married household in the event of the death of the higher-earning spouse, regardless of sex. However, to simplify the discussion of these benefits, we will refer to the higher-earning spouse as men and the lower-earning spouse as women.
} 
benefits. By comparison, the Statement devotes little attention and resources to promote workers' understanding of the survivor benefit provisions. Accordingly, studies show that a relatively smaller, but still remarkably high, proportion of workers are aware that their claim age can affect their spouse’s survivor benefit amount (Brown and Perron, 2011; Perron, 2015). However, the arguments and results presented here suggest that workers' knowledge about this particular survivor benefit provision is likely lower than previously reported and it is almost nonexistent for other important survivor benefit provisions relevant to the claiming decisions of married workers. ${ }^{2}$

As the Social Security Advisory Board (2009) noted in its review of the Statement, this document needs to include the information that workers need to know to make informed decisions. Yet, the omission of detailed information about the survivor benefit from the Statement may contribute to the asymmetries in workers' knowledge about the benefits they and their spouse will likely depend upon during the financial dislocations associated with late-life transitions into retirement and widowhood. By clearly articulating the survivor benefit provisions to workers through modifications to the Statement, the SSA may be able to improve workers' financial planning, signal the importance of this information to their claiming decision, and promote the financial security of survivor benefit beneficiaries in widowhood.

Due to the complex structure of the survivor benefit, however, there are unique challenges associated with this task. The SSA must balance the need to provide workers with relevant and complete information about their benefits with the need to avoid overburdening them with excessive details. The present study uses a randomized experimental design to analyze the effect of two modifications to the survivor benefit information within the Social Security Statement on benefit knowledge and expected claiming behavior, which, to date, has yet to be explored. Both modifications are modeled after the most prominent approaches the SSA currently uses to communicate benefit eligibility and expected benefit amounts to workers, which vary in terms of their scope of content: (1) benefit projections adjusted by claim age in the

\footnotetext{
${ }^{2}$ One such provision concerns the effect of any retirement benefit amount the lower-earning surviving spouse is entitled to receive based on her own earnings history. Her own retirement benefit amount offsets the amount of any survivor benefit she will receive. Thus, her survivor benefit amount is only equal to the difference in the amount of her own retirement benefit and that of her higher-earning, now deceased, spouse. As a result, the claim age of her higher-earning spouse has a steadily diminishing effect on her survivor benefit amount as their earnings histories approach parity.
} 
Statement's benefit table and (2) a special, age-targeted "insert" that the SSA mails to workers along with the Statement.

We find that the insert approach was more successful at fostering a deeper understanding of the complex interaction of the network of survivor benefit provisions. However, we also find this level of comprehension does not appear necessary to promote prosocial claiming behavior among workers. Instead, it is merely sufficient for workers to see how their claim age affects their spouse's survivor benefit amount after it has been adjusted to account for other, more esoteric, survivor benefit provisions. Thus, with only small adjustments to the information within the Statement, the SSA can make the effect of the worker's claim age on the survivor benefit more salient among the mix of considerations that workers factor into their claiming decision. However, the fade-out of the effect of both modifications on almost all of the outcomes considered in this analysis was rapid. The observed effects, along with their rate of decay, have important implications for the policies and practices the SSA employs to educate workers about Social Security benefits.

\section{Background}

The SSA initiated the annual mailing of Statements to workers in selected age groups in 1995 (Smith and Couch, 2014a). Prior to 1995, individuals could access earnings and benefits information by requesting it from the SSA. Since the development of the Statement, the SSA has made several changes to its appearance, content, and mailing schedule (Smith and Couch, 2014a). Currently, the Statement is mailed to workers aged 25, 30, 35, 40, 45, 50, 55, and 60 or older who have not applied for online access to their benefit information through the SSA's website. The purpose of this document is to improve the public's understanding of the provisions of the Social Security system. To this end, the Social Security Advisory Board-the independent federal agency established by Congress in 1994 to advise the President, the Congress, and the SSA on matters related to the Social Security program—considers improvements to the content and design of the Statement to be "one of the highest priorities of the [SSA]" (Social Security Advisory Board, 2009).

With exception of the introductory passage on the first page of the Statement, the format and content of the main body of the document are the same for all workers (see Appendix C). The introductory passage of the document varies slightly depending on the worker's age. The 
passages provided to younger and middle-age workers list the benefits that workers and their families are entitled to receive based on the worker's earnings history. They also emphasize the need for workers to supplement their Social Security benefits with other forms of retirement saving. In addition to this information, older workers nearing retirement receive information about online tools that they may use to estimate, apply for, and manage their benefits. Regardless of their age or current eligibility status, the SSA provides workers with a "benefit table" that contains individual-specific estimates of the benefit amounts that they project the worker and the worker's family will be entitled to receive from Social Security based on the worker's earnings history. The SSA then provides a brief explanation of the formula they use to calculate the amounts displayed in the table. This formula incorporates the history of the worker's annual earnings, which are displayed, by year, in a table on the following page along with the Social Security and Medicare taxes paid by the worker.

The content of the Statement emphasizes the importance of the worker's claim age to the monthly retirement benefit amount he can expect to receive from the SSA. From a retirement planning perspective, this information is critical because it helps establish the level of the income floor that Social Security provides. The specific implications of this provision are most clearly demonstrated in the benefit table displayed on the second page of the document. This table prominently displays the projected monthly amounts the worker will be entitled to receive if the benefit is claimed at age 62, the worker's FRA, or age 70. The corresponding amounts signal to workers that the longer they postpone their claiming decision past age 62, the larger their monthly benefit amount will be. The Statement then elaborates more explicitly on this key provision in the following passage, which, unfortunately, may confuse more than it clarifies, as it conflates the worker's retirement decision with their Social Security claiming decision, which are not necessarily mutually inclusive events:

"Some people retire before their full retirement age. You can retire as early as 62 and take benefits at a reduced rate. If you work after your full retirement age, you can receive higher benefits because of additional earnings and credits for delayed retirement."3

\footnotetext{
${ }^{3}$ A worker can retire while continuing to postpone claiming their Social Security retirement benefit, thereby increasing the monthly amount they are entitled to receive. Alternatively, a worker age 62 or older can choose to claim their benefit before they retire, though, depending on their age and earnings, the benefits they receive may be subject to the Social Security retirement earnings test.
} 
Finally, to reinforce the Statement's explanation of this provision to workers, in 2000, the SSA began supplementing the claim age information in the benefit table with a special "insert" titled, “Thinking of retiring?” to accompany the Statements mailed to workers age 55 or older (Smith and Couch, 2014a). The insert describes the claim age provision in considerable detail and includes examples and text that are less open to misinterpretation. Unlike the benefit table, the information provided to workers in the insert is conceptual and generic. It provides an overview of the retirement benefit provisions as they apply to all workers without regard to their individual-specific circumstances or earnings histories. The insert reports the specific numerical adjustment - expressed as a percent — that the SSA will make to the worker's benefit amount at each year of age between 62 and 70, which may help explain age-adjusted amounts included in the Statement's benefit table to the worker. The insert also demonstrates the implications of the claim age provisions of the Social Security retirement benefit in practice using a hypothetical worker who is entitled to receive a $\$ 1,000$ retirement benefit at age 66 . No individual-specific information pertaining to the worker's earnings history or benefit amounts are included in the insert. Workers must deduce and empirically apply this information to their own circumstances. Of course, the worker's claim age affects the auxiliary benefits that the worker's family is entitled to receive as well, most notably the amount of the survivor benefit the worker's spouse is entitled to receive in widowhood. However, this claim age provision receives considerably less attention in both the benefit table and special insert. The benefit table includes an estimate of the survivor benefit amount along with the amounts of the other auxiliary benefits that the worker's family and survivors are entitled to receive based on the worker's earnings history, but it does not indicate whether or to what extent this amount varies according to the worker's claim age. Nor is this amount adjusted by any Social Security retirement benefit that the worker's spouse is expected to receive based on her own earnings history. Instead, the table only reports an estimate of what the survivor benefit will be if the worker claims his own retirement benefit at his FRA. The text of the Statement merely mentions that this benefit exists.

The insert establishes the existence of the survivor benefit as well, but also notes that the amount of this benefit will depend on the worker's claim age. The full passage is as follows:

"If you are married and die before your spouse, he or she may be eligible for a benefit based on your work record. If you start benefits before your full retirement age, we cannot pay your surviving spouse a full benefit from your 
record. Also, if you wait until after your full retirement age to begin benefits, the surviving spouse benefits based on your record will be higher."

This statement is accurate, though it is far from complete. Most importantly, it fails to explain the survivor benefit formula used by the SSA to determine the eligibility of surviving spouses for this benefit as well as the amount they are entitled to receive. Workers need this information to understand whether and to what extent their claim age will actually affect their spouse's survivor benefit amount. Survivor benefits are structured such that only lower-earning spouses are entitled to receive a survivor benefit based on their deceased spouse's earnings record. This eligibility restriction is the result of the survivor benefit formula which entitles surviving spouses to a benefit equal only to the difference in the retirement benefits earned by each spouse. ${ }^{4}$ As a result, the importance of the worker's claim age is a function of the relative spousal earnings histories. At one extreme, the worker's claim age has a large effect on the survivor benefit amount when the worker has a longer history of higher earnings compared his spouse and is, therefore, entitled to receive a relatively larger retirement benefit. At the other extreme, the effect of the worker's claim age ranges from negligible to non-existent for a worker in a two-earner household whose spouse has a comparable history of earnings wherein each spouse is entitled to similarly sized retirement benefit amounts. The nuances are important for workers to understand if they want to choose a claim age that maximizes the monthly and lifetime benefit amount that they and their spouse can expect to receive from Social Security.

\section{Literature Review}

\section{What Do People Know?}

Workers tend to be quite knowledgeable about the information pertaining to their own retirement benefit emphasized in the Statement. Brown and Perron (2011) examined the knowledge of specific aspects of Social Security benefit knowledge among a nationally representative sample of workers age 55 to 66 . The authors found that the majority of

\footnotetext{
${ }^{4}$ Consider a worker who receives a $\$ 2,000$ monthly retirement benefit from Social Security and whose spouse is not entitled to receive a retirement benefit based on her own earnings history. In the event of the worker's death, his spouse will receive a survivor benefit of $\$ 2,000$, the full amount of the retirement benefit paid to the worker before his death. Now suppose that the worker again receives a $\$ 2,000$ monthly retirement benefit but that his spouse is entitled to receive a $\$ 1,300$ retirement benefit based on her own earnings history. In the event of the worker's death, his spouse will again receive $\$ 2,000$ from Social Security, but only $\$ 700$ of this amount will be based on his earnings history. Thus, the longer he postpones his own claiming decision, the higher the "cap" on the total amount his spouse can receive in widowhood, based on his earnings history.
} 
respondents were aware of the effect of their claim age on the amount of their monthly Social Security retirement benefit, with 95 percent correctly reporting that delaying claiming from age 62 to 66 results in higher benefits. Comparably high levels of knowledge about this particular provision were evident in related studies by Liebman and Luttmer (2012) and Perron (2015). Workers, however, appeared to be less aware of how long they must postpone their claiming decision after age 62 to receive the highest possible monthly retirement benefit amount. Only 30 percent of respondents in the study by Brown and Perron (2011) correctly reported age 70 as the benefit maximizing claim age.

By comparison, workers appear to be somewhat less knowledgeable about the survivor benefit. Brown and Perron (2011) found that 78 percent of workers correctly stated that a worker's claim age can affect the survivor benefit amount the worker's spouse is eligible to receive. However, they also found that only 18 percent of these workers correctly identified age 70 as the age that maximizes the monthly survivor benefit amount. This last finding is consistent with survey results from Greenwald et al. (2010), who found that only about 20 percent of married individuals report being “very knowledgeable” about how their own or their spouse's claim age affects their own or their spouse's benefits. According to survey results from Liebman and Luttmer (2012), roughly 66 percent of higher-earning and lower-earning spouses in married households correctly indicated whether the amount they receive from Social Security would increase, decrease, or remain the same in the event of their spouse's death. The authors interpreted this result as evidence of "widespread awareness” of the survivor benefit rules, though one in three do not appear to understand whether or to what extent their claim age will affect their spouse's survivor benefit or vice versa. Equally important, it is not clear from their results whether workers understand the magnitude, in addition to the direction, of any changes in the amount they or their spouse can expect to receive in widowhood. From a financial planning perspective, it is critical to understand both. For example, a lower-earning spouse may correctly understand that the amount she can expect to receive from Social Security will increase in widowhood, but she may incorrectly assume that this increase is equal to the combination of the full amount of her own and her deceased spouse's retirement benefit, rather than an amount capped at the larger of the two. In this example, the lower-earning spouse is expecting to have much more financial protection from Social Security in widowhood than the program will provide. It is also not clear whether workers understand that their claim age reduces their 
retirement benefit and their eligible spouse's survivor benefit by corresponding and equivalent amounts. Thus, it is not clear whether workers possess more than a vague sense of the relevance of their claim age for the survivor benefit they may leave to their spouse.

One possible explanation for the apparent gap between workers' knowledge about the retirement and the survivor benefit provisions is that the Statement, understandably, prioritizes information about the provisions pertaining to the former and, less understandably, provides very little information about the latter. Decisions concerning the content of the Statement are central to workers' benefit knowledge because this document is the primary resource that workers access to learn about their benefits, despite the growing number of similar resources the SSA makes available to them through the Internet (Greenwald et al., 2010). The paper Statement is also the preferred method of communication for workers. In an analysis of adults age 18 and over, Greenwald et al. (2010) found that 89 percent of respondents agreed that providing information through the mail is the best way for the SSA to disseminate educational materials. Only 15 percent of respondents in their sample reported that they had recently visited the SSA's website, but almost 70 percent reported that they had recently received a Statement. Of those who remembered receiving a Statement, 83 percent reported that they read the Statement carefully and 85 percent reported that it improved their understanding of their own benefits. The insert was only slightly more successful at improving workers' knowledge of their benefits (90 percent). In a related study, Perron (2012) found that if forced to choose between receiving a Statement by mail or on the Internet, 75 percent reported that they would choose to receive the documents in paper format only. Even younger respondents (age 25 to age 49) preferred the paper Statement by a sizable majority (66 percent).

Workers may prefer the paper Statement for good reason. Empirical studies generally confirm that the Statement has improved workers' knowledge of the retirement benefit provisions (Sass, 2015). Interestingly, the magnitude of these improvements is a function of the conspicuousness of this information within the document (Smith and Couch, 2014b). Several of these studies focus on the retirement benefit provisions and demonstrate that the Statement is responsible for improving the level of knowledge among workers about the monthly retirement benefit amount they can expect to receive as well as about the provisions that determine the amount of this particular benefit. Mastrobuoni (2011) used the staggered introduction of the Statement beginning in 1995 to analyze the effect of the Statement on workers' knowledge of the 
amount of the retirement benefits they can expect to receive. He found that the Statement reduced the share of workers unable to provide an estimate of their expected benefit amount and improved the accuracy of the estimates provided. In a similar study using self-reported rather than administrative data, Biggs (2010) found that, while the initial distribution of the Statement did not result in an immediate increase in knowledge of retirement benefit levels, the continued receipt of this document over many years appears to have reduced errors in predicting benefits. Smith and Couch (2014b) also used the staggered introduction of the Statement to analyze its effect on Social Security benefit knowledge among younger workers. To do so, they compared correct responses to questions about the program from younger workers in 1998, who had never received a Statement, to those from younger workers in 2001, who had received a Statement. They found that the receipt of a Statement was associated with a better understanding of the program and how the SSA determines their benefit amounts. Importantly, the authors found that the increase in benefit knowledge associated with Statement receipt was largest for those provisions of the program featured more prominently within the body of the Statement. Taken together, the results from these studies suggest workers may better understand survivor benefit rules if this information were clearly and more prominently displayed within the Statement.

\section{Why Does It Matter?}

Whether and to what extent modifications to the Statement can improve workers' knowledge of survivor benefit provisions and make this information more salient among the considerations that workers take into account when deciding at what age to claim their own retirement benefit, can have important implications for the well-being of surviving spouses, particularly women. Shortly after the onset of widowhood, elderly women tend to experience a significant decline in both their income and income-to-needs ratio (Karamcheva and Munnell, 2007; Sevak, Weir, and Willis, 2005; Zick and Holden, 2000). Gillen and Kim (2009) estimate that the household income of older women entering widowhood declines by 41 percent, placing these women at a greater risk of entering poverty. The survivor benefit is instrumental in helping offset this loss of income and keeping widows out of poverty. Following the death of their spouse, Social Security payments become the most important source of income for widows and, for a vast majority, the survivor benefit will account for some or all of the amount of the payment they receive (Social Security Administration, 2016a). As a result, the generosity of the 
survivor benefit payment is strongly associated with the widow's risk of entering poverty following the death of her spouse. Weaver (2010) found that poverty rates among elderly widows declined substantially in the years after Congress increased the amount of the survivor benefit from 75 percent of the value of the deceased worker's retirement benefit to 100 percent in 1972.

Despite these improvements, the level of financial security the survivor benefit provides to eligible widows is still subject to the provision indirectly linking the amount they will receive to the claim age of their deceased spouse. Known, as the “widow(er)'s limit," this provision stipulates that a widow(er)'s total Social Security income may not exceed the amount of the benefit the primary earner would receive if he (or she) was still alive, regardless of their own retirement benefit. If the primary earner claims his retirement benefit early, he reduces the amount he is entitled to receive and, consequently, the amount of the survivor benefit his spouse will receive in the event of his death. The earlier he claims his own retirement benefit before age 70 , the larger the reduction in the survivor benefit. By claiming at age 62 as opposed to age 70 , he can reduce the amount of the survivor benefit by as much as 40 percent.

The evidence from empirical studies indicate that early claiming by men diminishes the effectiveness of the survivor benefit as an income maintenance mechanism for their widowed spouses. Diebold, Moulton, and Scott (2016) found that the annual income a widow receives from Social Security is about $\$ 650$ less for each year that her husband claimed before age 70 . Extrapolating from these results, by claiming at age 62 as opposed to age 70, a worker reduces his spouse’s annual income in widowhood by $\$ 5,200$, a substantial sum considering that 42 percent of widows live in or near poverty (Social Security Administration, 2016c). The authors also found that delayed claiming by the widow's husband significantly reduced her risk of entering poverty in widowhood and that these reductions are most dramatic for those widows who are most dependent on Social Security and the survivor benefit for their income. Their results are consistent with an analysis by Sass, Sun, and Webb (2007) that projected that the reduction in survivor benefit income that results from early claiming by husbands is sufficiently large to move 13 percent of widows into poverty and 23 percent into near poverty, assuming that these widows had little or no income from other sources. Both studies conclude that the Social Security Statement should be modified to specifically outline the effect of claim ages on the amount of the survivor benefit. These recommendations are consistent with those of the Social 
Security Advisory Board to provide "personalized information...and summaries of things that people need to know to make informed decisions” (Social Security Advisory Board, 2009).

\section{What Should These Changes Look Like?}

It is not immediately clear, however, how to most effectively expand and emphasize information about the survivor benefit provisions within the Statement. Provisions like the “widow(er)'s limit" are complex and there is a clear tension between the need to provide workers with relevant and complete benefit information and the need to avoid overwhelming them with extraneous detail. Indeed, research shows that additional information improves the quality of decision-making up to a certain point, beyond which additional information is no longer absorbed or integrated, but, rather, contributes to a heightened sense of being overwhelmed, confused, or stressed (Eppler and Mengis, 2004). Once the available information exceeds an individual's processing capacity, its marginal effect on their decision-making process is no longer positive and may even be negative.

Adding to the difficulty of striking the balance between sufficient and excess benefit information is the fact that a substantial share of the American population cannot perform basic economic calculations and lacks an understanding of simple financial concepts (Lusardi and Mitchell, 2007; Lusardi, 2008; Lusardi, Mitchell, and Curto, 2009; Kimball and Shumway, 2010). Moreover, many people are unable to correctly identify optimal financial behaviors or fully comprehend the consequences of certain financial decisions (Hilgert, Hogarth, and Beverly, 2003). On the one hand, this implies that the threshold for what some consider burdensome may be well short of even the most basic descriptions of how survivor benefits are determined. On the other hand, research on "information overload" and the most effective ways to communicate complex retirement benefit information to workers is limited (Fleishman-Mayer et al., 2013). One such study by Agnew and Szykman (2005) analyzed the effect of simplifying complex financial information about investment choices on the quality of investment decisions. In contrast with their expectations, they found that more comprehensive financial information actually improved the investment decisions of less financially sophisticated individuals.

One possible solution is for the SSA to adapt the instruments it already uses to explain the effect that the worker's claim age has on their retirement benefit amount-through early claiming penalties and the delayed retirement credit—within the Statement to the survivor 
benefit provisions. Perhaps the simplest approach is to provide estimates of the survivor benefit amount at each claim age within the benefit table. A more comprehensive and rigorous, but less personalized and more costly, approach would be to develop a special insert that describes the survivor benefit provisions in detail. The relative impact of each approach on benefit knowledge and claiming behavior is not clear, though they may depend importantly on both the amount of information provided to workers as well as on the manner in which it is presented. In essence, the relative effect of these modifications may depend on whether individuals are more sensitive to an understanding of a provision when the consequences of that provision are not immediately clear or to an understanding of the consequences of a provision when the provision itself is not clear. Such distinctions are important from a theoretical and practical standpoint to the SSA and other organizations that need to provide all of the information their constituents need to make informed decisions without providing needlessly complex information that may negatively affect their decision-making process.

\section{How Long Do Any Improvements Last?}

The periodic distribution of the Social Security Statement raises important practical questions about the fade-out of any effect the information in this document may have on benefit knowledge and expected claiming behavior. Over time, fewer workers will remember the benefit information they read. However, according to the online model of information processing, it is possible for any immediate effect of this information on their expected claim age to endure even while they no longer remember the information that prompted the adjustment to their expectations. In this context, the model posits that individuals will update their claiming preferences based on the new information provided to them and, once integrated, the information contributing to the adjusted claiming preference can be forgotten while the effect of that information remains. In essence, the effect of new information on an individual's preferences is thought to be more stable than his or her recollection of the specific information that contributed to the stated preference. Political scientists have employed this model to understand the effect of campaign information on voter preferences (Gerber et al., 2011; Lodge, Steenbergen, and Brau, 1995). In this study, it is possible that the longevity of any adjustment in claiming preferences associated with a modification to the survivor benefit information within the Statement is a function of the scope and scale of that modification. It is possible, for example, that more 
comprehensive information, like that provided in the insert, leads to more deliberative decisionmaking and therefore, more durable attachments to newly established preferences.

\section{Analysis}

This analysis will test whether modifications to the Social Security Statement can improve workers' knowledge about the survivor benefit provisions and influence their expected claim ages. To do this, we developed two approaches for explaining survivor benefits to workers whose spouses can expect to receive a survivor benefit. Both approaches are consistent with those employed by the SSA to inform workers about the retirement benefit provisions. The first, the Modified Table, simply adds projected survivor benefit amounts that the worker's spouse can expect to receive in widowhood if the worker claims at age 62, age 66, and age 70 to the benefit table in the Statement, beneath the corresponding projections of the worker's retirement benefit amounts. The second, the Insert, is modeled after the "Thinking of Retiring" informational retirement benefit insert that the SSA sends to workers. Like this document, we provide generic information about the survivor benefit provisions along with examples that demonstrate how they function using hypothetical benefit information for married couples.

We are interested in whether these modifications can improve workers' knowledge of the survivor benefit provisions. Because it is more comprehensive and explicit, we expect the Insert to be the more effective of the two approaches at promoting knowledge about the specific provisions of the survivor benefit due to the comprehensiveness of the information that this vehicle allows. We expect the Modified Table, by contrast, to have a smaller, more limited effect on workers' survivor benefit knowledge because the modification simply shows workers the value of the survivor benefit available to their spouses when the worker claims their own benefit at different ages, leaving it to them to intuit that their claim age affects the amount of the benefit. It does not explain how the spouse's own earnings history factors into the amounts displayed in the table. Specifically, we expect that workers who receive the Insert will be more likely to know the following: that their claim age has an effect on the amount of the survivor benefit their spouse can expect to receive, that their spouse will receive the largest benefit if the worker claims at age 70, and that the survivor benefit they leave to their spouse is equal to the difference between the amount of their retirement benefit and the amount of their spouse's own retirement benefit. 
We are also interested in whether these modifications to the Statement influence workers' expected claim ages. Any such effect may also vary by modification type but, a priori, it is not obvious which modification will yield the largest increase. On the one hand, if the Insert is most effective at improving survivor benefit knowledge as expected, then it may also lead to later expected claim ages, as workers assigned to this modification may better understand the impact that their claim age has on their spouse's monthly survivor benefit amount. On the other hand, unlike the Modified Table, it does not convey the specific survivor benefit information to the worker like the amount the worker's spouse can expect to receive when the worker claims at a given age. Instead, workers must determine whether and how these amounts change depending on when they claim for themselves by combining the complex, depersonalized information contained within the Insert. Due to the computational complexity of this task, it is possible that the implications of expected claiming decisions for survivor benefit amounts are more effective when these calculations are performed for them and the results are displayed prominently within the benefit table. In other words, information on the practical implications of the survivor benefit provisions are easier to evaluate in the Modified Table and, therefore, this modification may be more useful to workers.

\section{Survey}

To examine these issues, we administered an experimental survey to a group of married men who have at least 5 years of covered employment. ${ }^{5}$ We informed all respondents that the survey concerned their understanding of the benefits provided through the Social Security system. Then, we randomly assigned these men to one of the following four conditions: the Default Table, the Modified Table, the Insert, and the combination of the Modified Table and the Insert. Each condition provided the respondents with benefit projections and benefit information that varied in terms of form and content depending on their treatment assignment. Using the same basic formula constructed by Brown, Kapteyn, and Mitchell (2016), we generated projections of the retirement and survivor benefit amounts that the respondents and their spouses can expect to receive, respectively, based on the earnings history of each, as reported by the

\footnotetext{
${ }^{5}$ Covered employment refers to employment in a position that reports wage or salary information to the SSA for the purpose of determining the worker's eligibility for Social Security benefits and the amount of those benefits.
} 
respondent. These projections were then included in the benefit information we presented to respondents assigned to conditions viewing the Modified Table.

Respondents assigned to the control condition viewed the benefit information in the Default Table in Figure 1, which is identical in form and content to that of the Social Security Statement currently distributed by the SSA.

Respondents assigned to the Modified Table condition viewed the benefit table in Figure 2, which is identical to the Default Table except that it also details the respondent-specific estimates of the survivor benefit amount the respondent's spouse can expect to receive if he claims at age 62, age 66, or age 70 .

Those assigned to the Insert condition viewed the Default Table in Figure 1 as well as the passages in Figure 3 that explain the survivor benefit provisions but do not provide any respondent-specific projections of the survivor benefit amounts that will be available to the respondent's spouse at each claim age.

Finally, those respondents assigned to the combination of the Modified Table and the Insert condition were exposed to both of these treatments. That is, this group of respondents viewed the benefit information in Figure 2 and Figure 3.

After viewing the information associated with their assigned experimental condition, the respondents were asked a series of questions assessing their knowledge of the survivor benefit and a question about their expected claim age. First, we asked respondents to indicate whether their claim ages can affect their spouses’ survivor benefit amount. Then, we asked those who answered this question correctly to identify the claim age that maximizes the amount of the survivor benefit. Third, we asked all respondents to assume that they are entitled to receive a retirement benefit of $\$ 1,800$ and that their spouse is entitled to receive a retirement benefit of $\$ 700$ based on her own work history. Using these hypothetical amounts, we asked the respondents to calculate the amount of the survivor benefit that their spouse could expect to receive from the respondent's earnings history. Correct responses of \$1,100 were coded “ 1 ” and all other responses were coded “ 0 .” Next, we asked the respondents to indicate the age at which they expect to claim Social Security between age 62 and age 70. Finally, we asked respondents a series of questions about factors that may moderate the impact of the survivor benefit information on responses to these questions including their financial literacy, their financial time 
preferences, the status of their own health as well as the health of their spouse, and their perceived likelihood that Social Security benefits will be reduced over the next 10 years.

To evaluate the duration of any initial changes in benefit knowledge or expected claiming behavior associated with the modifications, we administered a follow-up survey to those respondents who completed the initial experimental survey. At follow-up, we asked each of the survivor benefit knowledge and claiming expectation questions again, although we changed the hypothetical amounts of the retirement benefits in the question asking them to derive their spouse's survivor benefit. Both the initial and follow-up surveys are presented in Appendix B.

\section{Data}

We administered the experimental survey to 560 married men between the ages of 30 and 61 from the RAND American Life Panel (ALP). The ALP is an Internet-based survey of 6,000 working age adults living in the U.S. The probability-based sample is representative of the U.S. population on key demographic and economic characteristics following a weighting adjustment. Several related studies also recruited participants through the ALP to examine Social Security knowledge and the claiming decision (Brown, Kapteyn, and Mitchell, 2016; Brown, Kapteyn, Mitchell, and Mattox, 2013; Greenwald et al., 2010). The survey was administered by the RAND Corporation between July $28^{\text {th }}$ and September $9^{\text {th }}$. A follow-up survey was administered between October $13^{\text {th }}$ and December $2^{\text {nd }}$. Of the 560 men who completed the initial survey, 531 completed the follow-up survey for a response rate of 94.8 percent. The 531 men who completed both surveys comprise the estimation sample of this study. We found no evidence of differential attrition across the experimental conditions at follow-up (see Table 1A and Table 2A in Appendix A). We merged our survey data with the respondents' socioeconomic and demographic data available for all ALP respondents from RAND.

We restricted the sample to married, working age men because they are more likely to leave a survivor benefit to their spouse in the event of their death due to the fact that they tend to have higher lifetime earnings compared to their spouse (Munnell and Sass, 2008). As noted, 97 percent of all current survivor benefit recipients are female (Social Security Administration, 2016b). As a result, the husband's claim age is more likely to have implications for his wife's financial security in widowhood than the converse. Finally, we focus on heterosexual couples 
because the SSA had not begun to recognize survivor benefit claims from same-sex marriages until after we administered the initial survey.

\section{Descriptive Statistics}

Table 1 displays the mean values of the variables included in this analysis for the men assigned to each condition in the initial and the follow-up surveys. The table indicates the statistically significant differences between the means of the treatment groups and the control group. A few notable differences emerged across the experimental conditions in this analysis which underscores the fact that randomization provides the expectation, but not the guarantee, of equivalence across the experimental conditions. However, each of the statistically significant differences do not appear to be meaningfully large. Most notably, there is a significant difference $(p<0.05$ ) between the average Survivor Benefit Amount of those assigned to the combination of the Modified Table and the Insert condition and those assigned to the Control group. Fewer respondents assigned to the Modified Table condition report having finished college compared to those in the Control condition. This difference was also significant at the 0.05 level. Other differences were detected at the 0.10 level between the Primary Insurance Amounts of those assigned to the Control condition and those assigned to the Modified Table and the combination of the Modified Table and the Insert conditions. Another such difference exists between the proportion of those who report being neither likely nor unlikely to outlive their spouse between those assigned to the Control condition and those assigned to the Insert and the combination of the Modified Table and the Insert conditions. Finally, the share of Hispanic respondents is lower among the Modified Table condition relative to the Control condition.

\section{Results}

Regression results estimating the effects of the various modifications to the Social Security Statement on knowledge about the survivor benefit provisions and expected claim ages are displayed in Table 2 and in Table 3.

\section{Worker's Claim Age affects Spouse's Survivor Benefit Amount}

Columns 1 through 4 of Table 2 report the effect of these modifications on whether the respondent understands that the age at which a worker claims his own retirement benefit can 
affect the amount of the survivor benefit his spouse can expect to receive. Although the amount of the survivor benefit in the Modified Table varied according to the possible claim age of the respondent, individuals in this treatment condition were no more likely to report that a worker's claim age has an effect on this amount than those in the control group. That is, presenting respondents in this group with the corollary implications of this provision does not improve their understanding of the provision itself. Detectable differences were not present between these two groups even after limiting the estimation sample to include only those workers who are projected to bequeath a benefit to their spouse and, therefore, had nonzero amounts in this portion of the Modified Table. ${ }^{6}$

The Insert, by contrast, had a large and statistically significant effect on the likelihood that a respondent correctly reported that a worker's own claim age affects the amount of their spouse's survivor benefit. The likelihood that respondents assigned to this condition understood this provision was 14 percentage points $(\mathrm{p}<0.05)$ higher than it was for those in the control group (column 1), a change that amounts to a 22 percent increase in the baseline likelihood. The magnitude of this effect is only slightly attenuated once control variables were added to the models (column 2). This improvement suggests that, in general, respondents assigned to the Insert were not overwhelmed by the information about this provision provided through this comprehensive approach.

A comparable improvement was evident among respondents assigned to receive both the Modified Table and the Insert. The similarity of the point estimates across the two groups exposed to the Insert is evidence against a possible additive or multiplicative effect when the two modifications are combined. It also suggests that the Insert alone is responsible for the observed increase in the knowledge of this particular provision within this group.

The results in columns 3 and 4 of Table 2 indicate that any initial effects of the modifications were temporary. At follow-up, the group receiving the Insert was 10.7 percentage points more likely to correctly indicate that a worker's claim age can affect the amount of the survivor benefit the worker's spouse can expect to receive, but this difference was only significant at the 0.10 level. The increase evident among those receiving both the Modified Table and the Insert was no longer significant at any conventional level. This result is surprising given that the average time to follow-up was just 77 days and the fact that this particular

\footnotetext{
${ }^{6}$ Results available upon request.
} 
provision is so similar to the widely understood provision linking workers' claim ages to their retirement benefit amount.

\section{Worker's Claim Age that Maximizes His Spouse's Survivor Benefit Amount}

Columns 5 through 8 of Table 2 report the effects of these modifications on whether the respondent correctly identified the survivor benefit maximization age as 70 . Those assigned to receive the Modified Table were 11 percentage points $(\mathrm{p}<0.05)$ more likely than those in the control group to correctly identify the survivor benefit maximization age (column 5). This result is hard to reconcile with the evidence that respondents in this group were no more likely to report that their claim age can affect the survivor benefit amount their spouse can expect to receive in columns 1 through 4 . Taken together, these results imply that respondents exposed to only the Modified Table gained knowledge, but not an understanding, of the survivor benefit provisions.

A larger effect size is evident for the other two treatment conditions. Respondents assigned to receive the Insert were 21 percentage points more likely to correctly identify the survivor benefit maximization age than those in the control group, with the difference growing to 23 percentage points for those who received both the Modified Table and the Insert. Each of these differences were significant at the 0.01 level. The results from unreported Wald tests found significant differences between the estimated effect of the Modified Table and the other two modification conditions but did not detect significant differences between the effects of the Insert and the Modified Table plus the Insert conditions.

Similar to the follow-up survey results for the first outcome, columns 7 and 8 indicate that these effects were not sustained over time. Surprisingly, those assigned to the Insert condition were 9 percentage points less likely than those in the control group to correctly identify the survivor benefit maximization age at follow-up (column 8). However, this difference was only significant at the 0.10 level. The effects of the other two treatment conditions were no longer significant at any conventional level.

\section{Survivor Benefit Estimate for Hypothetical Couple}

Only a very small share of the control group (8.7 percent) was able to correctly estimate the amount of the survivor benefit they would leave to their spouse given a hypothetical combination of retirement benefit amounts that each spouse is projected to receive based on their 
own work history. This suggests that most workers are either uniformed or misinformed about this particular provision. Surprisingly, exposure to the Modified Table alone appeared to add to this confusion. Exposure to the Modified Table reduced the likelihood that respondents correctly estimated this amount by 7.9 percentage points $(\mathrm{p}<0.05)$ relative to those in the control condition. By contrast, the Insert was highly successful at improving the knowledge of how survivor benefit amounts are determined. The likelihood that respondents were able to correctly calculate the survivor benefit amount the lower-earning spouse was entitled to receive increased by 20 percentage points ( $\mathrm{p}<0.05$ ). A nearly identical increase in this likelihood was evident among respondents viewing both the Modified Table and the Insert.

At follow-up, respondents were presented with a similar scenario, but with slightly different hypothetical retirement benefit amounts promised to each spouse. The lone sustained effect was evident among those respondents exposed to the Insert only. By this time, individuals in the Insert group were 7.1 percentage points $(\mathrm{p}<0.05)$ more likely than those in the control group to correctly calculate the survivor benefit amount the lower-earning spouse could expect to receive. While still considerable, this difference represents a substantial fade-out of the initial effect.

\section{Expected Claim Age}

The remaining and most important question is whether the modifications to the survivor benefit information in the Statement influenced expected claim ages. We analyzed this relationship among the full sample of respondents (columns 1-6) and among the subsample who were projected to bequeath a survivor benefit to their spouse (columns 7-12) and, therefore, were more likely to be sensitive to the information about this benefit in the Modified Table and the Insert. The estimated effects of the modification for the full and restricted estimation samples are presented in Table 3. The results provide strong evidence that viewing the Modified Table increased expected claim ages relative to the control group.

Among the full sample, viewing the Modified Table increased the expected claim age by 0.68 years but this relationship was only significant at the 0.10 level. Once controls were added to the model (column 3), the expected increase in the claim age for this group rose to 0.76 years, a change that is statistically significant at the 0.05 level. The most important reason for the change in the statistical significance of this estimated effect is the addition of variables indicating 
the employment status of respondents to the regression model in column 2. Specifically, retired respondents were much more likely to report earlier expected claim ages, regardless of their treatment assignment. Once we adjusted for employment status and retirement in particular, the effect of the Modified Table on expected claim ages became statistically significant. This pattern is evident across treatment conditions and the analytic samples in Table 3. Not surprisingly, the immediate effect of the Modified Table on expected claim ages were larger and more robust among those respondents projected to leave a survivor benefit behind to their spouse. The results in column 9 indicate that exposure to the Modified Table increased expected claim ages by one year $(\mathrm{p}<0.05)$. However, the effect of the Modified Table on expected claim ages was not sustained over time. At follow-up, there were no differences in the expected claim age of this group compared to the control group.

The immediate effect of the Insert on expected claim ages was limited to the subgroup of respondents projected to bequeath a survivor benefit to their spouse based on their relative earnings histories (columns 7-9). However, the effect was not significantly different from zero at the 0.05 level until we adjusted for employment status. This modification increased expected claim ages by roughly 0.82 years $(\mathrm{p}<0.05)$ in the models in columns 8 and 9 . Here again, the effects of this modification to the Statement were short-lived. There were no significant differences in the expected claim ages between this group and the control at follow-up.

Finally, the magnitude of the effects of exposure to both the Modified Table and the Insert on expected claim ages are largely consistent with those of the other two treatment groups. This is evidence against the possibility of an additive or multiplicative effect of the combined modifications. Among the full sample, respondents in this group reported claim ages that were roughly 0.80 years later than those in the control group immediately following their exposure to these modifications (columns 1-3). This effect was statistically significant at the 0.05 level. Among the subgroup of respondents with higher earnings relative to their spouse (columns 7-9), the magnitude of the increase in expected claim ages increased slightly. These individuals reported expected claim ages that were roughly one year later than those in the control condition $(\mathrm{p}<0.05)$. Consistent with the other treatments groups, these differences were no longer evident at follow-up. 


\section{Discussion}

There are four major findings from this study. The first is that the baseline level of knowledge about the survivor benefit provisions may be lower than expected. Only 65 percent of the men assigned to the control condition understand that their own claim age may affect their spouse's survivor benefit amount. In other nationally representative surveys, around 80 percent of respondents appear to understand this provision (Brown and Perron, 2011; Perron, 2015). There are several possible explanations for this discrepancy. Most importantly, unlike the other studies, the estimation sample in this study is comprised entirely of men who are not representative of the broader population. However, most of the men in this study have at least a college degree, which, ostensibly, makes the relatively low level of knowledge about this basic survivor benefit provision among the respondents in this study more surprising. It is also possible that women are much more familiar with survivor benefit provisions because they are almost always the exclusive recipients of this benefit (Social Security Administration, 2016b). However, evidence from Brown and Perron (2011) suggest that excluding women from the sample is not responsible for the low level of knowledge, as they found women to be less knowledgeable than men about survivor benefit provisions.

The relatively lower level of survivor benefit knowledge evident among respondents in this study may also be due, in part, to the fact that this study focuses on this particular benefit in isolation. Other studies that assess respondent knowledge of survivor benefit provisions also assess their knowledge across all or several of the benefits Social Security provides. This distinction is important from the standpoint of possible anchoring effects that may result from the ordering of the survey questions in the more comprehensive surveys. For example, of the survey instruments we could access, without exception, questions about the survivor benefit followed those about the retirement benefit (Brown and Perron, 2011; Leibman and Luttmer, 2012; Perron, 2015). When asked, respondents in these surveys overwhelmingly understand that their claim age affects their retirement benefit amount. As a result, they may respond similarly to subsequent, similarly worded, questions about their claim age and the survivor benefit amount even if they are less certain that the two are related. Anchoring effects related to ordering of questions within a survey can occur when respondents are uncertain about their responses but they are able to draw from their responses to preceding questions in the survey. This survey design issue is well established and is a basic concept covered in survey design textbooks 
(Dillman, Smyth, and Christian, 2009). Thus, the lower level of survivor benefit knowledge evident in this study may be due, in part, to the lack of such anchoring, as this study did not ask respondents any questions about the effect of their claim age on their retirement benefit.

Second, when information is provided to workers about the impact of their claiming decision on the amount of the survivor benefit their spouse may receive, they appear to integrate this fact into the mix of considerations that determine when they expect to claim. This provides additional evidence in support of the conclusion drawn by Sass, Sun, and Webb (2007) that married men claim early out of ignorance rather than caddishness. It is possible that the information provided to the men in this study fostered a sense of responsibility that they have to financially indemnify their spouses for the reduction in income that would accompany their death. It is possible that men would give additional weight to the survivor benefit information when evaluating their claiming decision if it were combined with information on the financial hardship typically associated with widowhood, as well as information on how dependent widows become on this particular source of income to maintain a level of income above the amount minimally necessary to meet their needs (Diebold, Moulton, and Scott, 2016).

Third, the Insert was the dominant modification for improving survivor benefit knowledge. In the immediate term, however, the Modified Table was equally successful as the Insert at encouraging workers to report later expected claim ages. Thus, from the standpoint of encouraging socially optimal claiming decisions, it does not appear necessary to promote a deep understanding of survivor benefits provisions among workers but, rather, it appears sufficient merely to ensure that they are aware of the ramifications of their decision for the projected amounts their spouse will receive. Respondents were not, however, able to intuit the survivor benefit provisions from the information in the Modified Table. It appears necessary to explain these provisions directly in order for respondents to be aware that they exist. In addition, the observed improvement in survivor benefit knowledge among those exposed to the Insert provides evidence against the concern that respondents may not be able to process the detailed information within this particular modification or feel overwhelmed by it. This last finding is consistent with those from Agnew and Szykman (2005) and is of practical import to the SSA as they continue to modify their approach to informing workers about their benefits in the Statement and online through their website. 
Finally, almost all of the observed effects of the modifications to the Statement on survivor benefit knowledge and the expected claiming behaviors of workers in this study were temporary. These results are not consistent with the online model of information processing and suggest that improving knowledge and claiming behavior may require more sustained access to the benefit information than is currently available to workers. Very little attention has been given to the fade-out as it relates to the impact of the Statement. This is an important oversight given the SSA's periodic, and frequently amended, distribution schedule of this document. The apparent inability of workers to retain benefit information, even over short intervals, has important practical implications for the SSA policy to provide continuous and instantaneous online access to their electronic earnings histories and projected benefit amounts to only those workers who agree to no longer receive a paper Statement. Workers may benefit most if the SSA supplied online and paper records as complements as opposed to substitutes. Indeed, online records obviate the need for workers to retain information within the Statement or the Statement itself, while the paper copy can function as an occasional automated nudge to workers to review their records and assess their projected benefits.

\section{Conclusion}

The Social Security Statement is one of the most important financial documents retiring workers receive as they contemplate when to claim their benefits. However, the connection between the primary earner's claim age and the survivor benefit amount his spouse can expect to receive in the event of his death is not clearly communicated in this document. The omission of this information may result in some workers making suboptimal claiming decisions because they are less than fully informed about the negative consequences of that decision for the financial security of their lower-earning spouses in widowhood. In this study, we used an experimental survey design to examine the effects of slight modifications to the Social Security Statement on respondent survivor benefit knowledge and expected claiming behavior. The results indicate a low level of baseline knowledge regarding the relationship between the primary earner's claim age and their spouse's survivor benefit amount among workers. However, when this relationship is highlighted in the Statement, workers' knowledge improves and they report that they are more likely to delay their expected claim age. While the modifications tested here provide evidence that the Statement can be an effective medium for communicating survivor benefit provision 
information, workers did not appear to retain the information, with most of the initial effects having either disappeared or faded substantially at follow-up. Both the relative strength of the initial effect of the Insert and the fade out of those effects have important policy implications for whether and how the SSA should inform workers about these provisions as well as for the restrictive conditions under which they will provide workers with immediate and permanent access to their benefit information online.

Several limitations of this study should be noted. First, the generalizability of the results is limited due to the sampling frame and the self-selection of ALP panel members into the study. In order to focus our analysis on those who are most likely to leave a survivor benefit to their spouse, we restricted the sample to working-age, married, heterosexual men. Due to this restriction, we ignore the possibility that male primary earners would respond differently than female primary earners to the modifications analyzed in this study. This is potentially important as the male breadwinner model is gradually being replaced with dual-earner households in which women receive Social Security benefits based, at least in part, on their own earnings history (Tamborini and Whitman, 2007). The same is true of primary earners in same-sex marriages, who are now entitled to receive benefits based on their spouse's earnings record. Also, the relatively high levels of educational attainment of the respondents in the sample means that this study is too under-powered to detect any differential effects of the augmented survivor benefit information by socioeconomic circumstances.

Second, a worker's claiming decision is likely the result of a more complicated process than was allowed for in this experiment. Our study assumes, for example, that married workers evaluate their benefit information and make a decision about when to claim independently, without input from their spouse. While the occurrence, scope, and scale of such deliberations will vary by household, given the financial implications of this decision for each spouse, the assumption that married workers make this decision unilaterally is somewhat tenuous. The information provided in these modifications may inform such deliberations or even increase the likelihood that they occur in ways not captured in this experiment. For example, it is possible that households would give greater weight to the survivor benefit provisions when both spouses understand them, particularly when there is a wider disparity in income or expected longevity between spouses. Unfortunately, our study cannot speak to these possibilities. 
Policymakers and retirement researchers might want to consider a continued focus on the effect of the content and format of the Statement on benefit knowledge and claiming behavior. It is important that the document provide complete and clear information in order to avoid influencing retirement and claiming decisions in unintended ways (Social Security Advisory Board, 2009). One critical unanswered question related to this study concerns the effects of inexact descriptions of the retirement benefit provisions appearing in the Statement. For example, in the benefit table, workers are told the amounts they can expect to receive if they “continue working” until age 62, their full retirement age, and age 70. However, monthly retirement benefit amounts are not a function of when they retire or exit the labor force. Instead, this table could describe these amounts as what they can expect to receive if they "claim" or “start receiving benefits” at these ages. The conflation of these two related, but not interchangeable decisions, within the Statement may unintentionally encourage suboptimal early claiming as well as early retirement. As long as the Statement remains the preferred resource that workers use to become informed about what is, for most, their most valuable financial asset, the document could be modified in ways that may improve workers' understanding of their benefits and their financial planning for retirement. 


\section{References}

Agnew, J. R., \& Szykman, L. R. (2005). “Asset allocation and information overload: The influence of information display, asset choice, and investor experience.” The Journal of Behavioral Finance, 6(2), 57-70.

Biggs, A. (2010). Improving the Social Security Statement. Financial Literacy Consortium Report to the SSA, October.

Brown, J. R., Kapteyn, A., \& Mitchell, O. S. (2016). "Framing and Claiming: How InformationFraming Affects Expected Social Security Claiming Behavior.” Journal of Risk and Insurance, 83(1), 139-162.

Brown, J., Kapteyn, A., Mitchell, O., \& Mattox, T. (2013). "Framing the Social Security Earnings Test.” Wharton Pension Research Council Working Paper, 6.

Brown, K.S., \& Perron, R. (2011). “Assessing current and future beneficiaries’ knowledge of Social Security benefits.” AARP report July.

Diebold, J., Moulton, J., \& Scott, J. (2016). "Early claiming of higher-earning husbands, the survivor benefit, and the incidence of poverty among recent widows.” Journal of Pension Economics and Finance, 1-24.

Dillman, D., Smyth, J., \& Christian, L. (2009). Internet, mail, and mixed-mode surveys: the tailored design method. Hoboken, NJ: Wiley \& Sons.

Eppler, M. J., \& Mengis, J. (2004). “The concept of information overload: A review of literature from organization science, accounting, marketing, MIS, and related disciplines.” The Information Society, 20(5), 325-344.

Fleishman-Mayer, L. A., Hung, A. A., Yoong, J. K., Clift, J., \& Tassot, C. (2013). “Designing Better Pension Benefits Statements: Current Status, Best Practices and Insights from the Field of Judgment and Decisionmaking.” Working Papers, 951, RAND Corporation.

Gerber, A. S., Gimpel, J. G., Green, D. P., \& Shaw, D. R. (2011). “How large and long-lasting are the persuasive effects of televised campaign ads? Results from a randomized field experiment.” American Political Science Review, 105(01), 135-150.

Gillen, M., \& Kim, H. (2009). “Older women and poverty transition: Consequences of income source changes from widowhood.” Journal of Applied Gerontology, 28(3), 320-341.

Greenwald, M., Kapteyn, A., Mitchell, O. S., \& Schneider, L. (2010). "What do people know about Social Security?” Financial Literacy Consortium Report to the SSA, September.

Hilgert, M. A., Hogarth, J. M., \& Beverly, S. G. (2003). Household financial management: The connection between knowledge and behavior. Federal Reserve Bulletin, 89, 309. 
Johnson, R. W., K. E. Smith, and O. Haaga (2013). "How Did the Great Recession Affect Social Security Claiming?” Program on Retirement Policy Brief, 37. Urban Institute.

Karamcheva, N., \& Munnell, A. H. (2007). “Why Are Widows So Poor?” Boston, MA: Center for Retirement Research at Boston College.

Kimball, M. S., \& Shumway, T. (2010). "Investor sophistication and the home bias, diversification, and employer stock puzzles.” Available at: https://ssrn.com/abstract=1572866 or http://dx.doi.org/10.2139/ssrn.1572866

Liebman, J. B., \& Luttmer, E. F. (2012). “The perception of Social Security incentives for labor supply and retirement: The median voter knows more than you'd think.” Tax Policy and the Economy, 26(1), 1-42.

Lodge, M., Steenbergen, M. R., \& Brau, S. (1995). “The responsive voter: Campaign information and the dynamics of candidate evaluation.” American Political Science Review, 89(02), 309-326.

Lusardi, A., Mitchell, O. S., \& Curto, V. (2009). "Financial literacy and financial sophistication among older Americans.” (No. w15469). National Bureau of Economic Research.

Lusardi, A. (2008). “Financial literacy: An essential tool for informed consumer choice?” (No. w14084). Cambridge, MA: National Bureau of Economic Research.

Lusardi, A., \& Mitchell, O. S. (2007). "Financial literacy and retirement preparedness: Evidence and implications for financial education.” Business Economics 42(1), 35-44.

Mastrobuoni, G. (2011). “The role of information for retirement behavior: Evidence based on the stepwise introduction of the Social Security Statement.” Journal of Public Economics 95(7), 913-925.

Munnell, A. H., \& Sass, S. A. (2008). "Working longer: The solution to the retirement income challenge.” Washington, DC: Brookings Institution Press.

Perron, R. (2012). "Paper by Choice: People of all ages prefer to receive retirement plan information on paper.” AARP Research.

Perron, R. (2015). “Social Security planning in 2015 \& beyond: Perspectives of future beneficiaries and financial planners.” AARP and the Financial Planning Association (FPA).

Poterba, J., Venti, S., \& Wise, D. (2013). “Correction: The Composition and Drawdown of Wealth in Retirement.” The Journal of Economic Perspectives 27(4), 219-221.

Sass, S. A. (2015). “Does the Social Security 'Statement’ Add Value?” Issues in Brief ib201511. Chestnut Hill, MA: Center for Retirement Research. 
Sass, S.A., Sun, W. \& Webb, A. (2007). "Why Do Married Men Claim Social Security Benefits So Early? Ignorance or Caddishness?” CRR Working Paper 2007-17. for Retirement Research at Boston College

Sevak, P., Weir, D.R., \& Willis, R.J. (2005). “The economic consequences of a husband's death: Evidence from the HRS and AHEAD.” Social Security Bulletin, 65(3), 31-44.

Smith, B. A., \& Couch, K. A. (2014a). "Social Security Statement: Background, Implementation, and Recent Developments.” Social Security Bulletin, 74(2), 1-25.

Smith, B.A., \& Couch, K.A. (2014b). "How effective is the Social Security Statement? Informing younger workers about Social Security.” Social Security Bulletin, 74(4), 1-19.

Social Security Advisory Board. (2009). “The Social Security Statement: How it can be improved.” Available at: http://www.ssab.gov/Portals/0/OUR_WORK/REPORTS/Social_Security_Statement_Rep ort_2009.pdf

Social Security Administration. (2016a). Income of the Aged Chartbook, 2014 (SSA Publication No. 13-11700). Washington, DC: Government Printing Office.

Social Security Administration. (2016b). Annual statistical supplement to the Social Security Bulletin, 2015 (SSA Publication No. 13-11700). Washington, DC: Government Printing Office.

Social Security Administration. (2016c). Income of the population 55 or older, 2014 (SSA Publication No. 13-11871). Washington, DC: Government Printing Office.

Tamborini, C., \& Whitman, K. (2007). "Women, marriage, and Social Security benefits revisited.” Social Security Bulletin, 67, 1.

Weaver, D. A. (2010). “Widows and Social Security.” Social Security Bulletin, 70(3), 89-109.

Zick, C. D., \& Holden, K. (2000). “An assessment of the wealth holdings of recent widows.” The Journals of Gerontology Series B: Psychological Sciences and Social Sciences, 55(2), S90-S97. 
Tables and Figures

Table 1. Descriptive Statistics by Treatment Assignment

\begin{tabular}{|c|c|c|c|c|}
\hline \multirow[b]{3}{*}{ Primary Insurance Amount } & \multicolumn{4}{|c|}{ Means and Proportions } \\
\hline & Control & Modified Table & Insert & Modified Table + Insert \\
\hline & 1931 & $2051^{*}$ & 1986 & $2065^{*}$ \\
\hline Survivor Benefit Amount & 1117 & 1304 & 1274 & $1370^{* *}$ \\
\hline Age & 48 & $50 *$ & 48 & 49 \\
\hline \multicolumn{5}{|l|}{ Educational Attainment } \\
\hline High School & 0.42 & 0.48 & 0.49 & 0.42 \\
\hline College & 0.36 & $0.23 * *$ & 0.35 & 0.32 \\
\hline Advanced Degree & 0.22 & 0.29 & 0.16 & 0.26 \\
\hline \multicolumn{5}{|l|}{ Current Employment Status } \\
\hline Employed & 0.89 & 0.88 & 0.87 & 0.83 \\
\hline Unemployed & 0.03 & 0.02 & 0.02 & 0.05 \\
\hline Retired & 0.05 & 0.09 & 0.07 & 0.07 \\
\hline Other & 0.03 & 0.02 & 0.04 & 0.05 \\
\hline \multicolumn{5}{|l|}{ Ethnicity } \\
\hline White & 0.74 & 0.79 & 0.81 & 0.77 \\
\hline Black & 0.05 & 0.08 & 0.03 & 0.05 \\
\hline Hispanic & 0.15 & $0.08 *$ & 0.12 & 0.13 \\
\hline Other Ethnicity & 0.06 & 0.05 & 0.04 & 0.05 \\
\hline Financial Literacy & 0.63 & 0.59 & 0.65 & 0.66 \\
\hline Low Discount Rate & 0.84 & 0.77 & 0.80 & 0.81 \\
\hline Pr(Social Security Reduction) & 61.9 & 66.1 & 63.9 & 63.7 \\
\hline \multicolumn{5}{|l|}{$\operatorname{Pr}($ Outliving Spouse) } \\
\hline Likely & 0.20 & 0.26 & 0.23 & 0.23 \\
\hline Neither Likely or Unlikely & 0.39 & 0.36 & $0.28 *$ & $0.29 *$ \\
\hline Unlikely & 0.40 & 0.38 & 0.49 & 0.48 \\
\hline $\mathrm{N}$ & 104 & 128 & 148 & 151 \\
\hline
\end{tabular}

Notes: ***,**, and * indicate statistically significant at the 1, 5, 10 percent levels between the treatment and control group. The questions used to generate these variables are located in Appendix B. 
Table 2. Regression Results for Analysis Correct Responses Regarding the Survivor Benefit

\begin{tabular}{|c|c|c|c|c|c|c|c|c|}
\hline & \multicolumn{4}{|c|}{$\begin{array}{l}\text { Worker's Claim Age affects } \\
\text { Survivor Benefit Amount }\end{array}$} & \multicolumn{4}{|c|}{$\begin{array}{c}\text { Worker's Claim Age that Maximizes } \\
\text { Spouse's Survivor Benefit }\end{array}$} \\
\hline & \multicolumn{2}{|c|}{ Initial Survey } & \multicolumn{2}{|c|}{ Follow-Up } & \multicolumn{2}{|c|}{ Initial Survey } & \multicolumn{2}{|c|}{ Follow-Up } \\
\hline & (1) & (2) & (3) & (4) & (5) & (6) & (7) & (8) \\
\hline \multirow[t]{2}{*}{ Modified Table } & 0.022 & 0.005 & 0.042 & 0.056 & $.110 * *$ & $.116^{* *}$ & 0.025 & 0.018 \\
\hline & $(.063)$ & $(.064)$ & $(.063)$ & $(.062)$ & $(.054)$ & $(.054)$ & $(.060)$ & $(.059)$ \\
\hline \multirow[t]{2}{*}{ Insert } & $.142^{* *}$ & $.128 * *$ & $.107 *$ & 0.092 & $.208 * * *$ & $.192 * * *$ & -0.068 & $-.094 *$ \\
\hline & $(.059)$ & $(.058)$ & $(.060)$ & $(.060)$ & $(.054)$ & $(.053)$ & $(.055)$ & $(.054)$ \\
\hline \multirow[t]{2}{*}{$\begin{array}{l}\text { Modified Table } \\
+ \text { Insert }\end{array}$} & $.134 * *$ & $.118^{* *}$ & 0.059 & 0.052 & $.234 * * *$ & $.226 * * *$ & 0.007 & -0.026 \\
\hline & $(.059)$ & $(.059)$ & $(.061)$ & $(.060)$ & $(.054)$ & $(.053)$ & $(.057)$ & $(.055)$ \\
\hline \multirow[t]{2}{*}{ Constant } & $.635^{* * *}$ & $.321^{* *}$ & $.728 * * *$ & $.481^{* *}$ & $.163 * * *$ & -0.037 & $.366^{* *}$ & 0.107 \\
\hline & $(.047)$ & $(.154)$ & $(.172)$ & $(.226)$ & $(.036)$ & $(.151)$ & $(.157)$ & $(.238)$ \\
\hline Controls & No & Yes & No & Yes & No & Yes & No & Yes \\
\hline $\mathrm{N}$ & 531 & 531 & 531 & 531 & 531 & 531 & 531 & 531 \\
\hline
\end{tabular}

Notes: ***, **, and * indicate statistically significant at the 1, 5, 10 percent levels between the treatment and control group. Control variables include the respondents' primary insurance amount, the survivor benefit amount the respondent is expected to bequeath to his spouse, age, employment status, race, education, financial literacy, financial time preferences, their health, their spouse's health, and their reported probability that Social Security benefits will be reduced in the next 10 years. Each dichotomous dependent variable indicates whether the respondent answered the corresponding questions about the survivor benefit correctly. OLS was used to assess the likelihood of correct responses across the treatment and control conditions. The resulting coefficients express differences between the respective treatment group and the control group in terms of percentages points. We used robust standard errors to correct for the heteroscedasticity inherent in linear probability models. 
Table 2. Continued

\begin{tabular}{|c|c|c|c|c|}
\hline & \multicolumn{4}{|c|}{$\begin{array}{l}\text { Survivor Benefit Estimate for } \\
\text { Hypothetical Couple }\end{array}$} \\
\hline & \multicolumn{2}{|c|}{ Initial Survey } & \multicolumn{2}{|c|}{ Follow-Up } \\
\hline & (9) & (10) & (11) & (12) \\
\hline \multirow[t]{2}{*}{ Modified Table } & $-.079 * *$ & $-.081 * *$ & 0.003 & 0.013 \\
\hline & $(.029)$ & $(.030)$ & $(.030)$ & $(.030)$ \\
\hline \multirow[t]{2}{*}{ Insert } & $.197 * * *$ & $.184 * * *$ & $.071^{* *}$ & $.079 * *$ \\
\hline & $(.046)$ & $(.046)$ & $(.034)$ & $(.035)$ \\
\hline \multirow[t]{2}{*}{$\begin{array}{l}\text { Modified Table } \\
+ \text { Insert }\end{array}$} & $.205 * * *$ & $.183^{* * *}$ & 0.042 & 0.039 \\
\hline & $(.046)$ & $(.046)$ & $(.032)$ & $(.031)$ \\
\hline \multirow[t]{2}{*}{ Constant } & $.087^{* *}$ & -0.029 & 0.161 & 0.024 \\
\hline & $(.028)$ & $(.120)$ & $(.105)$ & $(.166)$ \\
\hline Controls & No & Yes & No & Yes \\
\hline $\mathrm{N}$ & 531 & 531 & 531 & 531 \\
\hline
\end{tabular}

Notes: ***, **, and * indicate statistically significant at the 1, 5, 10 percent levels between the treatment and control group. Control variables include the respondents' primary insurance amount, the survivor benefit amount the respondent is expected to bequeath to his spouse, age, employment status, race, education, financial literacy, financial time preferences, their health, their spouse's health, and their reported probability that Social Security benefits will be reduced in the next 10 years. Each dichotomous dependent variable indicates whether the respondent answered the corresponding questions about the survivor benefit correctly. OLS was used to assess the likelihood of correct responses across the treatment and control conditions. The resulting coefficients express differences between the respective treatment group and the control group in terms of percentages points. We used robust standard errors to correct for the heteroscedasticity inherent in linear probability models. 
Table 3. Expected Claim Age by Treatment Assignment for Respondents Whose Spouses May Receive a Survivor Benefit

\begin{tabular}{|c|c|c|c|c|c|c|}
\hline & \multicolumn{6}{|c|}{ All Respondents } \\
\hline & \multicolumn{3}{|c|}{ Initial Survey } & \multicolumn{3}{|c|}{ Follow-up } \\
\hline & $(1)$ & $(2)$ & (3) & (4) & (5) & (6) \\
\hline \multirow[t]{2}{*}{ Modified Table } & $.680^{*}$ & $.769 * *$ & $.758 * *$ & -0.121 & -0.032 & -0.061 \\
\hline & $(.366)$ & $(.356)$ & $(.371)$ & $(.345)$ & $(.340)$ & $(.348)$ \\
\hline \multirow[t]{2}{*}{ Insert } & 0.553 & $.627^{*}$ & $.628 *$ & -0.384 & -0.33 & -0.344 \\
\hline & (.353) & $(.341)$ & $(.344)$ & $(.321)$ & (.309) & $(.303)$ \\
\hline \multirow[t]{2}{*}{$\begin{array}{l}\text { Modified Table } \\
+ \text { Insert }\end{array}$} & $.769 * *$ & $.858 * *$ & $.799 * *$ & -0.109 & -0.052 & -0.129 \\
\hline & $(.352)$ & $(.342)$ & $(.346)$ & $(.321)$ & $(.314)$ & $(.314)$ \\
\hline \multirow[t]{2}{*}{ Retired } & & $-2.882 * * *$ & $-2.774 * * *$ & & $-2.510 * * *$ & $-2.230 * * *$ \\
\hline & & $(.455)$ & $(.442)$ & & $(.433)$ & $(.429)$ \\
\hline \multirow[t]{2}{*}{ Constant } & $4.913 * * *$ & $5.096 * * *$ & $4.528 * * *$ & $5.519 * * *$ & $5.654 * * *$ & $5.352 * * *$ \\
\hline & $(.271)$ & $(.267)$ & $(.912)$ & $(.248)$ & $(.242)$ & $(.846)$ \\
\hline Controls & No & No & Yes & No & No & Yes \\
\hline $\mathrm{N}$ & 531 & 531 & 531 & 531 & 531 & 531 \\
\hline
\end{tabular}

Notes: ***,**, and * indicate statistically significant at the 1, 5, 10 percent levels between the treatment and control group. Control variables include the respondents' primary insurance amount, the survivor benefit amount the respondent is expected to bequeath to his spouse, age, employment status, race, education, financial literacy, financial time preferences, their health, their spouse's health, and their reported probability that Social Security benefits will be reduced in the next 10 years. The dependent variable is a continuous measure of expected claim ages ranging from age 62 to age 70 . OLS was used to model this outcome, so the reported coefficients represent differences in the average claim age of the respective treatment group and the control group. The effect of the modifications is likely limited to those respondents who are the primary earners and, therefore, are projected to bequeath a survivor benefit to their spouse, so the table reports the results from the whole sample (columns 1-6) as well as from this subgroup (columns 7-12). 
Table 3. Continued

\begin{tabular}{|c|c|c|c|c|c|c|}
\hline & \multicolumn{6}{|c|}{ Respondents Projected to Bequeath a Survivor Benefit } \\
\hline & \multicolumn{3}{|c|}{ Initial Survey } & \multicolumn{3}{|c|}{ Follow-up } \\
\hline & (7) & (8) & (9) & (10) & $(11)$ & $(12)$ \\
\hline \multirow[t]{2}{*}{ Modified Table } & $.842^{* *}$ & $.984 * *$ & $1.006 * *$ & -0.038 & 0.078 & 0.073 \\
\hline & $(.392)$ & $(.378)$ & $(.392)$ & $(.364)$ & $(.362)$ & $(.368)$ \\
\hline \multirow[t]{2}{*}{ Insert } & $.664^{*}$ & $.813 * *$ & $.818^{* *}$ & -0.29 & -0.173 & -0.202 \\
\hline & $(.378)$ & $(.363)$ & $(.365)$ & $(.338)$ & $(.332)$ & $(.325)$ \\
\hline \multirow[t]{2}{*}{$\begin{array}{l}\text { Modified Table } \\
+ \text { Insert }\end{array}$} & $.881^{* *}$ & $1.079 * *$ & $1.007 * *$ & -0.016 & 0.127 & 0.028 \\
\hline & $(.375)$ & $(.360)$ & $(.364)$ & $(.335)$ & $(.336)$ & $(.333)$ \\
\hline \multirow[t]{2}{*}{ Retired } & & $-3.378 * * *$ & $-3.130 * * *$ & & $-2.644 * * *$ & $-2.255 * * *$ \\
\hline & & $(.424)$ & $(.434)$ & & $(.468)$ & $(.466)$ \\
\hline \multirow[t]{2}{*}{ Constant } & $4.761^{* * *}$ & $4.896 * * *$ & $4.097 * * *$ & $5.409 * * *$ & $5.494 * * *$ & $5.066 * * *$ \\
\hline & $(.294)$ & $(.288)$ & $(.943)$ & $(.260)$ & $(.260)$ & (.888) \\
\hline Controls & No & No & Yes & No & No & Yes \\
\hline $\mathrm{N}$ & 478 & 478 & 478 & 478 & 478 & 478 \\
\hline
\end{tabular}

Notes: ***,**, and * indicate statistically significant at the $1,5,10$ percent levels between the treatment and control group. Control variables include the respondents' primary insurance amount, the survivor benefit amount the respondent is expected to bequeath to his spouse, age, employment status, race, education, financial literacy, financial time preferences, their health, their spouse's health, and their reported probability that Social Security benefits will be reduced in the next 10 years. The dependent variable is a continuous measure of expected claim ages ranging from age 62 to age 70. OLS was used to model this outcome, so the reported coefficients represent differences in the average claim age of the respective treatment group and the control group. The effect of the modifications is likely limited to those respondents who are the primary earners and, therefore, are projected to bequeath a survivor benefit to their spouse, so the table reports the results from the whole sample (columns 1-6) as well as from this subgroup (columns 7-12). 
Figure 1. Default Table

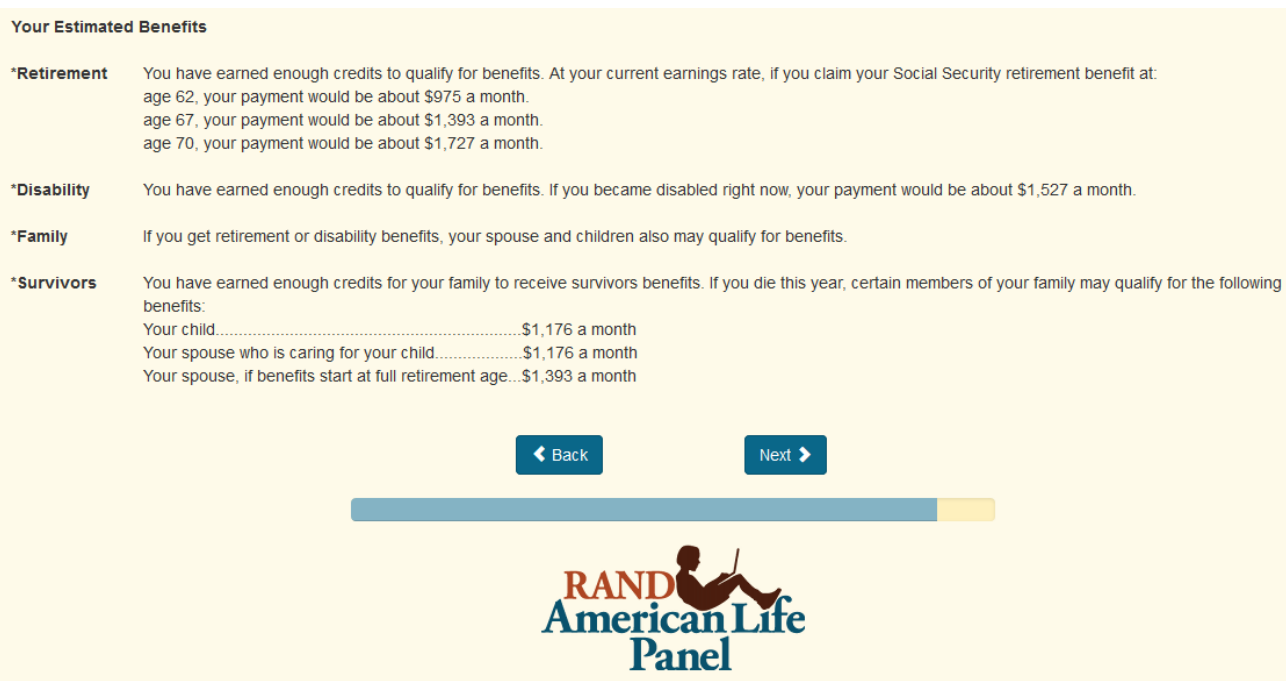

Figure 2. Modified Table

Your Estimated Benefits

*Retirement You have earned enough credits to qualify for benefits. At your current earnings rate, if you claim your Social Security retirement benefit at: age 62, your payment would be about $\$ 975$ a month. age 67 , your payment would be about $\$ 1,393$ a month age 70 , your payment would be about $\$ 1,727$ a month

*Survivor The amount of your spouse's survivor benefit will depend on your age when you claim your Social Security retirement benefit. If you claim at age 62, your spouse's payment would be about $\$ 975$ a month.

age 67, your spouse's payment would be about $\$ 1,393$ a month.

age 70 , your spouse's payment would be about $\$ 1,727$ a month

${ }^{*}$ Family If you get retirement or disability benefits, your spouse and children also may qualify for benefits.

Your child ............................

Your spouse who is caring for your child...\$1,176 a month

*Disability You have earned enough credits to qualify for benefits. If you became disabled right now, you payment would be about \$1,527 a month.

Back Next

Rack
Panel




\section{Figure 3. Insert}

If you are married and die before your spouse, he or she may be eligible for a "survivor" benefit from Social Security based on your work record. The amount of the survivor benefit that you leave to your surviving spouse will depend on two factors: (1) your spouse's own work record and (2) your age when you start receiving your retirement benefit (i.e., your "claim age"

The following examples illustrate how these factors affect the amount your spouse receives from Social Security based on your work record in the event of your death

(1) Your Spouse's Work Record Your spouse is eligible to receive a survivor benefit that is equal to the full amount of your retirement benefit, less the amount of any retirement benefit your spouse receives based on his or her own work record. To see how your spouse's work record affects the amount of the survivor benefit he or she will receive, consider the following hypothetical examples:

Hypothetical 1: You are entitled to receive a retirement benefit of $\$ 1,600$ per month. Your spouse is not entitled to receive a retirement benefit based on his or her own work record

- Your surviving spouse will receive $\$ 1,600$ each month from Social Security. The survivor benefit based on your work history will account for $\$ 1,600$ of this amount.

Hypothetical 2: You are entitled to receive a retirement benefit of $\$ 1,600$ per month. Your spouse is entitled to a retirement benefit of $\$ 600$ based on his or her own work record.

- Your surviving spouse will receive $\$ 1,600$ each month from Social Security. The survivor benefit based on your work history will account for $\$ 1,000$ of this amount.

(2) Your Claim Age Your spouse's survivor benefit is reduced for each month that you start receiving benefits before age 70. Thus, the earlier you claim your retirement benefit, the smaller your spouse's survivor benefit will be. By claiming at age 62 instead of at age 70 , you can reduce the amount that your surviving spouse can expect to receive by as much as 37.5 percent. The following hypothetical examples illustrate how your claim age can affect the amount of the survivor benefit your spouse is eligible to receive.

Hypothetical 3: You are entitled to receive a retirement benefit of $\$ 1,600$ per month at age 66 . Your spouse is not entitled to receive a retirement benefit based on his or her own work record

- If you claim at age 62 , your surviving spouse will receive $\$ 1,320$ each month from Social Security. The survivor benefit based on your work history will account for $\$ 1,320$ of this amount.

- If you claim at age 66 , your surviving spouse will receive $\$ 1,600$ each month from Social Security. The survivor benefit based on your work history will account for $\$ 1,600$ of - If you claim at
this amount.

- If you claim at age 70 , your surviving spouse will receive $\$ 2,110$ each month from Social Security. The survivor benefit based on your work history will account for $\$ 2,110$ of this amount.

Hypothetical 4: You are entitled to receive a retirement benefit of $\$ 1,600$ per month at age 66. Your spouse is entitled to a retirement benefit of $\$ 600$ based on his or her own work record

- If you claim at age 62 , your surviving spouse will receive $\$ 1,320$ each month from Social Security. The survivor benefit based on your work history will account for $\$ 720$ of this amount

- If you claim at age 66 , your surviving spouse will receive $\$ 1,600$ each month from Social Security. The survivor benefit based on your work history will account for $\$ 1,000$ of

this amount

- If you claim at age 70 , your surviving spouse will receive $\$ 2,110$ each month from Social Security. The survivor benefit based on your work history will account for $\$ 1,510$ of this amount. 


\section{Appendix A}

Table 1A. Test for Differential Attrition from Initial Survey to Follow-Up across Experimental Conditions

\begin{tabular}{ll}
\hline \hline & OLS \\
\cline { 2 - 2 } Modified Table & .008 \\
Insert & $(.026)$ \\
& .001 \\
Modified Table + Insert & $(.026)$ \\
& -.028 \\
Constant & $(.029)$ \\
& $\mathrm{N}$
\end{tabular}

Notes: ***,**, and * indicate statistically significant at the 1, 5, 10 percent levels between the treatment and control group. The dependent variable is a dichotomous variable coded "1" if the respondent completed both the initial and the follow-up survey and coded "0" if the respondent completed the initial survey, but not the follow-up survey. All models are estimated using robust standard errors.

The results from Table 1A indicate that the likelihood of respondents completing both interviews does not significantly differ between the treatment and control conditions. The results from Table 2A indicate that there are also no significant differences in these likelihoods between the treatment groups. The coefficients from the regression model in Table $1 \mathrm{~A}$ were used to derive the p-values from the Wald Tests for equality of coefficients in Table 2A.

Table 2A. Wald Tests for Equality of Coefficients

\begin{tabular}{lc}
\hline \hline & P-Value \\
\cline { 2 - 2 }$\beta($ Modified Table $)=\beta($ Insert $)$ & 0.75 \\
$\beta($ Modified Table $)=\beta$ (Modified Table + Insert $)$ & 0.17 \\
$\beta($ Insert $)=\beta$ (Modified Table + Insert $)$ & 0.28 \\
\hline
\end{tabular}

Notes: $* * *, * *$, and $*$ indicate statistically significant at the $1,5,10$ percent levels. The values in the table are the p-values generated from Wald Tests for equality of the coefficients from Table 1A. Significant differences would indicate differences in the likelihood of respondents completing the follow-up survey by group. 


\section{Appendix B}

Figure 2A. Initial Survey Instrument

Well Being 443

IF xrandom = empty THEN

I

ENDIF

introduction introduction

We are interested in understanding people's beliefs about Social Security benefits including how much they expect to receive and what factors might influence the amount they receive. We are also interested in understanding people's beliefs about survivor benefits that widowed spouses can expect to receive based on the deceased spouse's work history. This study will help create clearer and easier-to-understand materials about the Social Security program. In this survey, some questions may be hard to answer exactly. Please take time to consider the questions and give us your best guess even if you do not know the exact answer. Having even your best guess will be very helpful to us. Thank you very much for your help.

WORK_FOR_PAY work for pay

Have you worked for pay for more than 5 years?

1 Yes

2 No

SS_STATUS social security status

In this survey, the term "Social Security benefits" includes any benefits that you yourself receive or will receive from the Social Security program, including retiree, disability, spouse, or survivor benefits. Which of the following statements best describes you?

1 I receive Social Security benefits now.

2 I don't receive Social Security benefits now but, under current law, I will be eligible to receive them in the future.

3 I will never be eligible under current law to receive Social Security benefits.

IF WORK_FOR_PAY = No and SS_STATUS = I don't receive Social Security benefits now but, under current law, I will be eligible to receive them in the future.

THEN

|

| notlongenoughwork notlongenoughwork

| You have not worked long enough for us to estimate the amount of the | retirement benefit you can expect to receive from Social Security. The typical | Social Security retirement benefit is $\$ 1,488$ per month. For the purpose of | this survey, let's assume that you will receive a Social Security retirement 
| benefit of this amount.

I

ENDIF

IF SS_STATUS != I receive Social Security benefits now. THEN

I

| IF SS_STATUS = I will never be eligible under current law to receive Social

| Security benefits. THEN

|l

|| [The following questions are displayed as a table]

||

|| SS_ELIG social security eligibility

|| Why do you think you will never be eligible to receive Social Security

| benefits?

|| 1 My main job was/is not covered by Social Security.

|| 2 I don't have or will not have a sufficient work history to become eligible for Social Security benefits.

|| 3 I do not think Social Security will be around by the time I would start claiming benefits.

|| 4 Other (please specify): \$Answer2\$

1

|| SS_ELIG_other social security eligibility other

|l

|| String

|l

|| [End of table display]

|| IF SS_ELIG = I do not think Social Security will be around by the time I

|| would start claiming benefits. THEN

III

| | | IF WORK_FOR_PAY = No THEN

|l|

|| ELSE

|l|

|| ENDIF

|l|

|| Q5 asssume ss will be around

I | Please assume for the remainder of the survey that Social Security will be

| | | around when you start claiming benefits. [fill for Q5]

|l|

|| ELSE

|l|

|| Q4 not eligible but assume you are

| | | Even though we understand that you are not eligible to receive a Social

| | | Security retirement benefit, we would like to ask you to complete this

| | | survey assuming you would be eligible. In other words, please answer in

|| | this survey what you would have done or chosen if you would be eligible 


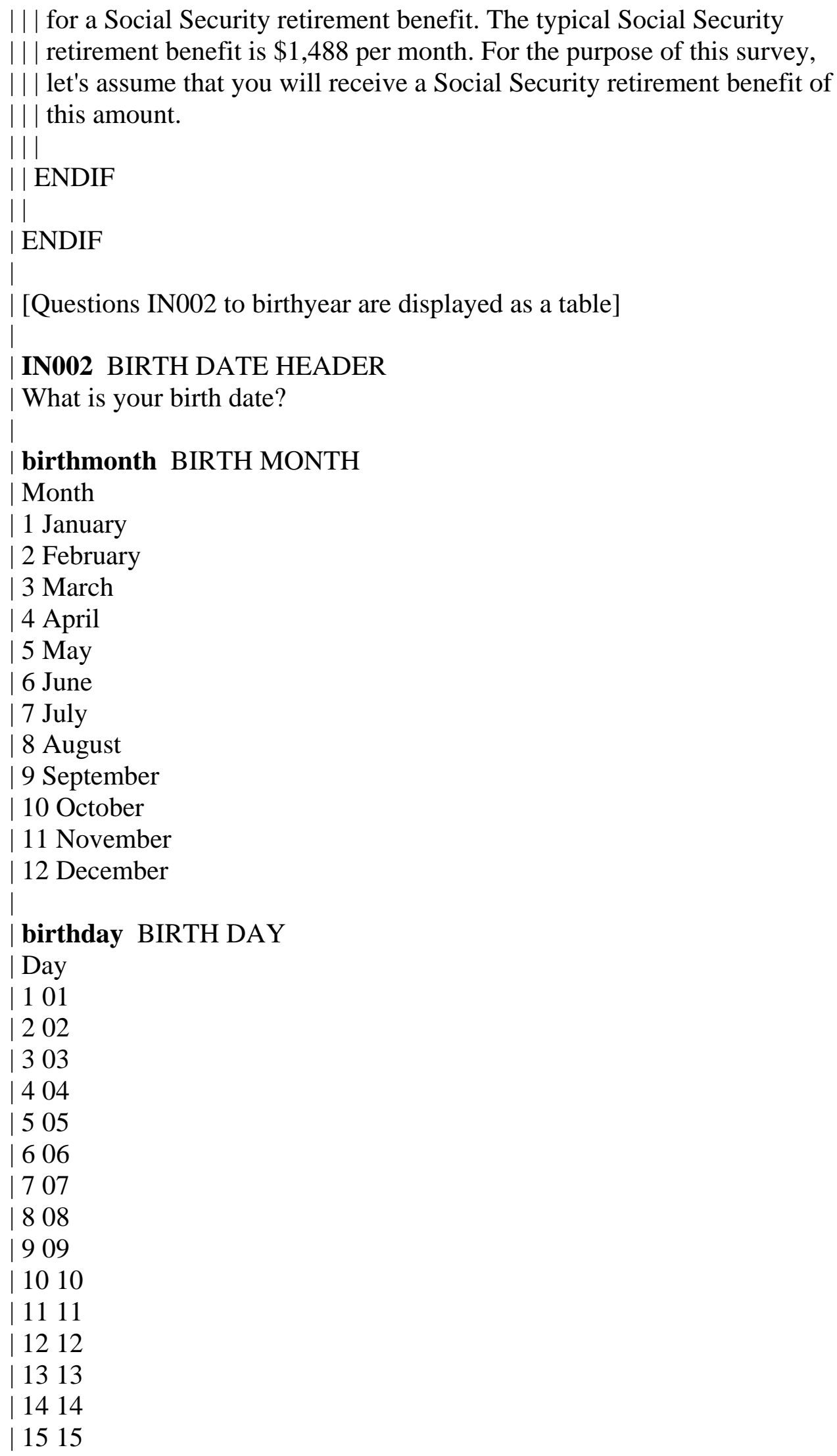




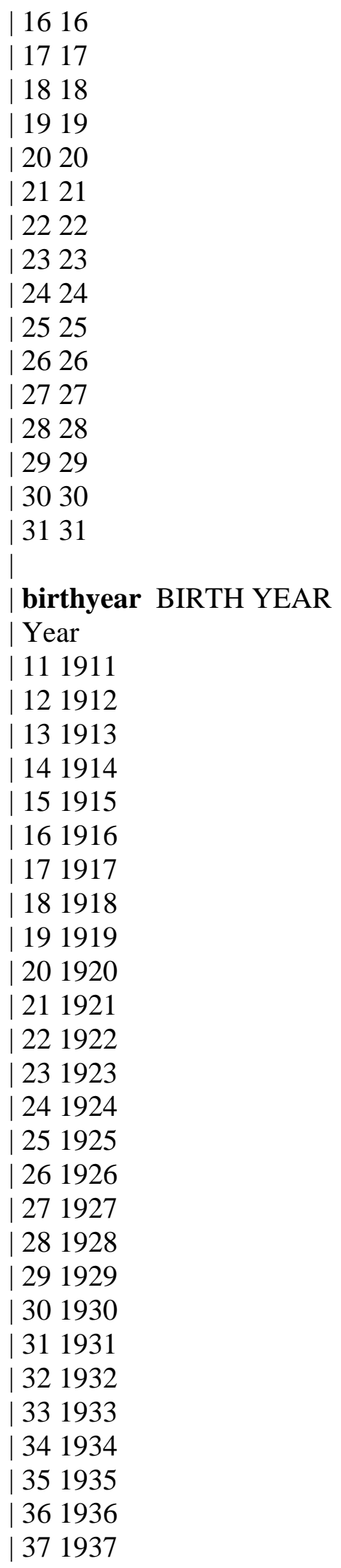




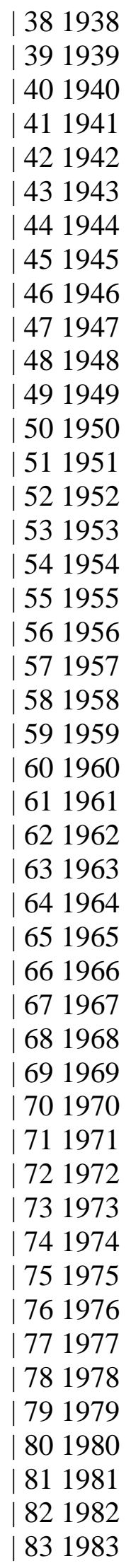




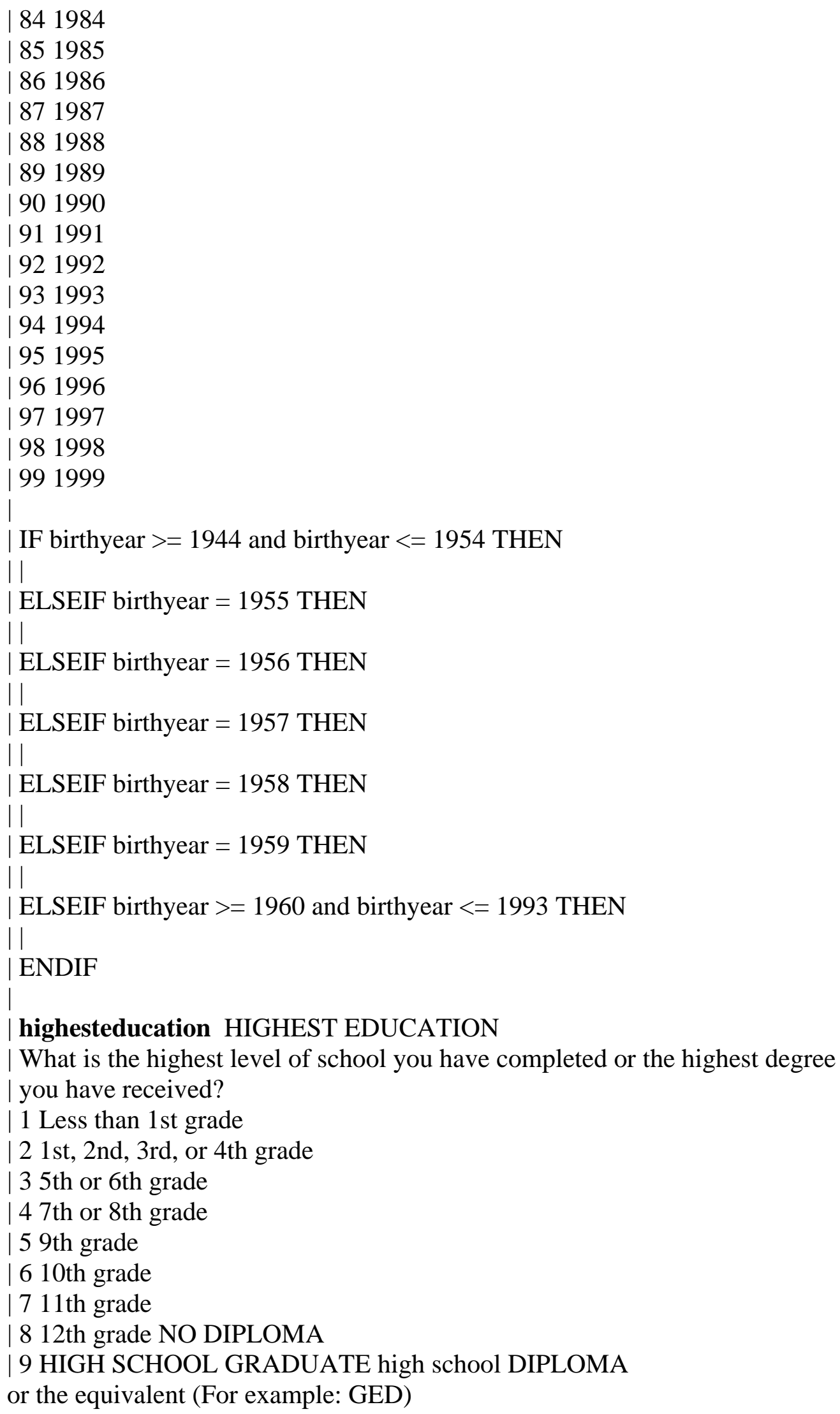


| 10 Some college but no degree

| 11 Associate degree in college Occupational/vocational program

12 Associate degree in college Academic program

| 13 Bachelor's degree (For example: BA,AB,BS)

14 Master's degree (For example: MA,MS,MEng,MEd,MSW,MBA)

| 15 Professional School Degree (For example: MD,DDS,DVM,LLB,JD)

| 16 Doctorate degree (For example: PhD,EdD)

| IF highesteducation $<=12$ th grade NO DIPLOMA THEN

|l

| ELSEIF highesteducation = HIGH SCHOOL GRADUATE high school DIPLOMA

or

|| the equivalent (For example: GED) THEN

|l

| ELSEIF highesteducation $>=$ Some college but no degree and

|| highesteducation <= Associate degree in college Academic program THEN

|l

| ELSEIF highesteducation = Bachelor's degree (For example: BA,AB,BS) THEN

|l

| ELSE

II

| ENDIF

IF EDUCATION = Less than high school $(<12$ years $)$ THEN

||

| ELSEIF EDUCATION = High school degree (12 years) THEN

|l

| ELSEIF EDUCATION $=$ Some college $(>12$ and $<16$ years $)$ THEN

||

| ELSEIF EDUCATION = College degree $(16$ years $)$ THEN

|l

| ELSE

|l

| ENDIF

| INTRODUCTON_TO_SECTION_1 introduction to section 1

| We are interested in understanding how and when people would like to receive | their Social Security benefits. In this survey, we sometimes ask questions | that are difficult to answer exactly. Please take time to consider the questions and give us your best guess even if you do not know the exact | answer. Having your best guess will be very helpful to us. Thank you very | much for your participation!

| IF !(( SS_STATUS = I will never be eligible under current law to receive | Social Security benefits. and ( SS_ELIG = My main job was/is not covered | by Social Security. or SS_ELIG = I don't have or will not have a sufficient 
| work history to become eligible for Social Security benefits. or SS_ELIG = | Other (please specify): \$Answer2\$ )) or WORK_FOR_PAY = No ) THEN |l

| | yearstartwork year start work for pay

| In what year did you first start to work for pay?

|| 19001900

|| 19011901

|| 19021902

|| 19031903

|| 19041904

|| 19051905

|| 19061906

|| 19071907

|| 19081908

| 19091909

|| 19101910

|| 19111911

|| 19121912

|| 19131913

|| 19141914

|| 19151915

|| 19161916

|| 19171917

|| 19181918

|| 19191919

|| 19201920

|| 19211921

|| 19221922

| | 19231923

|| 19241924

|| 19251925

|| 19261926

| 19271927

| 19281928

|| 19291929

|| 19301930

|| 19311931

|| 19321932

|| 19331933

|| 19341934

|| 19351935

|| 19361936

|| 19371937

|| 19381938

|| 19391939

|| 19401940 


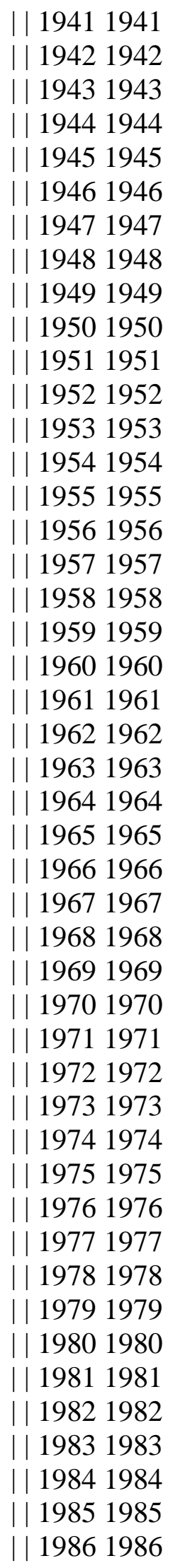


| | 19871987

|| 19881988

| 19891989

| 19901990

| | 19911991

|| 19921992

|| 19931993

| 19941994

| 19951995

|| 19961996

|| 19971997

|| 19981998

| 19991999

|| 20002000

| 20012001

| 20022002

| 20032003

| 20042004

| 20052005

| 20062006

|| 20072007

| 20082008

| 20092009

| 20102010

| 20112011

| 20122012

| 20132013

| | 20142014

| 20152015

| | 20162016

।

| IF yearstartwork < ( birthyear + 1900 ) + 1914 THEN

|l

|| | workedtooearly start working before 14

| | Y You indicated that you started working before you were 14 years old. For

|| | what follows, we will just assume that pay from age 14 on counts. If you

| | | believe you made an error in entering the date you began working, you may

| | go back and change it.

|l

|| ENDIF

||

| incomeintro income intro

|| We would now like to ask you some more about the time period from between

|| when you started working for pay (in [year start work for pay]) until now.

II

|| IF incomeyearsinperiod $>40$ THEN 


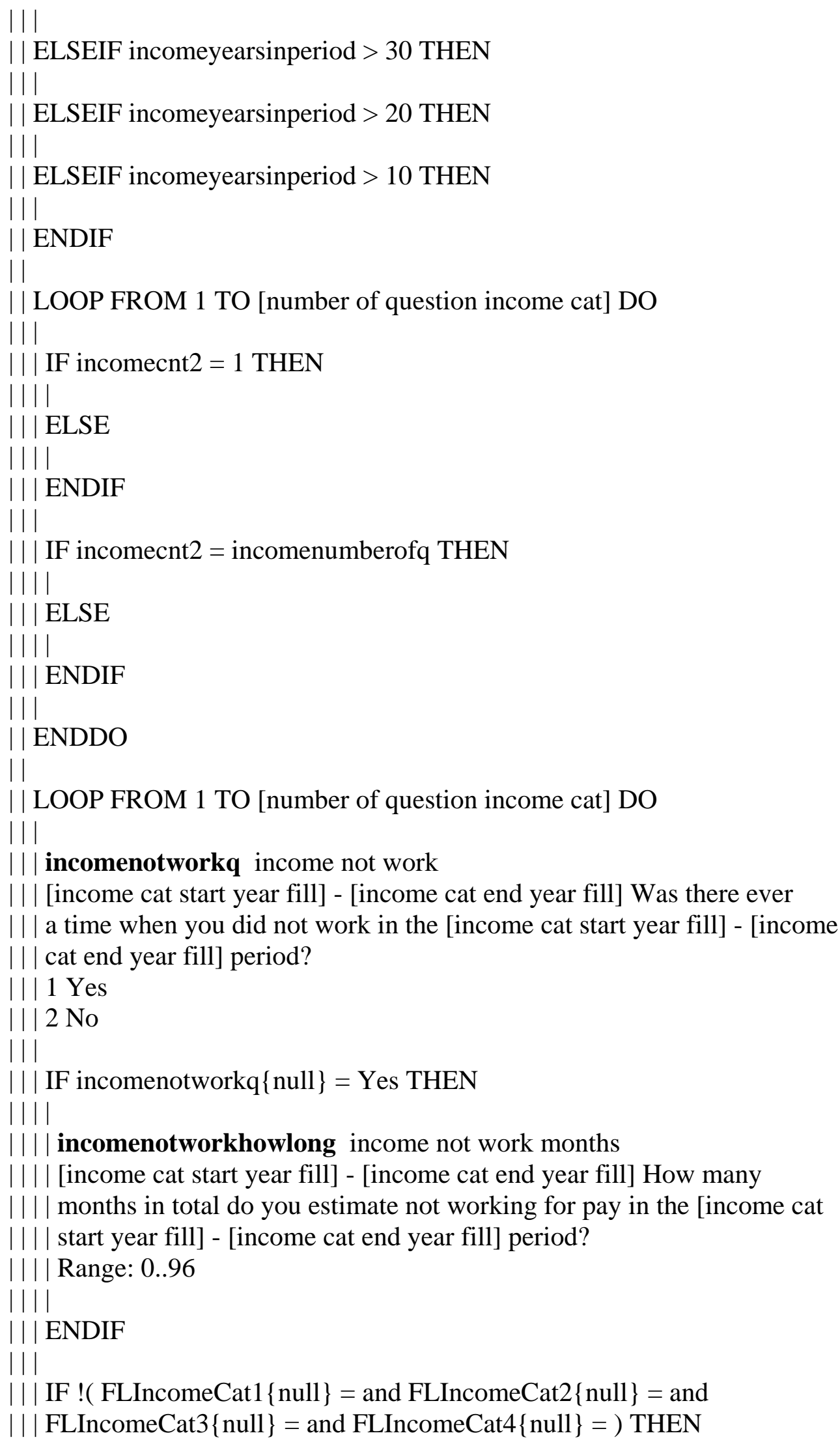




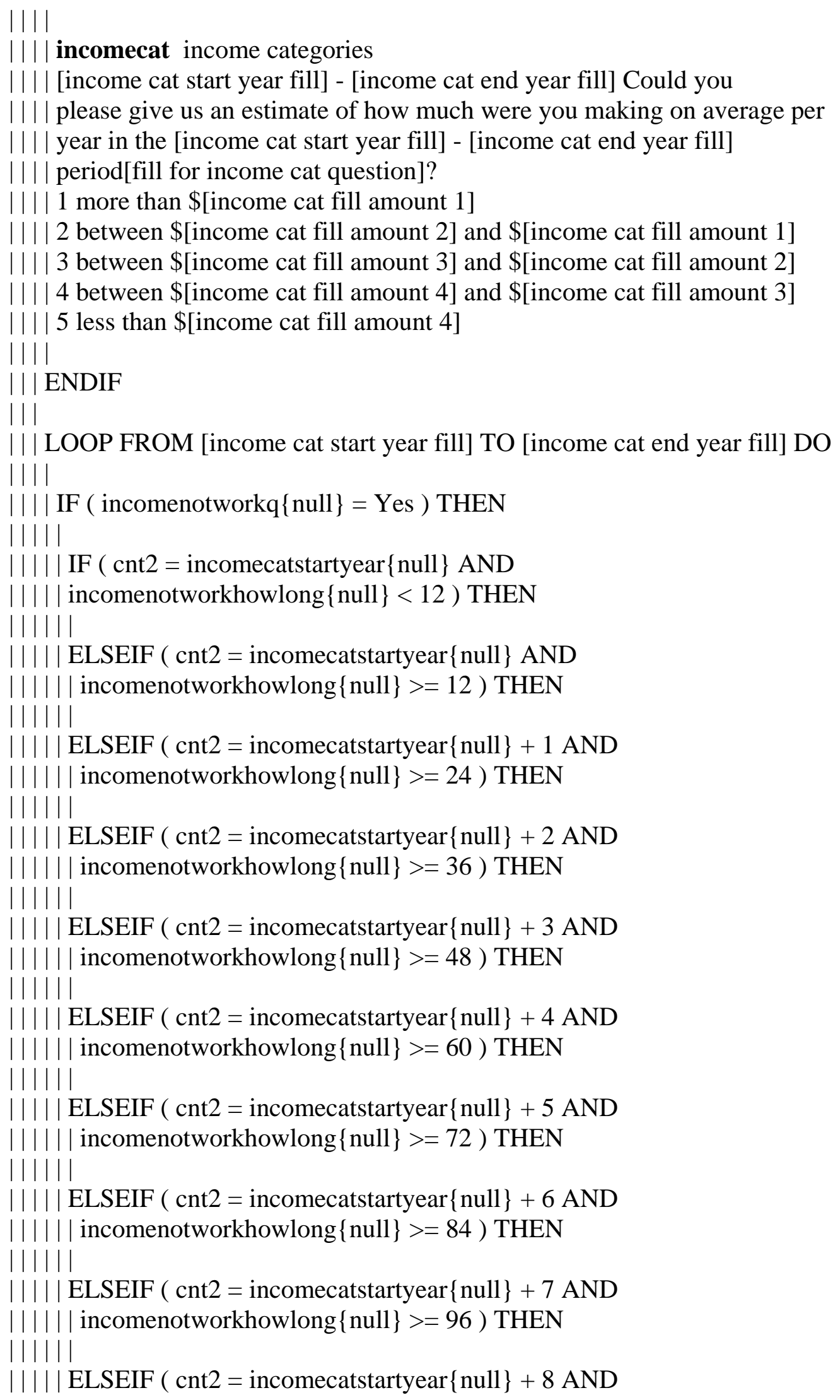




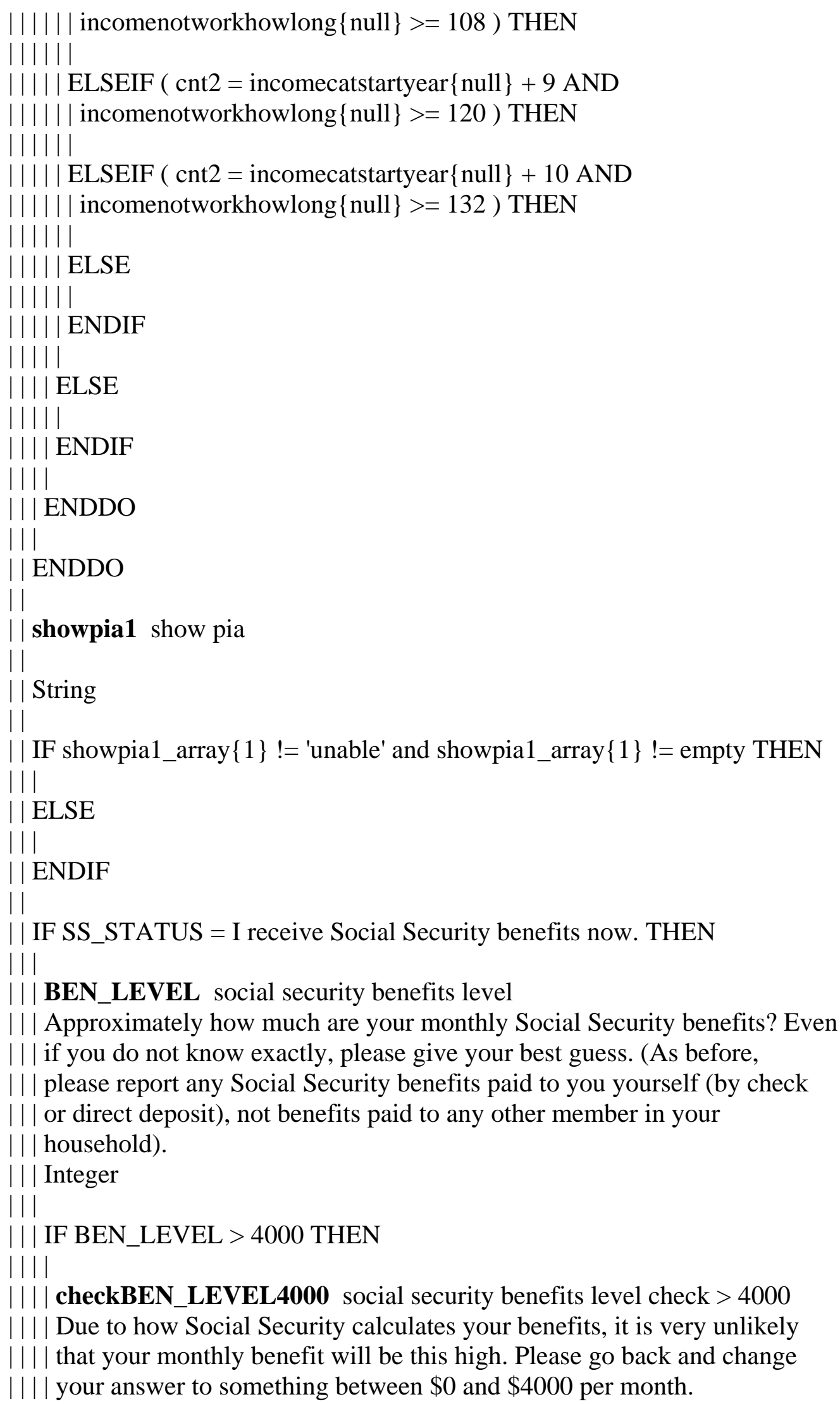




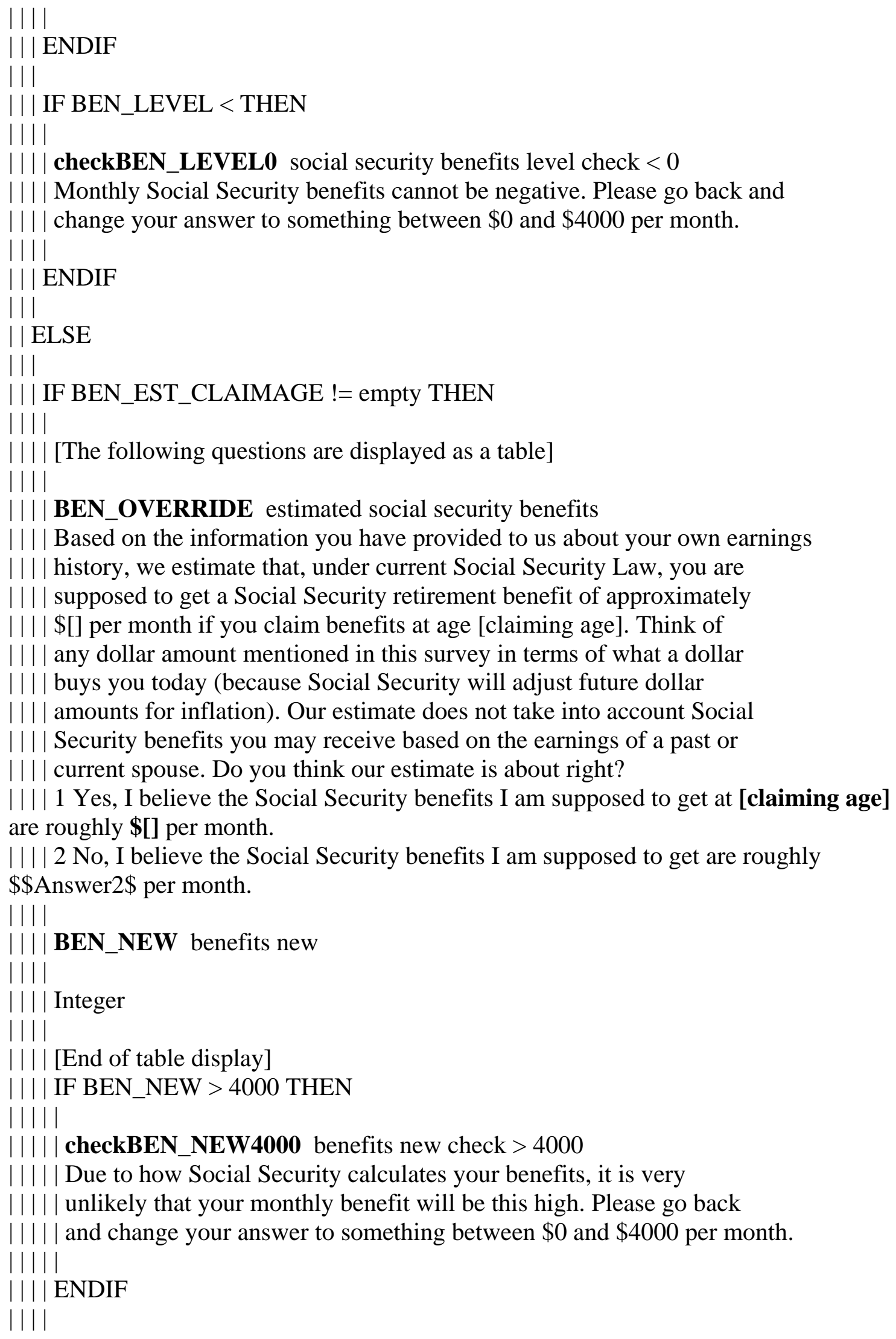




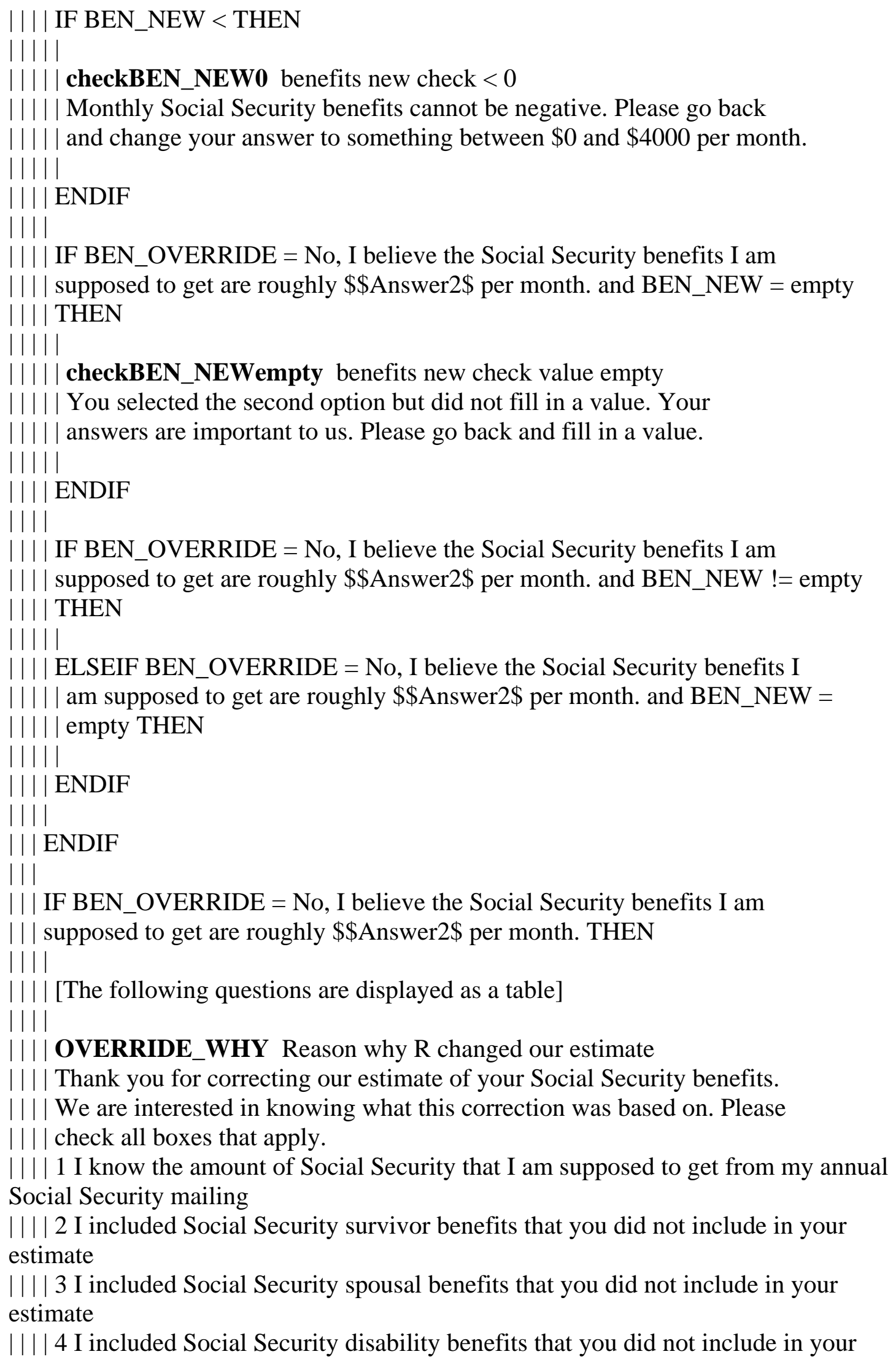




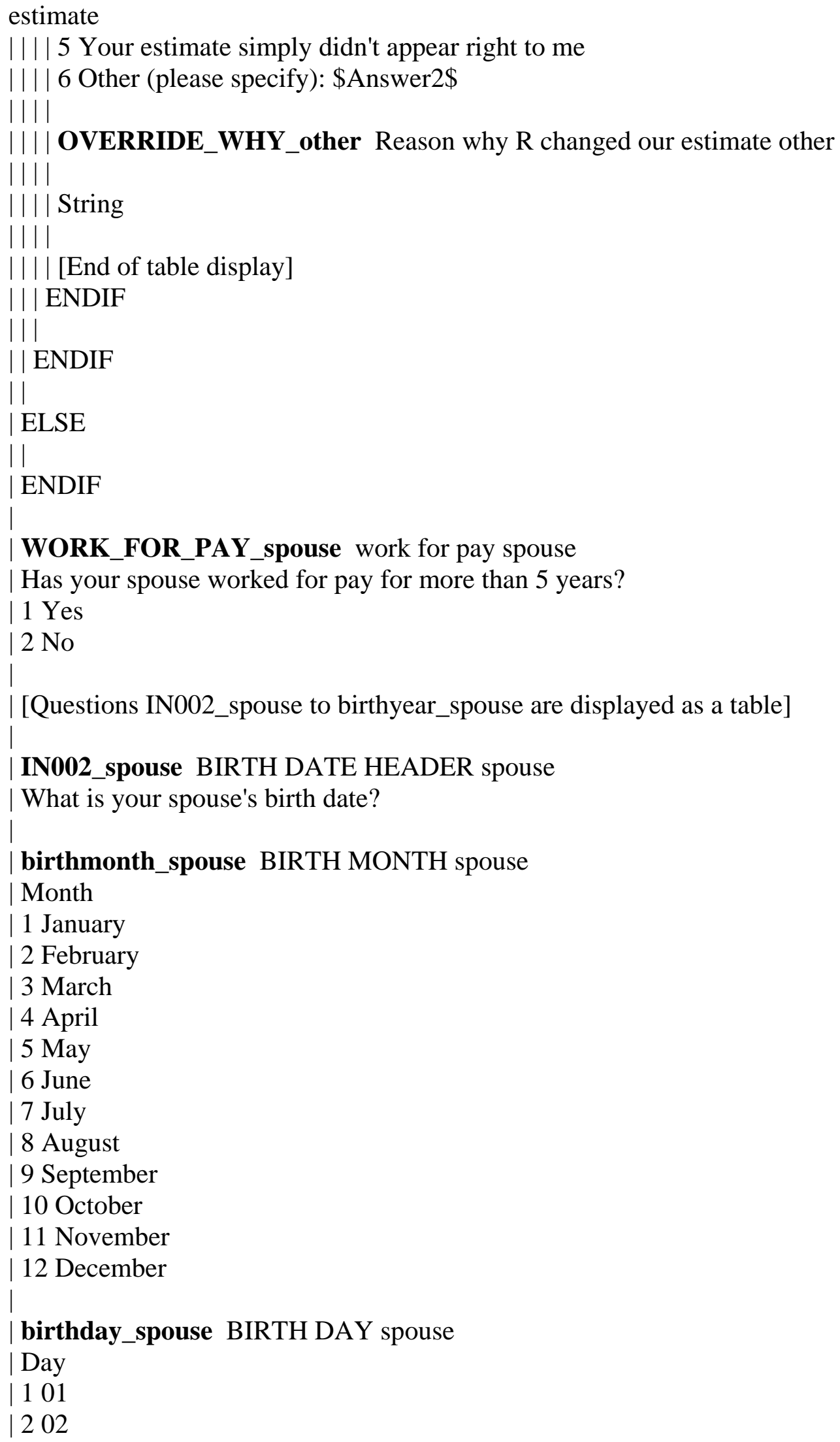




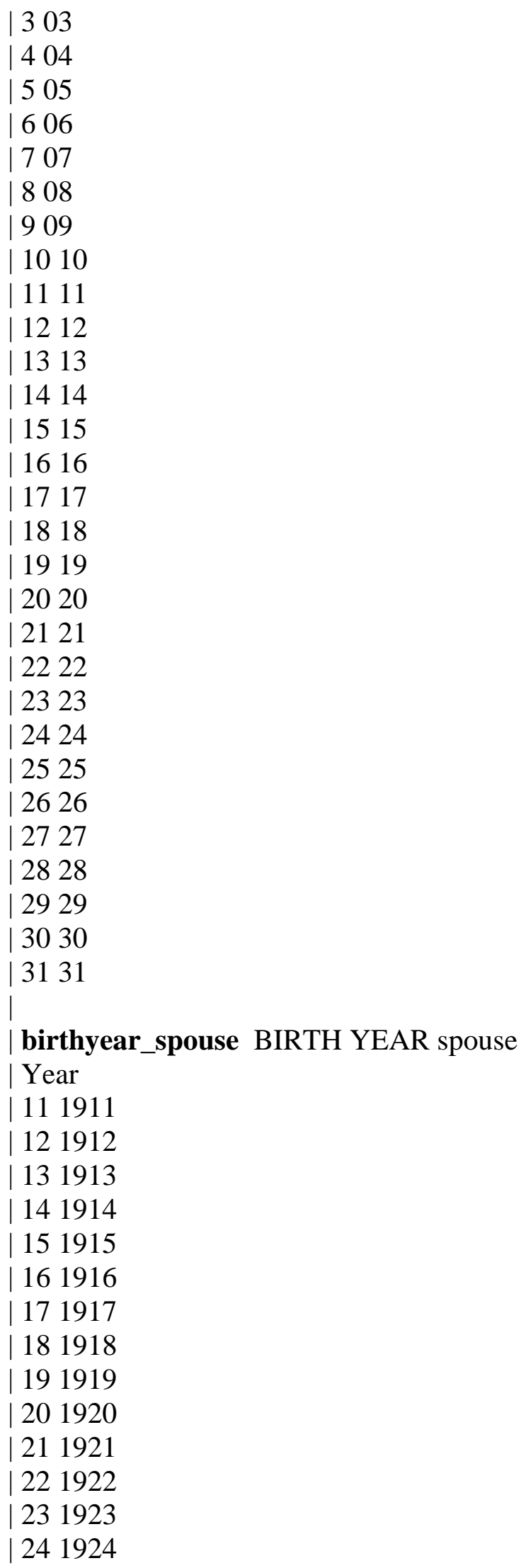




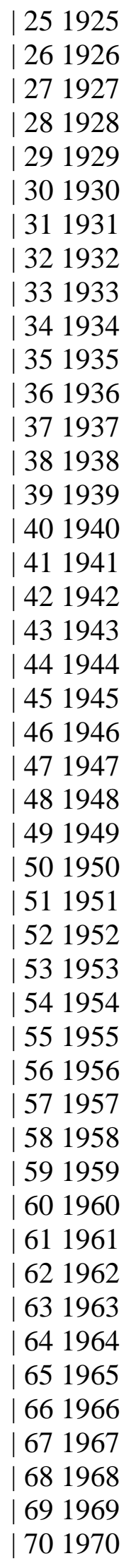


| 711971

| 721972

| 731973

| 741974

| 751975

| 761976

| 771977

| 781978

| 791979

| 801980

| 811981

| 821982

| 831983

| 841984

| 851985

| 861986

| 871987

| 881988

| 891989

| 901990

| 911991

| 921992

| 931993

| 941994

| 951995

| 961996

| 971997

| 981998

| 991999

| IF birthyear_spouse >= 1944 and birthyear_spouse <= 1954 THEN II

| ELSEIF birthyear_spouse $=1955$ THEN II

| ELSEIF birthyear_spouse $=1956$ THEN

|l

| ELSEIF birthyear_spouse $=1957$ THEN

|l

| ELSEIF birthyear_spouse $=1958$ THEN

||

| ELSEIF birthyear_spouse $=1959$ THEN

|l

| ELSEIF birthyear_spouse >= 1960 and birthyear_spouse $<=1993$ THEN |l

| ENDIF

| 


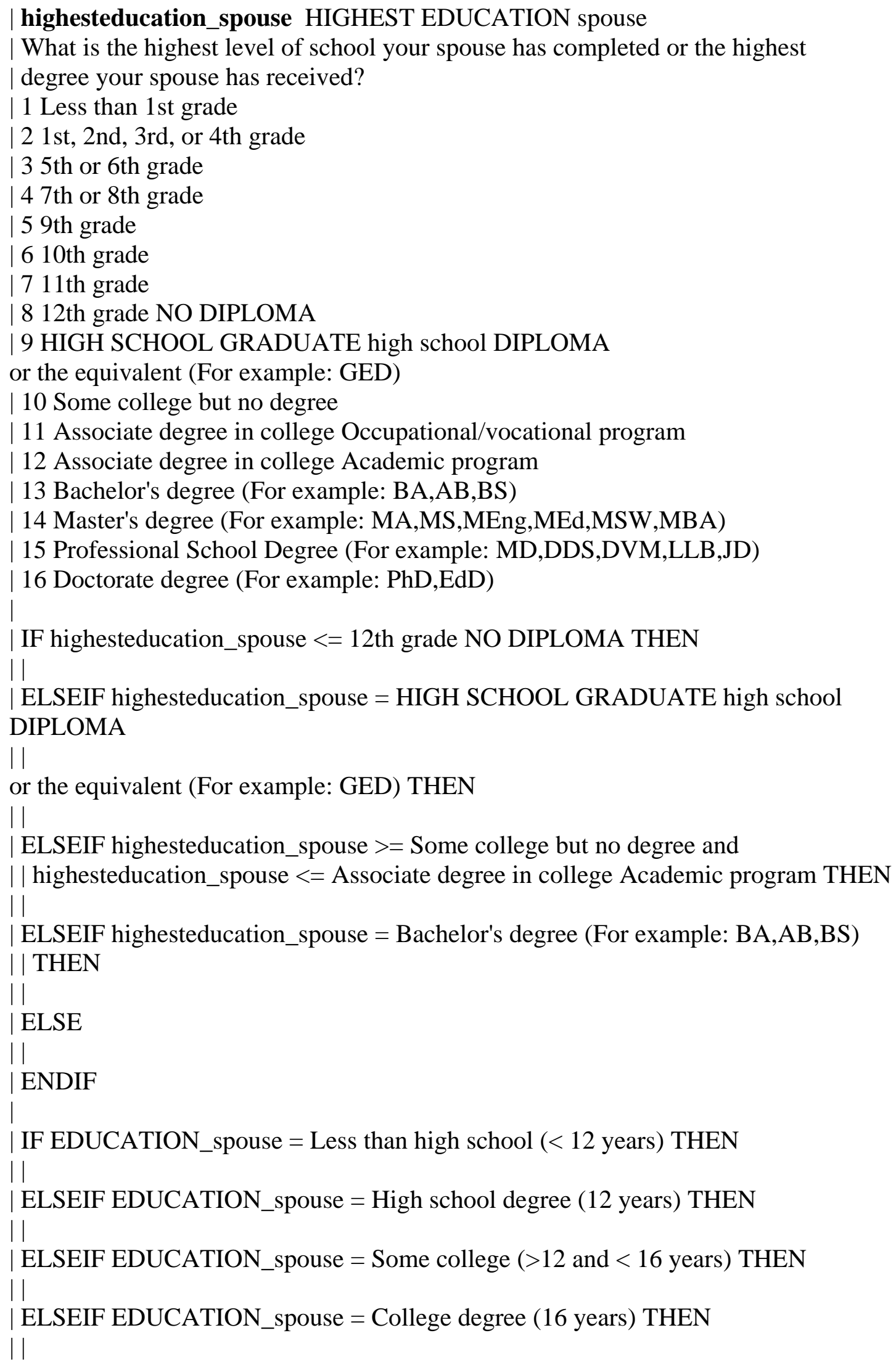




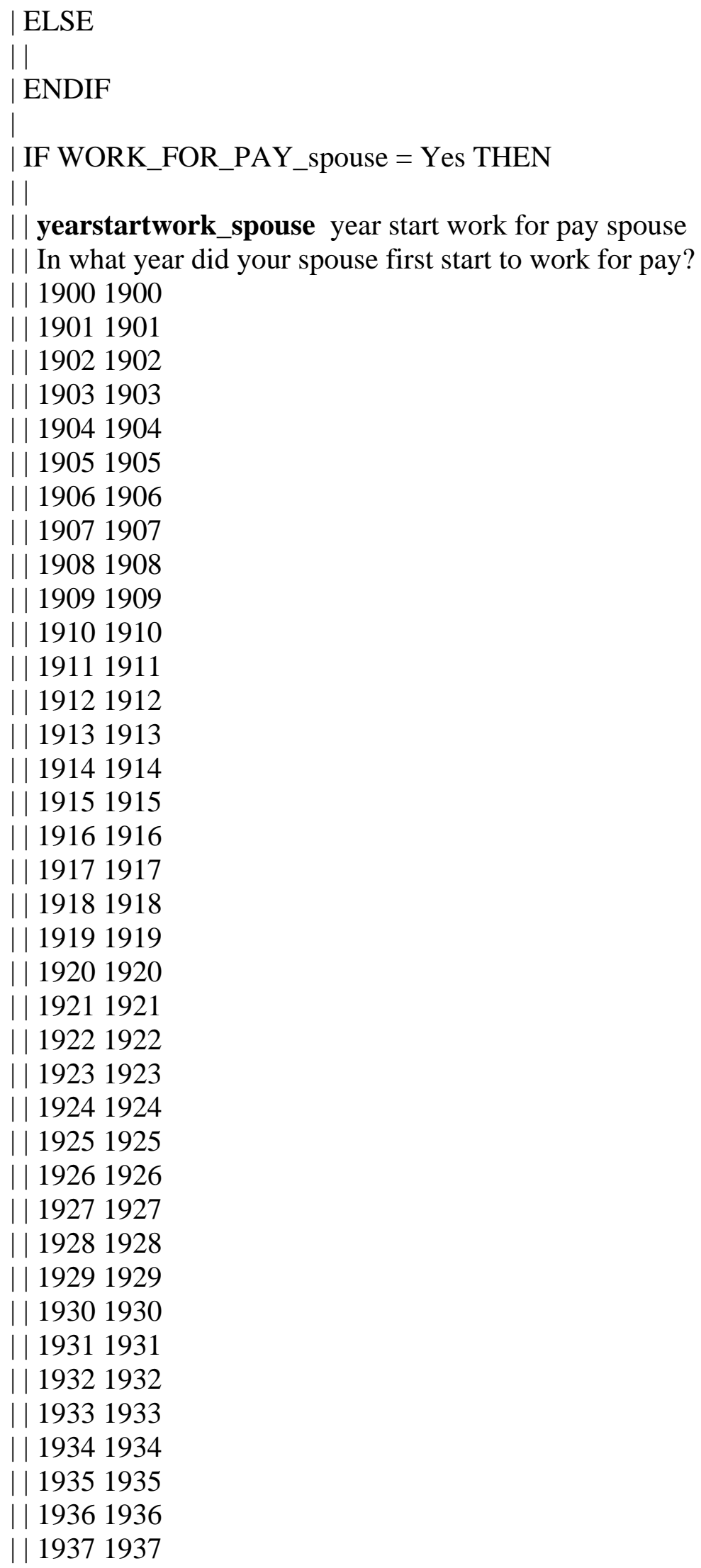




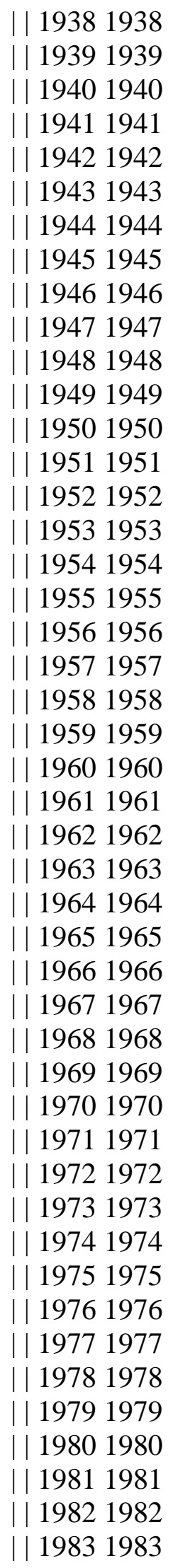


| | 19841984

|| 19851985

| 19861986

| 19871987

|| 19881988

|| 19891989

|| 19901990

| 19911991

|| 19921992

|| 19931993

|| 19941994

|| 19951995

|| 19961996

| 19971997

|| 19981998

|| 19991999

| 20002000

| 20012001

|| 20022002

| 20032003

| 20042004

| 20052005

| 20062006

|| 20072007

|| 20082008

|| 20092009

| 20102010

| 20112011

| 20122012

| 20132013

|| 20142014

| 20152015

| | 20162016

II

|| IF yearstartwork_spouse < ( birthyear_spouse + 1900 ) + 1914 THEN

|l

|| | workedtooearly_spouse start working before 14 spouse

|| | You indicated that your spouse started working before she was 14 years

| | old. For what follows, we will just assume that pay from age 14 on counts.

| | If you believe you made an error in entering the date your spouse began

| | | working, you may go back and change it.

|l|

|| ENDIF

||

|| incomeintro_spouse income intro spouse

|| We would now like to ask you some more about the time period from between 
|| when your spouse started working for pay (in [year start work for pay

| spouse]) until now.

|l

|| IF incomeyearsinperiod_spouse $>40$ THEN

III

|| ELSEIF incomeyearsinperiod_spouse > 30 THEN

|l

|| ELSEIF incomeyearsinperiod_spouse > 20 THEN

|l |

|| ELSEIF incomeyearsinperiod_spouse > 10 THEN

|l|

|| ENDIF

II

| LOOP FROM 1 TO [number of question income cat spouse] DO

|l|

| | IF incomecnt2_spouse $=1$ THEN

|l |

|| ELSE

|l|

|| ENDIF

|l|

| | IF incomecnt2_spouse = incomenumberofq_spouse THEN

|l|

|| ELSE

|l|

|| ENDIF

III

|| ENDDO

||

|| LOOP FROM 1 TO [number of question income cat spouse] DO

|l|

|| | incomenotworkq_spouse income not work spouse

I | | [income cat start year fill spouse] - [income cat end year fill spouse]

| | | Was there ever a time when your spouse did not work in the [income cat

| | start year fill spouse] - [income cat end year fill spouse] period?

|| 1 Yes

|| 2 No

|l

| | IF incomenotworkq_spouse $\{$ null $\}=$ Yes THEN

|l|

|| || incomenotworkhowlong_spouse income not work months spouse

| | | | [income cat start year fill spouse] - [income cat end year fill spouse]

| | | How many months in total do you estimate your spouse not working for pay

| | | in the [income cat start year fill spouse] - [income cat end year fill

| | | spouse] period?

| | | Range: $0 . .96$ 


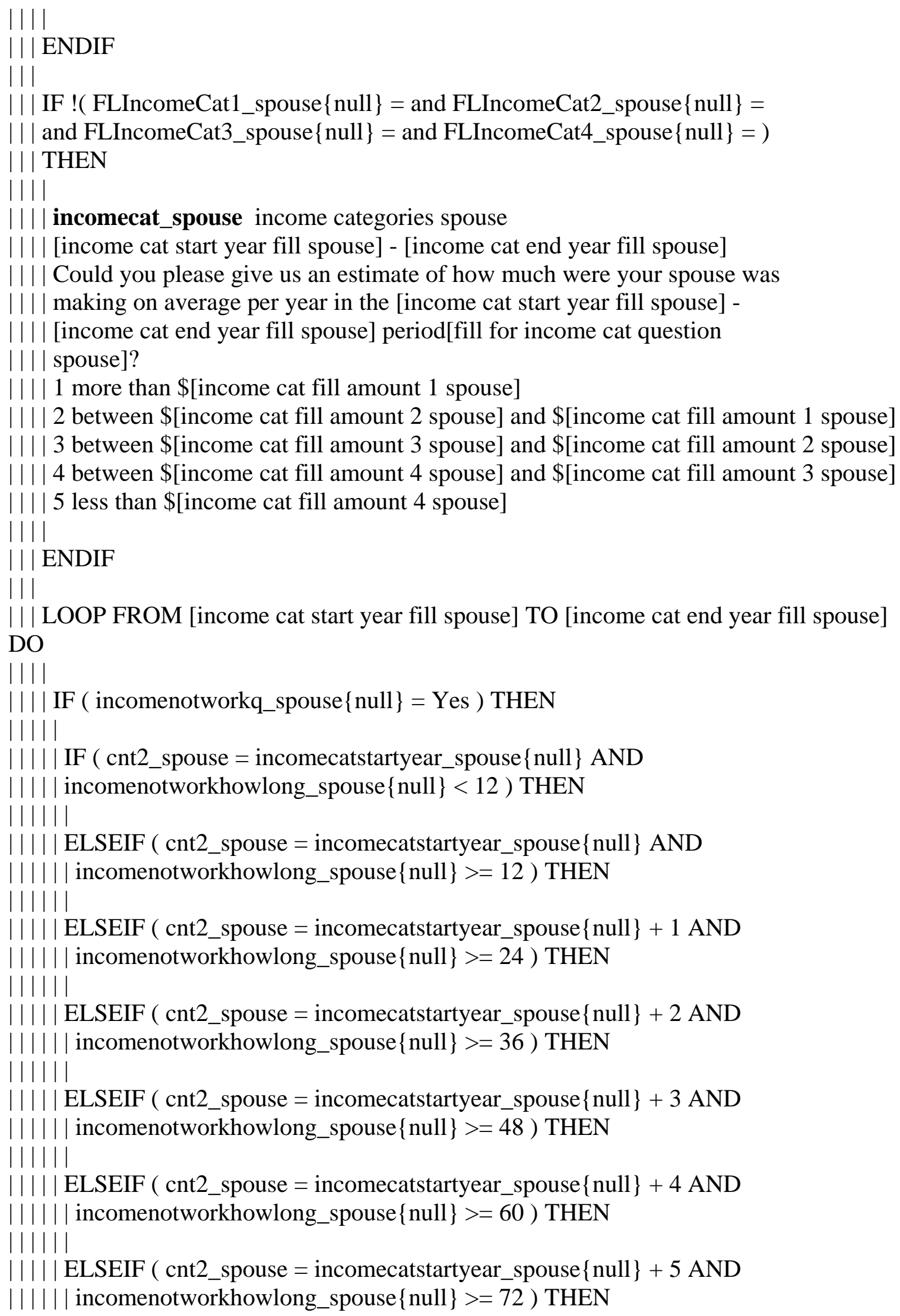




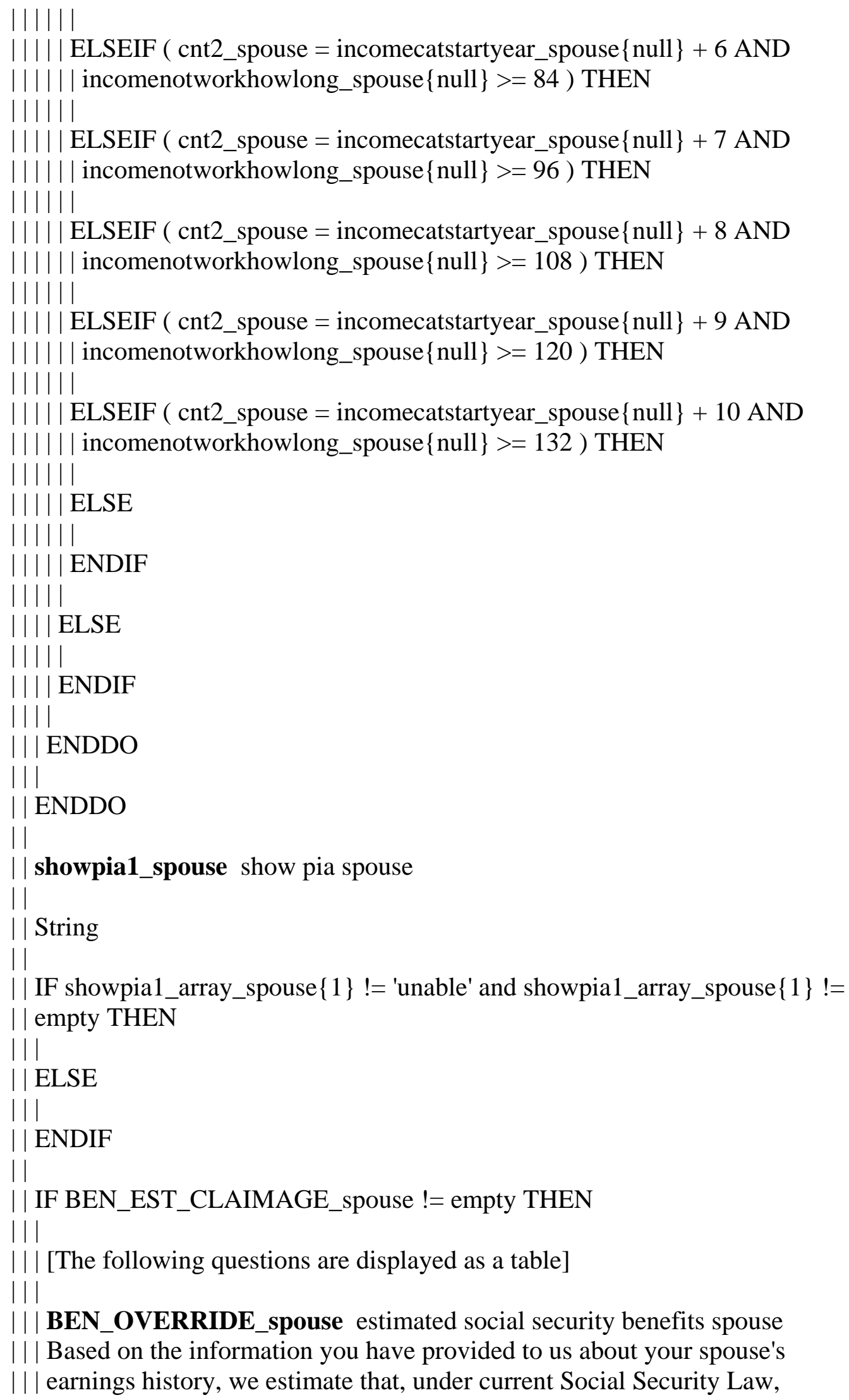


| | your spouse is supposed to get a Social Security retirement benefit of | | approximately \$[] per month if she claims benefits at age [claiming age II| spouse]. Think of any dollar amount mentioned in this survey in terms of

| | | what a dollar buys you today (because Social Security will adjust future

| | dollar amounts for inflation). Our estimate does not take into account

| | Social Security benefits you may receive based on the earnings of a past

| | or current spouse. Do you think our estimate is about right?

| | 1 Yes, I believe the Social Security benefits my spouse is supposed to get at [claiming age spouse] are roughly $\$[$ per month.

| || 2 No, I believe the Social Security benefits my spouse is supposed to get are roughly \$\$Answer2\$ per month.

|l|

| | BEN_NEW_spouse benefits new spouse

|l

| | Integer

||

| | | [End of table display]

| | | IF BEN_NEW_spouse > 4000 THEN

|l|

| | | checkBEN_NEW4000_spouse benefits new check $>4000$ spouse

| | | | Due to how Social Security calculates your spouse's benefits, it is very

| | | unlikely that your spouse's monthly benefit will be this high. Please

| | | go back and change your answer to something between $\$ 0$ and $\$ 4000$ per

|l | month.

|l|

| | ENDIF

|l |

| | | IF BEN_NEW_spouse < THEN

|ll|

| | | checkBEN_NEW0_spouse benefits new check < 0 spouse

| | | Monthly Social Security benefits cannot be negative. Please go back and

| | | change your answer to something between $\$ 0$ and $\$ 4000$ per month.

|ll|

| | ENDIF

|l|

| | IF BEN_OVERRIDE_spouse = No, I believe the Social Security benefits my

| | | spouse is supposed to get are roughly $\$ \$$ Answer 2 per month. and

| | BEN_NEW_spouse = empty THEN

|l|

| | | checkBEN_NEWempty_spouse benefits new check value empty spouse

| | | Y You selected the second option but did not fill in a value. Your answers

| | | | are important to us. Please go back and fill in a value.

|l|

|| ENDIF

|l|

| | | IF BEN_OVERRIDE_spouse = No, I believe the Social Security benefits my 
| | spouse is supposed to get are roughly $\$$ \$Answer2\$ per month. and

| | BEN_NEW_spouse != empty THEN

|l||

| | | ELSEIF BEN_OVERRIDE_spouse = No, I believe the Social Security benefits

| | | my spouse is supposed to get are roughly $\$$ \$Answer 2 per month. and

| | | BEN_NEW_spouse = empty THEN

|l||

|| ENDIF

III

|| ENDIF

||

|| IF BEN_OVERRIDE_spouse = No, I believe the Social Security benefits my

|| spouse is supposed to get are roughly \$\$Answer2\$ per month. THEN

|l|

| | | [The following questions are displayed as a table]

|l

| | OVERRIDE_WHY_spouse Reason why R changed our estimate spouse

| | | Thank you for correcting our estimate of your spouse's Social Security

| | | benefits. We are interested in knowing what this correction was based on.

| | Please check all boxes that apply.

|| 1 I know the amount of Social Security that my spouse supposed to get from her annual Social Security mailing

| | 2 I included Social Security survivor benefits that you did not include in your estimate

| | 3 I included Social Security spousal benefits that you did not include in your estimate

| | 4 I included Social Security disability benefits that you did not include in your estimate

| | 5 Your estimate simply didn't appear right to me

| | 6 Other (please specify): \$Answer2\$

|l|

| | OVERRIDE_WHY_other_spouse Reason why R changed our estimate other spouse

III

|| String

|l|

| | [End of table display]

|| ENDIF

|l

| ELSE

II

| ENDIF

I

| IF survivor1_round < THEN

II

| ENDIF

IF survivor2_round $<$ THEN 


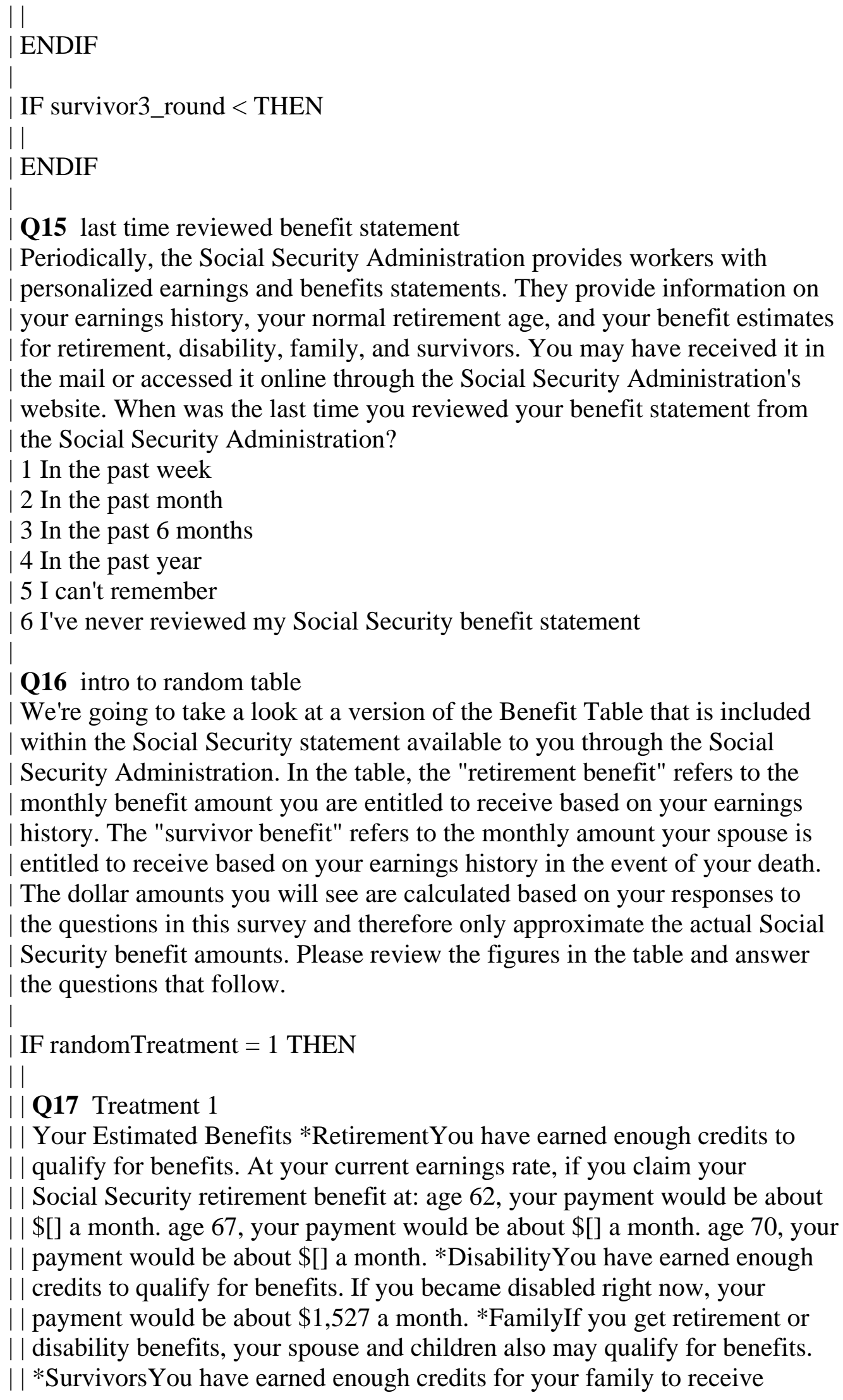


|| survivors benefits. If you die this year, certain members of your family may

|| qualify for the following benefits: Your

| child $\$ 1,176$

| | a month Your spouse who is caring for your child. $\$ 1,176$ a

|| month Your spouse, if benefits start at full retirement age...\$[] a month ||

| ELSEIF randomTreatment $=2$ THEN

||

| Q18 Treatment 2

|| Your Estimated Benefits *RetirementYou have earned enough credits to

|| qualify for benefits. At your current earnings rate, if you claim your

|| Social Security retirement benefit at: age 62, your payment would be about

|| \$[] a month. age 67, your payment would be about \$[] a month. age 70, your

| payment would be about $\$[$ a month. *SurvivorThe amount of your spouse's

|| survivor benefit will depend on your age when you claim your Social Security

|| retirement benefit. If you claim at: age 62, your spouse's payment would be

|| about \$[survivor 62] a month. age 67, your spouse's payment would be about

|| \$[survivor 67] a month. age 70, your spouse's payment would be about

|| \$[survivor 70] a month. *FamilyIf you get retirement or disability

|| benefits, your spouse and children also may qualify for benefits. Your

|| child...............................................\$1,176 a month Your

|| spouse who is caring for your child...\$1,176 a month *DisabilityYou have

| | earned enough credits to qualify for benefits. If you became disabled right

|| now, you payment would be about $\$ 1,527$ a month.

|l

| ELSEIF randomTreatment $=3$ THEN

||

|| Q19 vignette for treatment 3

| If you are married and die before your spouse, he or she may be eligible for

|| a "survivor" benefit from Social Security based on your work record. The

|| amount of the survivor benefit that you leave to your surviving spouse will

I depend on two factors: (1) your spouse's own work record and (2) your age

|| when you start receiving your retirement benefit (i.e., your "claim age").

|| The following examples illustrate how these factors affect the amount your

|| spouse receives from Social Security based on your work record in the event

|| of your death. (1) Your Spouse's Work Record Your spouse is eligible to

| receive a survivor benefit that is equal to the full amount of your

|| retirement benefit, less the amount of any retirement benefit your spouse

|| receives based on his or her own work record. To see how your spouse's work

|| record affects the amount of the survivor benefit he or she will receive,

|| consider the following hypothetical examples: Hypothetical 1: You are

| entitled to receive a retirement benefit of $\$ 1,600$ per month. Your spouse is

| not entitled to receive a retirement benefit based on his or her own work

| record. Your surviving spouse will receive \$1,600 each month from Social

|| Security. The survivor benefit based on your work history will account for

| \$1,600 of this amount. Hypothetical 2: You are entitled to receive a 
| retirement benefit of $\$ 1,600$ per month. Your spouse is entitled to a

|| retirement benefit of $\$ 600$ based on his or her own work record. Your

| | surviving spouse will receive \$1,600 each month from Social Security. The

| survivor benefit based on your work history will account for $\$ 1,000$ of this

| | amount. (2) Your Claim Age Your spouse's survivor benefit is reduced

|| for each month that you start receiving benefits before age 70 . Thus, the

|| earlier you claim your retirement benefit, the smaller your spouse's

| survivor benefit will be. By claiming at age 62 instead of at age 70, you

I| can reduce the amount that your surviving spouse can expect to receive by as

I much as 37.5 percent. The following hypothetical examples illustrate how

| your claim age can affect the amount of the survivor benefit your spouse is

|| eligible to receive. Hypothetical 3: You are entitled to receive a

|| retirement benefit of $\$ 1,600$ per month at age 66. Your spouse is not

I| entitled to receive a retirement benefit based on his or her own work

|| record. If you claim at age 62 , your surviving spouse will receive $\$ 1,320$

|| each month from Social Security. The survivor benefit based on your work

| history will account for $\$ 1,320$ of this amount. If you claim at age 66,

| | your surviving spouse will receive $\$ 1,600$ each month from Social Security.

|| The survivor benefit based on your work history will account for \$1,600 of

|| this amount. If you claim at age 70, your surviving spouse will receive

| \$ 2,110 each month from Social Security. The survivor benefit based on your

|| work history will account for $\$ 2,110$ of this amount. Hypothetical 4: You

| | are entitled to receive a retirement benefit of \$1,600 per month at age 66 .

|| Your spouse is entitled to a retirement benefit of $\$ 600$ based on his or her

| own work record. If you claim at age 62, your surviving spouse will

|| receive \$1,320 each month from Social Security. The survivor benefit based

| on your work history will account for $\$ 720$ of this amount. If you claim

| | at age 66, your surviving spouse will receive \$1,600 each month from Social

|| Security. The survivor benefit based on your work history will account for

| \$1,000 of this amount. If you claim at age 70 , your surviving spouse

|| will receive \$2,110 each month from Social Security. The survivor benefit

| | based on your work history will account for $\$ 1,510$ of this amount.

|l

|| Q20 Treatment 3

|| Your Estimated Benefits *RetirementYou have earned enough credits to

|| qualify for benefits. At your current earnings rate, if you claim your

|| Social Security retirement benefit at: age 62, your payment would be about

|| \$[] a month. age 67, your payment would be about \$[] a month. age 70, your

I| payment would be about \$[] a month. *DisabilityYou have earned enough

|| credits to qualify for benefits. If you became disabled right now, your

|| payment would be about $\$ 1,527$ a month. *FamilyIf you get retirement or

|| disability benefits, your spouse and children also may qualify for benefits.

|| *SurvivorsYou have earned enough credits for your family to receive

|| survivors benefits. If you die this year, certain members of your family may

|| qualify for the following benefits: Your

|| child $\$ 1,176$ 
|| a month Your spouse who is caring for your child...................\$1,176 a

|| month Your spouse, if benefits start at full retirement age...\$[] a month

||

| ELSE

|l

|| Q21 vignette for treatment 4

|| If you are married and die before your spouse, he or she may be eligible for

|| a "survivor" benefit from Social Security based on your work record. The

I amount of the survivor benefit that you leave to your surviving spouse will

I depend on two factors: (1) your spouse's own work record and (2) your age

|| when you start receiving your retirement benefit (i.e., your "claim age").

|| The following examples illustrate how these factors affect the amount your

|| spouse receives from Social Security based on your work record in the event

|| of your death. (1) Your Spouse's Work Record Your spouse is eligible to

|| receive a survivor benefit that is equal to the full amount of your

|| retirement benefit, less the amount of any retirement benefit your spouse

|| receives based on his or her own work record. To see how your spouse's work

|| record affects the amount of the survivor benefit he or she will receive,

|| consider the following hypothetical examples: Hypothetical 1: You are

| entitled to receive a retirement benefit of $\$ 1,600$ per month. Your spouse is

|| not entitled to receive a retirement benefit based on his or her own work

| record. Your surviving spouse will receive \$1,600 each month from Social

|| Security. The survivor benefit based on your work history will account for

| \$ \$,600 of this amount. Hypothetical 2: You are entitled to receive a

|| retirement benefit of $\$ 1,600$ per month. Your spouse is entitled to a

|| retirement benefit of $\$ 600$ based on his or her own work record. Your

| | surviving spouse will receive \$1,600 each month from Social Security. The

| | survivor benefit based on your work history will account for $\$ 1,000$ of this

|| amount. (2) Your Claim Age Your spouse's survivor benefit is reduced

|| for each month that you start receiving benefits before age 70 . Thus, the

|| earlier you claim your retirement benefit, the smaller your spouse's

|| survivor benefit will be. By claiming at age 62 instead of at age 70, you

|| can reduce the amount that your surviving spouse can expect to receive by as

|| much as 37.5 percent. The following hypothetical examples illustrate how

| your claim age can affect the amount of the survivor benefit your spouse is

|| eligible to receive. Hypothetical 3: You are entitled to receive a

|| retirement benefit of \$1,600 per month at age 66. Your spouse is not

| entitled to receive a retirement benefit based on his or her own work

|| record. If you claim at age 62, your surviving spouse will receive $\$ 1,320$

|| each month from Social Security. The survivor benefit based on your work

| history will account for $\$ 1,320$ of this amount. If you claim at age 66,

| | your surviving spouse will receive $\$ 1,600$ each month from Social Security.

|| The survivor benefit based on your work history will account for $\$ 1,600$ of

|| this amount. If you claim at age 70, your surviving spouse will receive

| \$2,110 each month from Social Security. The survivor benefit based on your

| | work history will account for $\$ 2,110$ of this amount. Hypothetical 4: You 
|| are entitled to receive a retirement benefit of $\$ 1,600$ per month at age 66 .

|| Your spouse is entitled to a retirement benefit of $\$ 600$ based on his or her | own work record. If you claim at age 62, your surviving spouse will

|| receive \$1,320 each month from Social Security. The survivor benefit based

|| on your work history will account for $\$ 720$ of this amount. If you claim

| | at age 66, your surviving spouse will receive \$1,600 each month from Social

|| Security. The survivor benefit based on your work history will account for

|| $\$ 1,000$ of this amount. If you claim at age 70 , your surviving spouse

| | will receive \$2,110 each month from Social Security. The survivor benefit

| | based on your work history will account for $\$ 1,510$ of this amount.

||

| Q22 Treatment 4

|| Your Estimated Benefits *RetirementYou have earned enough credits to

|| qualify for benefits. At your current earnings rate, if you claim your

|| Social Security retirement benefit at: age 62, your payment would be about

|| \$[] a month. age 67, your payment would be about \$[] a month. age 70, your

|| payment would be about \$[] a month. *SurvivorThe amount of your spouse's

|| survivor benefit will depend on your age when you claim your Social Security

| retirement benefit. If you claim at: age 62, your spouse's payment would be

|| about $\$$ [survivor 62] a month. age 67, your spouse's payment would be about

|| \$[survivor 67] a month. age 70, your spouse's payment would be about

|| \$[survivor 70] a month. *FamilyIf you get retirement or disability

| | benefits, your spouse and children also may qualify for benefits. Your

|| child...............................................\$1,176 a month Your

|| spouse who is caring for your child...\$1,176 a month *DisabilityYou have

|| earned enough credits to qualify for benefits. If you became disabled right

|| now, you payment would be about $\$ 1,527$ a month.

||

| ENDIF

Q23 age start SS affect spouse SS if die

| According to the table, can the age when you decide to start receiving your

| own Social Security retirement benefit affect the amount of the monthly

| survivor benefit your spouse can expect to receive from Social Security if you

die?

1 Yes, it can.

2 No, it cannot.

| 3 Not sure.

IF Q23 = Yes, it can. THEN

|l

|| Q24 earliest age spouse highest survivor benefit

|| What is the earliest age at which you should start receiving your Social

|| Security retirement benefit if you want your spouse to receive the highest

|| possible monthly survivor benefit in the event of your death?

|| 162 
Q25 monthly survivor benefit your spouse can expect to receive

If you claim at age 62, what is the approximate value of the monthly survivor | benefit your spouse can expect to receive? Please enter the dollar amount | below. (Do not use commas.)

| Integer

| Q26 survivor and retirement benefit concept

| Let's say you receive a retirement benefit of $\$ 1800$ from Social Security | based on your work history. Let's also say that your spouse receives a | retirement benefit of $\$ 700$ from Social Security based on her own work history. If you die, what is the amount of the survivor benefit your spouse will | receive from Social Security based on your work history? Please enter the | dollar amount below. (Do not use commas.) | Integer

Q27 thought about claim age

| You may start receiving your Social Security benefit at any time between age | 62 and age 70. Have you ever tried to figure out when you should start | receiving your retirement benefit from Social Security?

1 Yes

| 2 No

|

| IF Q27 = Yes THEN

II

|| Q28 thought about claim age

|| How much time would you say that you have spent thinking about when you will | start receiving your benefit?

|| 1 A great deal

|| 2 A lot

II 3 A moderate amount

|| 4 A little

| 5 None at all

||

| ENDIF

1 
| Q29 age think start receiving SS retirement benefit

| At what age do you think you will you start receiving your Social Security

| retirement benefit?

| 1 Age 62

| 2 Age 63

| 3 Age 64

| 4 Age 65

5 Age 66

| 6 Age 67

| 7 Age 68

| 8 Age 69

| 9 Age 70

।

\section{ENDIF}

IF ! ( WORK_FOR_PAY = Yes and SS_STATUS = I receive Social Security benefits now. ) THEN

| [The following questions are displayed as a table]

Q30 factors in claiming

| What are the factors do you think will matter the most to you when you decide | when to start receiving your benefit? Please check all that apply.

| 1 How my claim age will affect the amount I will receive

| 2 How my claim age will affect the amount my family is eligible to receive

| 3 The financial strength of the Social Security system

| 4 The age when I will stop working

5 My health and longevity

| 6 My income needs at the time

7 My retirement savings

| 8 Other (please specify): \$Answer2\$

| Q30_other factors in claiming other

|

| String

| [End of table display]

Q31 chance of reduction

| On a scale from 0 to 100 - where $0=$ "absolutely no chance" and $100=$

| "absolutely certain" - what do you think is the percent chance that over the

| next 10 years there will be changes to Social Security that will reduce your

| future benefits compared to what you would get under the current system?

100

111

22

133 


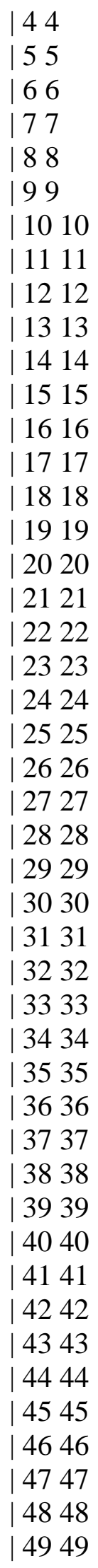




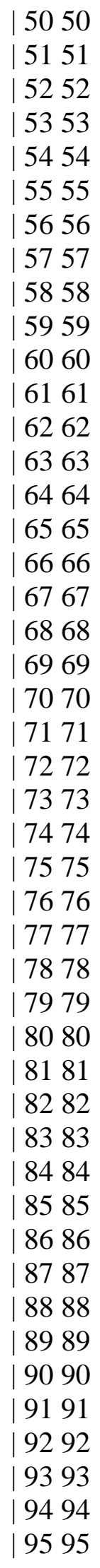


| IF Q31 > 0 THEN

II

| Q32 promised benefit

|| Thinking about changes to Social Security that will reduce your future | | benefit, indicate how much of your promised benefit you expect to receive | from the options below.

| 1 I expect to receive most of the benefits currently promised to me.

|| 2 I expect to receive about half of the benefits currently promised to me.

|| 3 I expect to receive very little of the benefits currently promised to me.

|| 4 I do not expect to receive any of the benefits currently promised to me. 11

| ENDIF

|

| Q33 discount

| Next we would like to ask you some questions which assess how people use | numbers in everyday life. Would you rather receive 100 Dollars today or 200 Dollars in 12 months?

| 1100 Dollars today

| 2200 Dollars in 12 months

\section{Q34 lottery}

If 5 people all have the winning numbers in the lottery and the prize is two | million dollars, how much will each of them get? (Do not use commas.) | Integer

|

\section{Q35 disease}

If the chance of getting a disease is 10 percent, how many people out of 1,000 | would be expected to get the disease?

| Integer

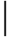

| Q36 interest

| Suppose you had \$100 in a savings account and the interest rate was 2\% per year. After 5 years, how much do you think you would have in the account if | you left the money to grow?

| 1 More than $\$ 102$

| 2 Exactly $\$ 102$

| 3 Less than $\$ 102$

| 4 Do not know

| Q37 inflation 1 
| Imagine that the interest rate on your savings account was 1\% per year and | inflation was $2 \%$ per year. After 1 year, would you be able to buy more than | today, exactly the same as today, or less than today with the money in this | account?

1 More than today

| 2 Exactly the same as today

3 Less than today

4 Do not know

|

Q38 stocks

| Do you think that the statement "Buying a single company stock usually | provides a safer return than a stock mutual fund." Is this true or false?

1 True

2 False

| 3 Do not know

1

ENDIF

lifeexpectancyself life expectancy self

The life expectancy of the average male is currently 76.3 years of age. The life expectancy of the average female is 81.1 years of age. With this in mind, how likely do you believe it is that you will live longer than the average life expectancy?

1 Very likely

2 Somewhat likely

3 Neither likely nor unlikely

4 Somewhat unlikely

5 Very unlikely

lifeexpectancyspouse life expectancy spouse

The life expectancy of the average male is currently 76.3 years of age. The life expectancy of the average female is 81.1 years of age. With this in mind, how likely do you believe it is that your spouse will live longer than the average life expectancy?

1 Very likely

2 Somewhat likely

3 Neither likely nor unlikely

4 Somewhat unlikely

5 Very unlikely

relativelifeexpectancy relative life expectancy

How likely do you believe it is that you will live longer than your spouse?

1 Very likely

2 Somewhat likely

3 Neither likely nor unlikely

4 Somewhat unlikely 
5 Very unlikely

\section{CS_001 HOW PLEASANT INTERVIEW}

Could you tell us how interesting or uninteresting you found the questions in this interview?

1 Very interesting

2 Interesting

3 Neither interesting nor uninteresting

4 Uninteresting

5 Very uninteresting

CS_003 comments

Do you have any other comments on the interview? Please type these in the box below.

Open

Figure 3A. Follow-up Survey Instrument

\section{Well Being 463}

Introduction introduction

This is a brief follow-up to a survey you took a few weeks ago. We would like to ask you a few questions about the information you read when you took the survey. As before, we are interested in understanding people's beliefs about Social Security benefits including how much they expect to receive and what factors might influence the amount they receive. We are also interested in understanding people's beliefs about the survivor benefits that widowed spouses can expect to receive based on the deceased spouse's work history. This study will help create clearer and easier-to-understand materials about the Social Security program. Like the previous survey, some questions may be hard to answer exactly. Please take time to consider the questions and give us your best guess even if you do not know the exact answer. Having even your best guess will be very helpful to us. Thank you very much for your help.

Q1 remember taking survey

A few weeks ago, you took part in a survey that calculated the Social Security benefits you and your spouse can expect to receive based on your earnings history. After they were calculated, these benefits were presented to you in a table and you were asked a few questions related to them. Do you remember taking the survey described above?

1 Yes

2 No 
IF Q1 = No THEN

|

Q2 participation helpful

| Even if you did not take the survey, or do remember taking the survey, please

| take time to consider the questions that follow to the best of your ability.

| Your participation will be very helpful to us.

|

\section{ENDIF}

Q7 age think start receiving SS retirement benefit

At what age do you think you will you start receiving your Social Security retirement benefit?

162

263

364

465

566

667

768

869

970

Q3 age start SS affect spouse SS if die

Can the age when you decide to start receiving your own Social Security

retirement benefit affect the amount of the monthly survivor benefit your spouse can expect to receive from Social Security if you die?

1 Yes, it can

2 No, it cannot

3 Not sure

IF Q3 = Yes, it can THEN

Q4 earliest age spouse highest survivor benefit

| What is the earliest age at which you should start receiving your Social

| Security retirement benefit if you want your spouse to receive the highest

| possible monthly survivor benefit in the event of your death?

162

263

1364

465

1566

1 667

1768

869

| 970 
| Q6 survivor and retirement benefit concept

| Let's say you receive a retirement benefit of $\$ 2200$ from Social Security based | on your work history. Let's also say that your spouse receives a retirement | benefit of $\$ 1000$ from Social Security based on her own work history. If you die, what is the amount of the survivor benefit your spouse will receive from | Social Security based on your work history? Please enter the dollar amount | below. (Do not use commas.)

| Integer

I

ELSE

|

| Q6_noback survivor and retirement benefit concept

| Let's say you receive a retirement benefit of $\$ 2200$ from Social Security based on your work history. Let's also say that your spouse receives a retirement | benefit of $\$ 1000$ from Social Security based on her own work history. If you | die, what is the amount of the survivor benefit your spouse will receive from | Social Security based on your work history? Please enter the dollar amount | below. (Do not use commas.)

| Integer

|

\section{ENDIF}

Q8 retirement benefit recall

How much did the survey indicate that you can expect to receive from Social Security if you claim at age 66? Please enter the dollar amount below. (Do not use commas.)

Integer

Q9 spouse retirement benefit recall

How much did the survey indicate that your spouse can expect to receive from Social Security if your spouse claims at age 66? Please enter the dollar amount below. (Do not use commas.)

Integer

Q10 spouse survivor benefit recall

If you claim at age 66, what is the approximate value of the monthly survivor benefit your spouse can expect to receive? Please enter the dollar amount below. (Do not use commas.)

Integer

Q5 monthly survivor benefit your spouse can expect to receive

If you claim at age 62, what is the approximate value of the monthly survivor benefit your spouse can expect to receive? Please enter the dollar amount below. (Do not use commas.)

Integer 


\section{CS_001 HOW PLEASANT INTERVIEW}

Could you tell us how interesting or uninteresting you found the questions in this interview?

1 Very interesting

2 Interesting

3 Neither interesting nor uninteresting

4 Uninteresting

5 Very uninteresting

CS_003 comments

Do you have any other comments on the interview? Please type these in the box below.(If you have no comments, please click next to complete this survey.) Open 


\section{Appendix C}

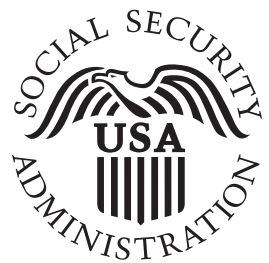

\section{Your payment would be about}

$\$ 1,115$ a month at full retirement age

WANDA WORKER

456 ANYWHERE AVENUE

MAINTOWN, USA 11111-1111

January 2, 2017

\section{Your Social Security Statement}

Your Social Security Statement shows how much you have paid in Social Security and Medicare taxes. It explains about how much you would get in Social Security benefits when you reach full retirement age. If you become disabled and unable to work, you may be eligible for disability benefits. In addition, if the family members who depend on you outlive you, they may be eligible for survivor benefits.

Take a look at your earnings. Your earnings determine how much you get in benefits. If you find an error, please let us know right away.

Social Security benefits are not intended to be your only income source when you retire. On average, Social Security will replace about 40 percent of your annual pre-retirement earnings. You will need other savings, investments, pensions, or retirement accounts to live comfortably. Use this Statement as a tool for planning your financial future.

To see your Statement online anytime, create a my Social Security account at myaccount.socialsecurity.gov.

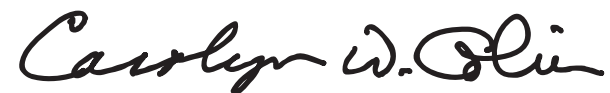

Carolyn W. Colvin

Acting Commissioner 


\section{Your Estimated Benefits}

*Retirement You have earned enough credits to qualify for benefits. At your current earnings rate, if you continue working until...

your full retirement age (67 years), your payment would be about..............................................\$ 1,115 a month

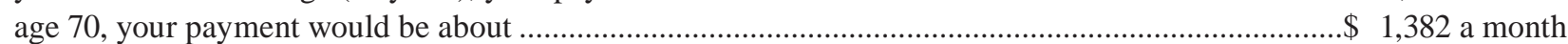

age 62, your payment would be about ...................................................................................\$ 785 a month

*Disability You have earned enough credits to qualify for benefits. If you became disabled right now, your payment would be about

\$ 1,075 a month

*Family If you get retirement or disability benefits, your spouse and children also may qualify for benefits.

*Survivors You have earned enough credits for your family to receive survivors benefits. If you die this year, certain members of your family may qualify for the following benefits:

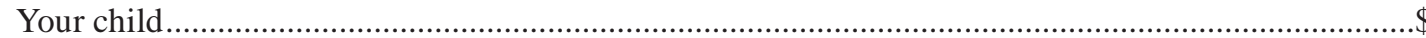

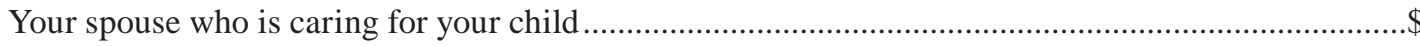

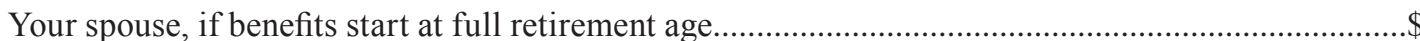

Total family benefits cannot be more than

835 a month

835 a month

\$1,114 a month

Your spouse or minor child may be eligible for a special one-time death benefit of $\$ 255$.

Medicare $\quad$ You have enough credits to qualify for Medicare at age 65. Even if you do not retire at age 65, be sure to contact Social Security three months before your 65th birthday to enroll in Medicare.

* Your estimated benefits are based on current law. Congress has made changes to the law in the past and can do so at any time. The law governing benefit amounts may change because, by 2034, the payroll taxes collected will be enough to pay only about 79 percent of scheduled benefits.

We based your benefit estimates on these facts:

Your date of birth (please verify your name on page 1 and this date of birth)

April 5, 1992

Your estimated taxable earnings per year after 2017 ....

$\$ 22,555$

Your Social Security number (only the last four digits are shown to help prevent identity theft).

XXX-XX-1234

\section{How Your Benefits Are Estimated}

To qualify for benefits, you earn "credits" through your work up to four each year. This year, for example, you earn one credit for each $\$ 1,300$ of wages or self-employment income. When you've earned $\$ 5,200$, you've earned your four credits for the year. Most people need 40 credits, earned over their working lifetime, to receive retirement benefits. For disability and survivors benefits, young people need fewer credits to be eligible.

We checked your records to see whether you have earned enough credits to qualify for benefits. If you haven't earned enough yet to qualify for any type of benefit, we can't give you a benefit estimate now. If you continue to work, we'll give you an estimate when you do qualify.

What we assumed - If you have enough work credits, we estimated your benefit amounts using your average earnings over your working lifetime. For 2017 and later (up to retirement age), we assumed you'll continue to work and make about the same as you did in 2015 or 2016 . We also included credits we assumed you earned last year and this year.

Generally, the older you are and the closer you are to retirement, the more accurate the retirement estimates will be because they are based on a longer work history with fewer uncertainties such as earnings fluctuations and future law changes. We encourage you to use our online Retirement Estimator at www.socialsecurity.gov/estimator to obtain immediate and personalized benefit estimates.

We can't provide your actual benefit amount until you apply for benefits. And that amount may differ from the estimates stated above because:

(1) Your earnings may increase or decrease in the future.

(2) After you start receiving benefits, they will be adjusted for cost-of-living increases.
(3) Your estimated benefits are based on current law. The law governing benefit amounts may change.

(4) Your benefit amount may be affected by military service, railroad employment or pensions earned through work on which you did not pay Social Security tax. Visit www.socialsecurity.gov to learn more.

Windfall Elimination Provision (WEP) - In the future, if you receive a pension from employment in which you do not pay Social Security taxes, such as some federal, state or local government work, some nonprofit organizations or foreign employment, and you also qualify for your own Social Security retirement or disability benefit, your Social Security benefit may be reduced, but not eliminated, by WEP. The amount of the reduction, if any, depends on your earnings and number of years in jobs in which you paid Social Security taxes, and the year you are age 62 or become disabled. For more information, please see Windfall Elimination Provision (Publication No. 05-10045) at www.socialsecurity.gov/WEP.

Government Pension Offset (GPO) — If you receive a pension based on federal, state or local government work in which you did not pay Social Security taxes and you qualify, now or in the future, for Social Security benefits as a current or former spouse, widow or widower, you are likely to be affected by GPO. If GPO applies, your Social Security benefit will be reduced by an amount equal to two-thirds of your government pension, and could be reduced to zero. Even if your benefit is reduced to zero, you will be eligible for Medicare at age 65 on your spouse's record. To learn more, please see Government Pension Offset (Publication No. 05-10007) at www.socialsecurity.gov/GPO. 


\section{Your Earnings Record}

$\begin{array}{ccc}\begin{array}{c}\text { Years You } \\ \text { Worked }\end{array} & \begin{array}{c}\text { Youred } \\ \text { Social Security } \\ \text { Earnings }\end{array} & \begin{array}{c}\text { Your Taxed } \\ \text { Medicare } \\ \text { Earnings }\end{array} \\ 2008 & 1,186 & 1,186 \\ 2009 & 2,804 & 2,804 \\ 2010 & 4,983 & 4,983 \\ 2012 & 8,489 & 8,489 \\ 2013 & 11,608 & 11,608 \\ 2014 & 14,069 & 14,069 \\ 2015 & 17,516 & 17,516 \\ 2016 & 22,555 & 22,555 \\ & \text { Not yet recorded }\end{array}$

You and your family may be eligible for valuable benefits:

When you die, your family may be eligible to receive survivors benefits.

Social Security may help you if you become disabledeven at a young age.

A young person who has worked and paid Social Security taxes in as few as two years can be eligible for disability benefits.

Social Security credits you earn move with you from job to job throughout your career.

Total Social Security and Medicare taxes paid over your working career through the last year reported on the chart above:

Estimated taxes paid for Social Security:

You paid:

Your employers paid:
$\$ 4,757$

$\$ 5,159$
Estimated taxes paid for Medicare:

You paid: $\quad \$ 1,207$

Your employers paid:
$\$ 1,207$

Note: Currently, you and your employer each pay a 6.2 percent Social Security tax on up to $\$ 127,200$ of your earnings and a $1.45 *$ percent Medicare tax on all your earnings. If you are self-employed, you pay the combined employee and employer amount, which is a 12.4 percent Social Security tax on up to $\$ 127,200$ of your net earnings and a $2.9 *$ percent Medicare tax on your entire net earnings.

*If you have earned income of more than $\$ 200,000$ ( $\$ 250,000$ for married couples filing jointly), you must pay 0.9 percent more in Medicare taxes.

\section{Help Us Keep Your Earnings Record Accurate}

You, your employer and Social Security share responsibility for the accuracy of your earnings record. Since you began working, we recorded your reported earnings under your name and Social Security number. We have updated your record each time your employer (or you, if you're self-employed) reported your earnings.

Remember, it's your earnings, not the amount of taxes you paid or the number of credits you've earned, that determine your benefit amount. When we figure that amount, we base it on your average earnings over your lifetime. If our records are wrong, you may not receive all the benefits to which you're entitled.

Review this chart carefully using your own records to make sure our information is correct and that we've recorded each year you worked. You're the only person who can look at the earnings chart and know whether it is complete and correct.

Some or all of your earnings from last year may not be shown on your Statement. It could be that we still were processing last year's earnings reports when your Statement was prepared. Your complete earnings for last year will be shown on next year's Statement. Note: If you worked for more than one employer during any year, or if you had both earnings and self-employment income, we combined your earnings for the year.

There's a limit on the amount of earnings on which you pay Social Security taxes each year. The limit increases yearly. Earnings above the limit will not appear on your earnings chart as Social Security earnings. (For Medicare taxes, the maximum earnings amount began rising in 1991. Since 1994, all of your earnings are taxed for Medicare.)

Call us right away at 1-800-772-1213 (7 a.m.-7 p.m. your local time) if any earnings for years before last year are shown incorrectly. Please have your W-2 or tax return for those years available. (If you live outside the U.S., follow the directions at the bottom of page 4.) 


\section{Some Facts About Social Security}

\begin{abstract}
About Social Security and Medicare...
Social Security pays retirement, disability, family and survivors benefits. Medicare, a separate program run by the Centers for Medicare \& Medicaid Services, helps pay for inpatient hospital care, nursing care, doctors' fees, drugs, and other medical services and supplies to people age 65 and older, as well as to people who have been receiving Social Security disability benefits for two years or more. Medicare does not pay for long-term care, so you may want to consider options for private insurance. Your Social Security covered earnings qualify you for both programs. For more information about Medicare, visit www.medicare.gov or call 1-800-633-4227 (TTY 1-877-486-2048 if you are deaf or hard of hearing).
\end{abstract}

Retirement - If you were born before 1938, your full retirement age is 65 . Because of a 1983 change in the law, the full retirement age will increase gradually to 67 for people born in 1960 and later.

Some people retire before their full retirement age. You can retire as early as 62 and take benefits at a reduced rate. If you work after your full retirement age, you can receive higher benefits because of additional earnings and credits for delayed retirement.

Disability - If you become disabled before full retirement age, you can receive disability benefits after six months if you have:

- enough credits from earnings (depending on your age, you must have earned six to 20 of your credits in the three to 10 years before you became disabled); and

- a physical or mental impairment that's expected to prevent you from doing "substantial" work for a year or more or result in death.

If you are filing for disability benefits, please let us know if you are on active military duty or are a recently discharged veteran, so that we can handle your claim more quickly.

Family - If you're eligible for disability or retirement benefits, your current or divorced spouse, minor children or adult children disabled before age 22 also may receive benefits. Each may qualify for up to about 50 percent of your benefit amount.

Survivors - When you die, certain members of your family may be eligible for benefits:

- your spouse age 60 or older (50 or older if disabled, or any age if caring for your children younger than age 16); and

- your children if unmarried and younger than age 18, still in school and younger than 19 years old, or adult children disabled before age 22 .

If you are divorced, your ex-spouse could be eligible for a widow's or widower's benefit on your record when you die.
Extra Help with Medicare - If you know someone who is on Medicare and has limited resources and income, Extra Help is available for prescription drug costs. The Extra Help can help pay the monthly premiums, annual deductibles and prescription co-payments. To learn more or to apply, visit $w w w . s o c i a l s e c u r i t y . g o v$ or call 1-800-772-1213 (TTY 1-800-325-0778).

\section{Receive benefits and still work...}

You can work and still get retirement or survivors benefits. If you're younger than your full retirement age, there are limits on how much you can earn without affecting your benefit amount. When you apply for benefits, we'll tell you what the limits are and whether work would affect your monthly benefits. When you reach full retirement age, the earnings limits no longer apply.

\section{Before you decide to retire...}

Carefully consider the advantages and disadvantages of early retirement. If you choose to receive benefits before you reach full retirement age, your monthly benefits will be reduced.

To help you decide the best time to retire, we offer a free publication, When To Start Receiving Retirement Benefits (Publication No. 05-10147), that identifies the many factors you should consider before applying. Most people can receive an estimate of their benefit based on their actual Social Security earnings record by going to www.socialsecurity.gov/estimator. You also can calculate future retirement benefits by using the Social Security Benefit Calculators at www.socialsecurity.gov.

Other helpful free publications include:

- Retirement Benefits (No. 05-10035)

- Understanding The Benefits (No. 05-10024)

- Your Retirement Benefit: How It Is Figured (No. 05-10070)

- Windfall Elimination Provision (No. 05-10045)

- Government Pension Offset (No. 05-10007)

- Identity Theft And Your Social Security Number (No. 05-10064)

We also have other leaflets and fact sheets with information about specific topics such as military service, self-employment or foreign employment. You can request Social Security publications at our website, www.socialsecurity.gov, or by calling us at 1-800-772-1213. Our website has a list of frequently asked questions that may answer questions you have. We have easy-to-use online applications for benefits that can save you a telephone call or a trip to a field office.

You also may qualify for government benefits outside of Social Security. For more information on these benefits, visit www.benefits.gov.

If you need more information - Visit www.socialsecurity.gov on the Internet, contact any Social Security office, call 1-800-772-1213 or write to Social Security Administration, Office of Earnings Operations, P.O. Box 33026, Baltimore, MD 21290-3026. If you're deaf or hard of hearing, call TTY 1-800-325-0778. If you have questions about your personal information, you must provide your complete Social Security number. If your address is incorrect on this Statement, ask the IRS to send you a Form 8822. We don't keep your address if you're not receiving Social Security benefits. 


\section{Social Security - What's In It For You socialsecurity.gov}

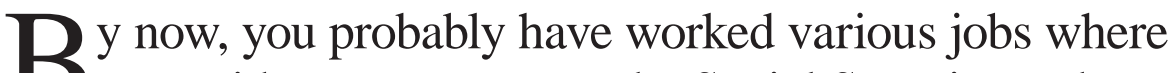
Dyou paid taxes to support the Social Security and Medicare programs. It's important you understand what these taxes are paying for, since you likely will be paying them for the rest of your working career.

The enclosed Social Security Statement shows how much you have paid in taxes and provides an estimate of how much you may receive in benefits when you are eligible. Please pay close attention to a few items:

- Check your earnings information. Your earnings will determine how much you will receive in Social Security benefit payments.

- If you find an error in your earnings, please let us know right away.

- If you change jobs or your marital status, please make sure your employer has the correct name and Social Security number on record.

\section{Why should I think about retirement now?}

We realize you have a long time to go until retirement. However, if you want to be able to look forward to financial security when the time comes, it is never too early to begin planning. The good news is that Social Security will provide the foundation for your retirement income.

Financial planners generally agree retirees will need about $70-80$ percent of preretirement earnings to enjoy a comfortable retirement. For an average worker, Social Security replaces about 40 percent of annual preretirement earnings, so you will need to save and invest to ensure an adequate income during retirement for you and your family.

While there are many unreliable and self-interested financial planning sources on the Internet, the federal government provides unbiased information at mymoney.gov.

You can maximize your savings through the power of compound interest and by starting early.

\section{Will Social Security be there for me?}

Social Security is there for you right now. Like most people, you probably think of Social Security as just a retirement program. However, depending on your circumstances, you may need the protection of Social Security well before retirement.

\section{Protection if you become disabled...}

Studies show that more than one in four 20-year-olds insured for disability benefits become disabled before reaching retirement age. As a result, they may need to rely on Social Security for income support.

\section{Protection when you die...}

Of course, we all hope to live long and healthy lives, but the truth is about one in seven of today's 20-year-olds will die before reaching age 67. More than two million children and surviving spouses caring for children receive Social Security survivor benefits because of a worker's death.

\section{How do I get my Statement in the future?}

You can get your Statement online anytime by creating your personal my Social

Security account. Create your account today at socialsecurity.gov/myaccount. We encourage you to check your earnings information on your Statement and compare it with your own records to make sure our information is correct.

We want to make sure you are getting full credit for the taxes you are paying, so you should review the earnings information each year. You also should access your Statement online periodically and get up-to-date estimates of your future benefits to see how your earnings are increasing the amount of those expected benefits.

There is a wealth of information and popular services available for you and your family at one convenient location on the Internet. Learn what you can do online by visiting socialsecurity.gov/onlineservices.

\section{Promise of security...}

It is true that Social Security faces financial problems, and action is needed soon to make sure the system can continue to pay approximately the same level of benefits. Social Security has been a contract between generations since 1935, and America has always kept the promise of security for workers and their families. 


\section{Your payment would be about $\$ 1,829$ a month at full retirement age}

WANDA WORKER

456 ANYWHERE AVENUE

MAINTOWN, USA 11111-1111

January 2, 2017

\section{Your Social Security Statement}

This Social Security Statement tells you about how much you or your family would receive in disability, survivor, or retirement benefits. It also includes our record of your lifetime earnings. Check out your earnings history, and let us know right away if you find an error. This is important because we base your benefits on our record of your lifetime earnings.

Social Security benefits are not intended to be your only source of income when you retire. On average, Social Security will replace about 40 percent of your annual pre-retirement earnings. You will need other savings, investments, pensions, or retirement accounts to make sure you have enough money to live comfortably when you retire.

To view your Statement online anytime, create a my Social Security account at myaccount.socialsecurity.gov.

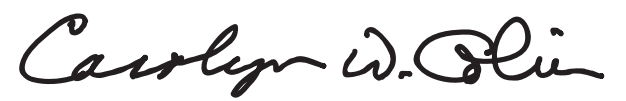

Carolyn W. Colvin

Acting Commissioner 


\section{Your Estimated Benefits}

\section{*Retirement You have earned enough credits to qualify for benefits. At your current earnings rate, if you}

continue working until...

your full retirement age (67 years), your payment would be about...............................................\$ 1,829 a month

age 70, your payment would be about .................................................................................\$ 2,280 a month

age 62, your payment would be about …....................................................................... 1,261 a month

*Disability You have earned enough credits to qualify for benefits. If you became disabled right now, your payment would be about

\$ 1,656 a month

*Family If you get retirement or disability benefits, your spouse and children also may qualify for benefits.

*Survivors You have earned enough credits for your family to receive survivors benefits. If you die this year, certain members of your family may qualify for the following benefits:

Your child..... \$ 1,277 a month

Your spouse who is caring for your child.

\$ 1,277 a month

Your spouse, if benefits start at full retirement age.

$\$ 1,703$ a month

Total family benefits cannot be more than

\$3,156 a month

Your spouse or minor child may be eligible for a special one-time death benefit of \$255.

Medicare You have enough credits to qualify for Medicare at age 65. Even if you do not retire at age 65, be sure to contact Social Security three months before your 65th birthday to enroll in Medicare.

* Your estimated benefits are based on current law. Congress has made changes to the law in the past and can do so at any time. The law governing benefit amounts may change because, by 2034 , the payroll taxes collected will be enough to pay only about 79 percent of scheduled benefits.

We based your benefit estimates on these facts:

Your date of birth (please verify your name on page 1 and this date of birth)

April 5, 1977

Your estimated taxable earnings per year after 2017 .....

$\$ 49,834$

Your Social Security number (only the last four digits are shown to help prevent identity theft).

XXX-XX-1234

\section{How Your Benefits Are Estimated}

To qualify for benefits, you earn "credits" through your work up to four each year. This year, for example, you earn one credit for each $\$ 1,300$ of wages or self-employment income. When you've earned $\$ 5,200$, you've earned your four credits for the year. Most people need 40 credits, earned over their working lifetime, to receive retirement benefits. For disability and survivors benefits, young people need fewer credits to be eligible.

We checked your records to see whether you have earned enough credits to qualify for benefits. If you haven't earned enough yet to qualify for any type of benefit, we can't give you a benefit estimate now. If you continue to work, we'll give you an estimate when you do qualify.

What we assumed - If you have enough work credits, we estimated your benefit amounts using your average earnings over your working lifetime. For 2017 and later (up to retirement age), we assumed you'll continue to work and make about the same as you did in 2015 or 2016 . We also included credits we assumed you earned last year and this year.

Generally, the older you are and the closer you are to retirement, the more accurate the retirement estimates will be because they are based on a longer work history with fewer uncertainties such as earnings fluctuations and future law changes. We encourage you to use our online Retirement Estimator at www.socialsecurity.gov/estimator to obtain immediate and personalized benefit estimates.

We can't provide your actual benefit amount until you apply for benefits. And that amount may differ from the estimates stated above because:

(1) Your earnings may increase or decrease in the future.

(2) After you start receiving benefits, they will be adjusted for cost-of-living increases.
(3) Your estimated benefits are based on current law. The law governing benefit amounts may change.

(4) Your benefit amount may be affected by military service, railroad employment or pensions earned through work on which you did not pay Social Security tax. Visit www.socialsecurity.gov to learn more.

Windfall Elimination Provision (WEP) — In the future, if you receive a pension from employment in which you do not pay Social Security taxes, such as some federal, state or local government work, some nonprofit organizations or foreign employment, and you also qualify for your own Social Security retirement or disability benefit, your Social Security benefit may be reduced, but not eliminated, by WEP. The amount of the reduction, if any, depends on your earnings and number of years in jobs in which you paid Social Security taxes, and the year you are age 62 or become disabled. For more information, please see Windfall Elimination Provision (Publication No. 05-10045) at www.socialsecurity.gov/WEP.

Government Pension Offset (GPO) — If you receive a pension based on federal, state or local government work in which you did not pay Social Security taxes and you qualify, now or in the future, for Social Security benefits as a current or former spouse, widow or widower, you are likely to be affected by GPO. If GPO applies, your Social Security benefit will be reduced by an amount equal to two-thirds of your government pension, and could be reduced to zero. Even if your benefit is reduced to zero, you will be eligible for Medicare at age 65 on your spouse's record. To learn more, please see Government Pension Offset (Publication No. 05-10007) at www.socialsecurity.gov/GPO. 


$\begin{array}{ccc}\begin{array}{c}\text { Your Taxed } \\ \text { Worked }\end{array} & \begin{array}{c}\text { Your Taxed } \\ \text { Social Security } \\ \text { Earnings }\end{array} & \begin{array}{c}\text { Medicare } \\ \text { Earnings }\end{array} \\ 1993 & 664 & 664 \\ 1994 & 1,636 & 1,636 \\ 1995 & 2,954 & 2,954 \\ 1996 & 5,118 & 5,118 \\ 1997 & 7,183 & 7,183 \\ 1998 & 9,046 & 9,046 \\ 1999 & 11,482 & 11,482 \\ 2000 & 15,079 & 15,079 \\ 2001 & 18,249 & 18,249 \\ 2002 & 20,722 & 20,722 \\ 2003 & 23,283 & 23,283 \\ 2004 & 26,321 & 26,321 \\ 2005 & 29,099 & 29,099 \\ 2006 & 32,064 & 32,064 \\ 2007 & 34,982 & 34,982 \\ 2008 & 37,125 & 37,125 \\ 2009 & 37,709 & 37,709 \\ 2010 & 39,610 & 39,610 \\ 2011 & 41,801 & 41,801 \\ 2012 & 43,952 & 43,952 \\ 2013 & 45,243 & 45,243 \\ 2014 & 47,539 & 47,539 \\ 2015 & 49,834 & 49,834 \\ 2014 & \text { Not yet recorded } & \\ & & \end{array}$

You and your family may be eligible for valuable benefits:

When you die, your family may be eligible to receive survivors benefits.

Social Security may help you if you become disabledeven at a young age.

A young person who has worked and paid Social Security taxes in as few as two years can be eligible for disability benefits.

Social Security credits you earn move with you from job to job throughout your career.

Total Social Security and Medicare taxes paid over your working career through the last year reported on the chart above:

Estimated taxes paid for Social Security:

You paid:

Your employers paid:
$\$ 34,288$

$\$ 36,003$
Estimated taxes paid for Medicare:

You paid:

$\$ 8,420$

Your employers paid:

Note: Currently, you and your employer each pay a 6.2 percent Social Security tax on up to $\$ 127,200$ of your earnings and a $1.45 *$ percent Medicare tax on all your earnings. If you are self-employed, you pay the combined employee and employer amount, which is a 12.4 percent Social Security tax on up to $\$ 127,200$ of your net earnings and a $2.9 *$ percent Medicare tax on your entire net earnings.

*If you have earned income of more than $\$ 200,000$ (\$250,000 for married couples filing jointly), you must pay 0.9 percent more in Medicare taxes.

\section{Help Us Keep Your Earnings Record Accurate}

You, your employer and Social Security share responsibility for the accuracy of your earnings record. Since you began working, we recorded your reported earnings under your name and Social Security number. We have updated your record each time your employer (or you, if you're self-employed) reported your earnings.

Remember, it's your earnings, not the amount of taxes you paid or the number of credits you've earned, that determine your benefit amount. When we figure that amount, we base it on your average earnings over your lifetime. If our records are wrong, you may not receive all the benefits to which you're entitled.

Review this chart carefully using your own records to make sure our information is correct and that we've recorded each year you worked. You're the only person who can look at the earnings chart and know whether it is complete and correct.

Some or all of your earnings from last year may not be shown on your Statement. It could be that we still were processing last year's earnings reports when your Statement was prepared. Your complete earnings for last year will be shown on next year's Statement. Note: If you worked for more than one employer during any year, or if you had both earnings and self-employment income, we combined your earnings for the year.

There's a limit on the amount of earnings on which you pay Social Security taxes each year. The limit increases yearly. Earnings above the limit will not appear on your earnings chart as Social Security earnings. (For Medicare taxes, the maximum earnings amount began rising in 1991. Since 1994, all of your earnings are taxed for Medicare.)

Call us right away at 1-800-772-1213 (7 a.m.-7 p.m. your local time) if any earnings for years before last year are shown incorrectly. Please have your W-2 or tax return for those years available. (If you live outside the U.S., follow the directions at the bottom of page 4.) 


\section{Some Facts About Social Security}

\begin{abstract}
About Social Security and Medicare...
Social Security pays retirement, disability, family and survivors benefits. Medicare, a separate program run by the Centers for Medicare \& Medicaid Services, helps pay for inpatient hospital care, nursing care, doctors' fees, drugs, and other medical services and supplies to people age 65 and older, as well as to people who have been receiving Social Security disability benefits for two years or more. Medicare does not pay for long-term care, so you may want to consider options for private insurance. Your Social Security covered earnings qualify you for both programs. For more information about Medicare, visit www.medicare.gov or call 1-800-633-4227 (TTY 1-877-486-2048 if you are deaf or hard of hearing).
\end{abstract}

Retirement - If you were born before 1938, your full retirement age is 65 . Because of a 1983 change in the law, the full retirement age will increase gradually to 67 for people born in 1960 and later.

Some people retire before their full retirement age. You can retire as early as 62 and take benefits at a reduced rate. If you work after your full retirement age, you can receive higher benefits because of additional earnings and credits for delayed retirement.

Disability - If you become disabled before full retirement age, you can receive disability benefits after six months if you have:

- enough credits from earnings (depending on your age, you must have earned six to 20 of your credits in the three to 10 years before you became disabled); and

- a physical or mental impairment that's expected to prevent you from doing "substantial" work for a year or more or result in death.

If you are filing for disability benefits, please let us know if you are on active military duty or are a recently discharged veteran, so that we can handle your claim more quickly.

Family - If you're eligible for disability or retirement benefits, your current or divorced spouse, minor children or adult children disabled before age 22 also may receive benefits. Each may qualify for up to about 50 percent of your benefit amount.

Survivors - When you die, certain members of your family may be eligible for benefits:

- your spouse age 60 or older (50 or older if disabled, or any age if caring for your children younger than age 16); and

- your children if unmarried and younger than age 18, still in school and younger than 19 years old, or adult children disabled before age 22 .

If you are divorced, your ex-spouse could be eligible for a widow's or widower's benefit on your record when you die.
Extra Help with Medicare - If you know someone who is on Medicare and has limited resources and income, Extra Help is available for prescription drug costs. The Extra Help can help pay the monthly premiums, annual deductibles and prescription co-payments. To learn more or to apply, visit $w w w . s o c i a l s e c u r i t y . g o v$ or call 1-800-772-1213 (TTY 1-800-325-0778).

\section{Receive benefits and still work...}

You can work and still get retirement or survivors benefits. If you're younger than your full retirement age, there are limits on how much you can earn without affecting your benefit amount. When you apply for benefits, we'll tell you what the limits are and whether work would affect your monthly benefits. When you reach full retirement age, the earnings limits no longer apply.

\section{Before you decide to retire...}

Carefully consider the advantages and disadvantages of early retirement. If you choose to receive benefits before you reach full retirement age, your monthly benefits will be reduced.

To help you decide the best time to retire, we offer a free publication, When To Start Receiving Retirement Benefits (Publication No. 05-10147), that identifies the many factors you should consider before applying. Most people can receive an estimate of their benefit based on their actual Social Security earnings record by going to www.socialsecurity.gov/estimator. You also can calculate future retirement benefits by using the Social Security Benefit Calculators at www.socialsecurity.gov.

Other helpful free publications include:

- Retirement Benefits (No. 05-10035)

- Understanding The Benefits (No. 05-10024)

- Your Retirement Benefit: How It Is Figured (No. 05-10070)

- Windfall Elimination Provision (No. 05-10045)

- Government Pension Offset (No. 05-10007)

- Identity Theft And Your Social Security Number (No. 05-10064)

We also have other leaflets and fact sheets with information about specific topics such as military service, self-employment or foreign employment. You can request Social Security publications at our website, www.socialsecurity.gov, or by calling us at 1-800-772-1213. Our website has a list of frequently asked questions that may answer questions you have. We have easy-to-use online applications for benefits that can save you a telephone call or a trip to a field office.

You also may qualify for government benefits outside of Social Security. For more information on these benefits, visit www.benefits.gov.

If you need more information - Visit www.socialsecurity.gov on the Internet, contact any Social Security office, call 1-800-772-1213 or write to Social Security Administration, Office of Earnings Operations, P.O. Box 33026, Baltimore, MD 21290-3026. If you're deaf or hard of hearing, call TTY 1-800-325-0778. If you have questions about your personal information, you must provide your complete Social Security number. If your address is incorrect on this Statement, ask the IRS to send you a Form 8822. We don’t keep your address if you're not receiving Social Security benefits. 


\section{Your Social Security Statement}

Are you thinking about retirement? Are you ready for retirement?

We have tools that can help you!

- Estimate your future retirement benefits at socialsecurity.gov/estimator

- Apply for retirement, spouse's, Medicare, or disability benefits at socialsecurity.gov/applyforbenefits

- And once you receive benefits, manage your benefits at myaccount.socialsecurity.gov

Your Social Security Statement tells you about how much you or your family would receive in disability, survivor, or retirement benefits. It also includes our record of your lifetime earnings. Check out your earnings history, and let us know right away if you find an error. This is important because we base your benefits on our record of your lifetime earnings.

Social Security benefits are not intended to be your only source of income when you retire. On average, Social Security will replace about
To view your Social Security Statement online anytime create a my Social Security account today!

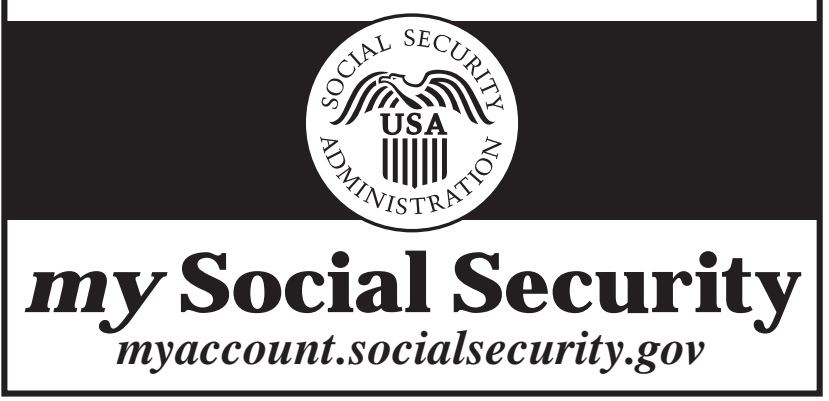

40 percent of your annual pre-retirement earnings. You will need other savings, investments, pensions, or retirement accounts to live comfortably when you retire.

To see your Statement online anytime, create a my Social Security account at myaccount.socialsecurity.gov.

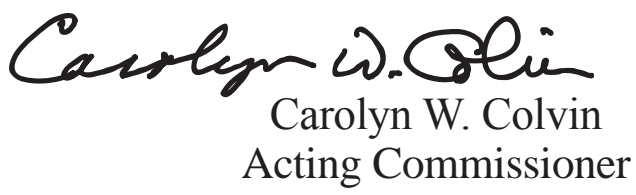




\section{Your Estimated Benefits}

\section{*Retirement You have earned enough credits to qualify for benefits. At your current earnings rate, if you}

continue working until...

your full retirement age (67 years), your payment would be about

\$ 1,827 a month

age 70 , your payment would be about

\$ 2,266 a month

age 62, your payment would be about

\$ 1,271 a month

*Disability You have earned enough credits to qualify for benefits. If you became disabled right now,

your payment would be about.....

\$ 1,809 a month

*Family If you get retirement or disability benefits, your spouse and children also may qualify for benefits.

*Survivors You have earned enough credits for your family to receive survivors benefits. If you die this

year, certain members of your family may qualify for the following benefits:

Your child

\$ 1,356 a month

Your spouse who is caring for your child.

1,356 a month

Your spouse, if benefits start at full retirement age.

\$ 1,809 a month

Total family benefits cannot be more than

3,298 a month

Your spouse or minor child may be eligible for a special one-time death benefit of \$255.

Medicare You have enough credits to qualify for Medicare at age 65. Even if you do not retire at age 65, be

sure to contact Social Security three months before your 65th birthday to enroll in Medicare.

* Your estimated benefits are based on current law. Congress has made changes to the law in the past and can do so at any time. The law governing benefit amounts may change because, by 2034, the payroll taxes collected will be enough to pay only about 79 percent of scheduled benefits.

We based your benefit estimates on these facts:

Your date of birth (please verify your name on page 1 and this date of birth)

April 5, 1957

Your estimated taxable earnings per year after 2017 .....

$\$ 45,468$

Your Social Security number (only the last four digits are shown to help prevent identity theft).

XXX-XX-1234

\section{How Your Benefits Are Estimated}

To qualify for benefits, you earn "credits" through your work up to four each year. This year, for example, you earn one credit for each $\$ 1,300$ of wages or self-employment income. When you've earned \$5,200, you've earned your four credits for the year. Most people need 40 credits, earned over their working lifetime, to receive retirement benefits. For disability and survivors benefits, young people need fewer credits to be eligible.

We checked your records to see whether you have earned enough credits to qualify for benefits. If you haven't earned enough yet to qualify for any type of benefit, we can't give you a benefit estimate now. If you continue to work, we'll give you an estimate when you do qualify.

What we assumed - If you have enough work credits, we estimated your benefit amounts using your average earnings over your working lifetime. For 2017 and later (up to retirement age), we assumed you'll continue to work and make about the same as you did in 2015 or 2016 . We also included credits we assumed you earned last year and this year.

Generally, the older you are and the closer you are to retirement, the more accurate the retirement estimates will be because they are based on a longer work history with fewer uncertainties such as earnings fluctuations and future law changes. We encourage you to use our online Retirement Estimator at www.socialsecurity.gov/estimator to obtain immediate and personalized benefit estimates.

We can't provide your actual benefit amount until you apply for benefits. And that amount may differ from the estimates stated above because:

(1) Your earnings may increase or decrease in the future.

(2) After you start receiving benefits, they will be adjusted for cost-of-living increases.
(3) Your estimated benefits are based on current law. The law governing benefit amounts may change.

(4) Your benefit amount may be affected by military service, railroad employment or pensions earned through work on which you did not pay Social Security tax. Visit www.socialsecurity.gov to learn more.

Windfall Elimination Provision (WEP) — In the future, if you receive a pension from employment in which you do not pay Social Security taxes, such as some federal, state or local government work, some nonprofit organizations or foreign employment, and you also qualify for your own Social Security retirement or disability benefit, your Social Security benefit may be reduced, but not eliminated, by WEP. The amount of the reduction, if any, depends on your earnings and number of years in jobs in which you paid Social Security taxes, and the year you are age 62 or become disabled. For more information, please see Windfall Elimination Provision (Publication No. 05-10045) at www.socialsecurity.gov/WEP.

Government Pension Offset (GPO) — If you receive a pension based on federal, state or local government work in which you did not pay Social Security taxes and you qualify, now or in the future, for Social Security benefits as a current or former spouse, widow or widower, you are likely to be affected by GPO. If GPO applies, your Social Security benefit will be reduced by an amount equal to two-thirds of your government pension, and could be reduced to zero. Even if your benefit is reduced to zero, you will be eligible for Medicare at age 65 on your spouse's record. To learn more, please see Government Pension Offset (Publication No. 05-10007) at www.socialsecurity.gov/GPO. 


$\begin{array}{ccc}\begin{array}{c}\text { Years You } \\ \text { Worked }\end{array} & \begin{array}{c}\text { Your Taxed } \\ \text { Social Security } \\ \text { Earnings }\end{array} & \begin{array}{c}\text { Your Taxed } \\ \text { Medicare } \\ \text { Earnings }\end{array} \\ 1973 & 218 & 218 \\ 1974 & 553 & 553 \\ 1975 & 1,032 & 1,032 \\ 1976 & 1,822 & 1,822 \\ 1977 & 2,561 & 2,561 \\ 1978 & 3,309 & 3,309 \\ 1979 & 4,326 & 4,326 \\ 1980 & 5,868 & 5,868 \\ 1981 & 7,634 & 7,634 \\ 1982 & 9,056 & 9,056 \\ 1983 & 10,416 & 10,416 \\ 1984 & 11,913 & 11,913 \\ 1985 & 13,247 & 13,247 \\ 1986 & 14,370 & 14,370 \\ 1987 & 15,953 & 15,953 \\ 1988 & 17,365 & 17,365 \\ 1989 & 18,617 & 18,617 \\ 1990 & 19,986 & 19,986 \\ 1991 & 21,213 & 21,213 \\ 1992 & 22,744 & 22,744 \\ 1993 & 23,315 & 23,315 \\ 1994 & 24,294 & 24,294 \\ 1995 & 25,597 & 25,597 \\ 1996 & 27,177 & 27,177 \\ 1997 & 29,061 & 29,061 \\ & & \end{array}$

$\begin{array}{ccc}\begin{array}{c}\text { Yours You } \\ \text { Worked }\end{array} & \begin{array}{c}\text { Yocial Security } \\ \text { Earnings }\end{array} & \begin{array}{c}\text { Your Taxed } \\ \text { Medicare } \\ \text { Earnings }\end{array} \\ 1998 & 30,873 & 30,873 \\ 1999 & 32,872 & 32,872 \\ 2000 & 34,902 & 34,902 \\ 2001 & 35,962 & 35,962 \\ 2002 & 36,516 & 36,516 \\ 2003 & 37,589 & 37,589 \\ 2004 & 39,453 & 39,453 \\ 2005 & 40,909 & 40,909 \\ 2006 & 42,753 & 42,753 \\ 2007 & 44,609 & 44,609 \\ 2008 & 45,451 & 45,451 \\ 2009 & 44,401 & 44,401 \\ 2010 & 44,938 & 44,938 \\ 2011 & 45,730 & 45,730 \\ 2012 & 46,289 & 46,289 \\ 2013 & 45,488 & 45,488 \\ 2014 & 45,585 & 45,585 \\ 2015 & 45,468 & 45,468 \\ 2014 & \text { Not yet recorded } & \end{array}$

Total Social Security and Medicare taxes paid over your working career through the last year reported on the chart above:

Estimated taxes paid for Social Security:

You paid:

Your employers paid:
$\$ 63,775$

$\$ 65,651$
Estimated taxes paid for Medicare:

You paid:

$\$ 15,375$

Your employers paid:
$\$ 15,375$

Note: Currently, you and your employer each pay a 6.2 percent Social Security tax on up to $\$ 127,200$ of your earnings and a $1.45^{*}$ percent Medicare tax on all your earnings. If you are self-employed, you pay the combined employee and employer amount, which is a $\mathbf{1 2 . 4}$ percent Social Security tax on up to $\$ \mathbf{1 2 7 , 2 0 0}$ of your net earnings and a $2.9 *$ percent Medicare tax on your entire net earnings.

*If you have earned income of more than $\$ 200,000$ (\$250,000 for married couples filing jointly), you must pay 0.9 percent more in Medicare taxes.

\section{Help Us Keep Your Earnings Record Accurate}

You, your employer and Social Security share responsibility for the accuracy of your earnings record. Since you began working, we recorded your reported earnings under your name and Social Security number. We have updated your record each time your employer (or you, if you're self-employed) reported your earnings.

Remember, it's your earnings, not the amount of taxes you paid or the number of credits you've earned, that determine your benefit amount. When we figure that amount, we base it on your average earnings over your lifetime. If our records are wrong, you may not receive all the benefits to which you're entitled.

Review this chart carefully using your own records to make sure our information is correct and that we've recorded each year you worked. You're the only person who can look at the earnings chart and know whether it is complete and correct.

Some or all of your earnings from last year may not be shown on your Statement. It could be that we still were processing last year's earnings reports when your Statement was prepared. Your complete earnings for last year will be shown on next year's Statement. Note: If you worked for more than one employer during any year, or if you had both earnings and self-employment income, we combined your earnings for the year.

There's a limit on the amount of earnings on which you pay Social Security taxes each year. The limit increases yearly. Earnings above the limit will not appear on your earnings chart as Social Security earnings. (For Medicare taxes, the maximum earnings amount began rising in 1991. Since 1994, all of your earnings are taxed for Medicare.)

Call us right away at 1-800-772-1213 (7 a.m.-7 p.m. your local time) if any earnings for years before last year are shown incorrectly. Please have your W-2 or tax return for those years available. (If you live outside the U.S., follow the directions at the bottom of page 4.) 


\section{Some Facts About Social Security}

\begin{abstract}
About Social Security and Medicare...
Social Security pays retirement, disability, family and survivors benefits. Medicare, a separate program run by the Centers for Medicare \& Medicaid Services, helps pay for inpatient hospital care, nursing care, doctors' fees, drugs, and other medical services and supplies to people age 65 and older, as well as to people who have been receiving Social Security disability benefits for two years or more. Medicare does not pay for long-term care, so you may want to consider options for private insurance. Your Social Security covered earnings qualify you for both programs. For more information about Medicare, visit www.medicare.gov or call 1-800-633-4227 (TTY 1-877-486-2048 if you are deaf or hard of hearing).
\end{abstract}

Retirement - If you were born before 1938, your full retirement age is 65 . Because of a 1983 change in the law, the full retirement age will increase gradually to 67 for people born in 1960 and later.

Some people retire before their full retirement age. You can retire as early as 62 and take benefits at a reduced rate. If you work after your full retirement age, you can receive higher benefits because of additional earnings and credits for delayed retirement.

Disability - If you become disabled before full retirement age, you can receive disability benefits after six months if you have:

- enough credits from earnings (depending on your age, you must have earned six to 20 of your credits in the three to 10 years before you became disabled); and

- a physical or mental impairment that's expected to prevent you from doing "substantial" work for a year or more or result in death.

If you are filing for disability benefits, please let us know if you are on active military duty or are a recently discharged veteran, so that we can handle your claim more quickly.

Family - If you're eligible for disability or retirement benefits, your current or divorced spouse, minor children or adult children disabled before age 22 also may receive benefits. Each may qualify for up to about 50 percent of your benefit amount.

Survivors - When you die, certain members of your family may be eligible for benefits:

- your spouse age 60 or older (50 or older if disabled, or any age if caring for your children younger than age 16); and

- your children if unmarried and younger than age 18, still in school and younger than 19 years old, or adult children disabled before age 22 .

If you are divorced, your ex-spouse could be eligible for a widow's or widower's benefit on your record when you die.
Extra Help with Medicare - If you know someone who is on Medicare and has limited resources and income, Extra Help is available for prescription drug costs. The Extra Help can help pay the monthly premiums, annual deductibles and prescription co-payments. To learn more or to apply, visit $w w w . s o c i a l s e c u r i t y . g o v$ or call 1-800-772-1213 (TTY 1-800-325-0778).

\section{Receive benefits and still work...}

You can work and still get retirement or survivors benefits. If you're younger than your full retirement age, there are limits on how much you can earn without affecting your benefit amount. When you apply for benefits, we'll tell you what the limits are and whether work would affect your monthly benefits. When you reach full retirement age, the earnings limits no longer apply.

\section{Before you decide to retire...}

Carefully consider the advantages and disadvantages of early retirement. If you choose to receive benefits before you reach full retirement age, your monthly benefits will be reduced.

To help you decide the best time to retire, we offer a free publication, When To Start Receiving Retirement Benefits (Publication No. 05-10147), that identifies the many factors you should consider before applying. Most people can receive an estimate of their benefit based on their actual Social Security earnings record by going to www.socialsecurity.gov/estimator. You also can calculate future retirement benefits by using the Social Security Benefit Calculators at www.socialsecurity.gov.

Other helpful free publications include:

- Retirement Benefits (No. 05-10035)

- Understanding The Benefits (No. 05-10024)

- Your Retirement Benefit: How It Is Figured (No. 05-10070)

- Windfall Elimination Provision (No. 05-10045)

- Government Pension Offset (No. 05-10007)

- Identity Theft And Your Social Security Number (No. 05-10064)

We also have other leaflets and fact sheets with information about specific topics such as military service, self-employment or foreign employment. You can request Social Security publications at our website, www.socialsecurity.gov, or by calling us at 1-800-772-1213. Our website has a list of frequently asked questions that may answer questions you have. We have easy-to-use online applications for benefits that can save you a telephone call or a trip to a field office.

You also may qualify for government benefits outside of Social Security. For more information on these benefits, visit www.benefits.gov.

If you need more information - Visit www.socialsecurity.gov on the Internet, contact any Social Security office, call 1-800-772-1213 or write to Social Security Administration, Office of Earnings Operations, P.O. Box 33026, Baltimore, MD 21290-3026. If you're deaf or hard of hearing, call TTY 1-800-325-0778. If you have questions about your personal information, you must provide your complete Social Security number. If your address is incorrect on this Statement, ask the IRS to send you a Form 8822. We don't keep your address if you're not receiving Social Security benefits. 


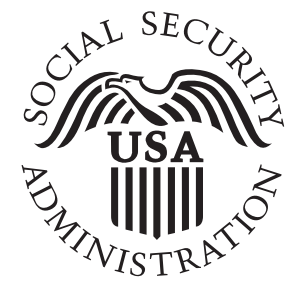

\section{Thinking of} retiring?

www.socialsecurity.gov

\section{Some things to consider}

$\mathbf{R}$ etirement can have more than Rone meaning these days. It can mean that you have applied for Social Security retirement benefits or that you are no longer working. Or it can mean that you have chosen to receive Social Security while still working, either full or part-time. All of these choices are available to you. Your retirement decisions can have very real effects on your ability to maintain a comfortable retirement.
If you retire early, you may not have enough income to enjoy the years ahead of you. Likewise, if you retire late, you'll have a larger income, but fewer years to enjoy it. Everyone needs to try to find the right balance, based on his or her own circumstances.

We hope the following information will help you as you plan for your future retirement and consider your retirement options.

\section{What is the best option for you?}

Everyone's situation is different. That is why Social Security has created several retirement planners to help you decide what would be best for you and your family. Social Security has an online calculator that can provide immediate and accurate retirement benefit estimates to help you plan for your retirement.

The online Retirement Estimator is a convenient, secure, and quick financial planning tool. It uses your own earnings record information, thereby eliminating any need to manually key in years of earnings information. The estimator also will let you create "what if" scenarios. You can, for example, change your "stop work" date or expected future earnings to create and compare different retirement options. To use the Retirement Estimator, go to our website at www.socialsecurity.gov/estimator.

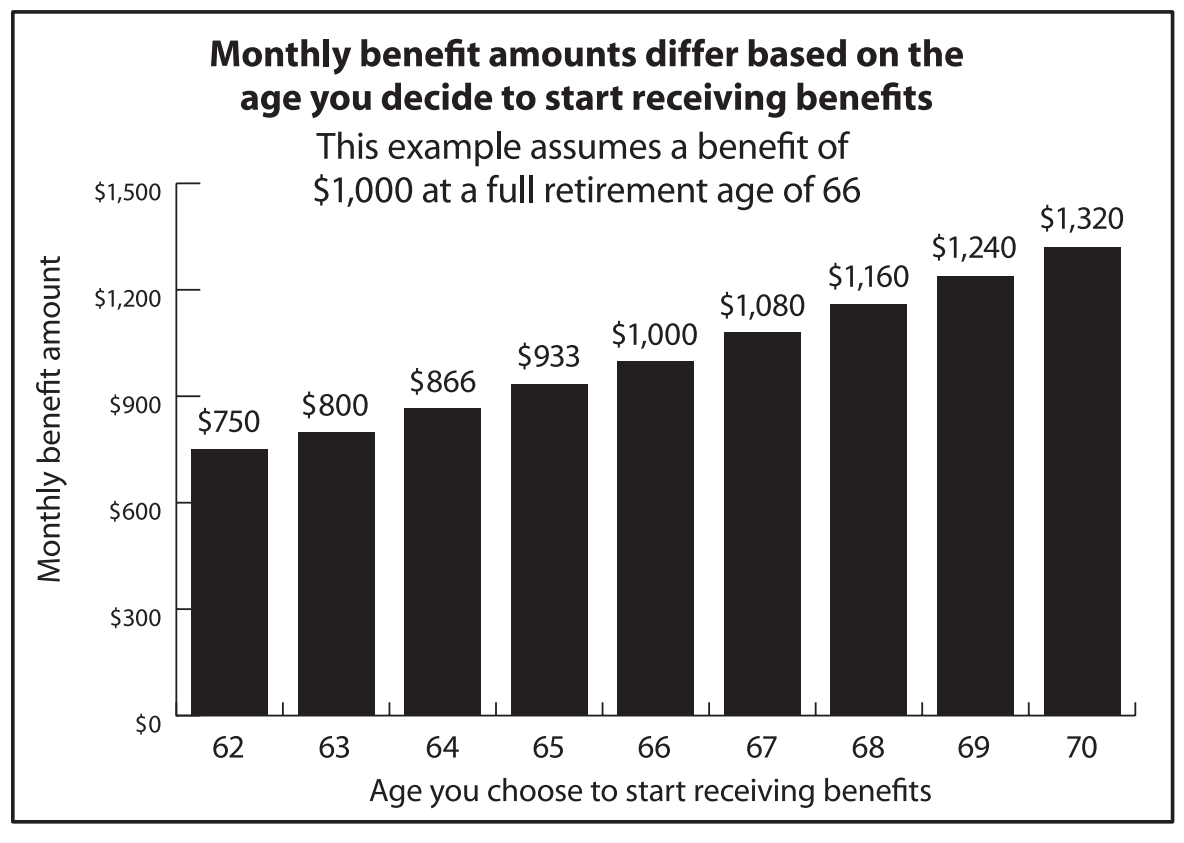
for you to actually retire, remember to complete your application three months before the month in which you want retirement benefits to begin.

\section{It's so easy to apply online for benefits}

The easiest way to apply for Social Security retirement benefits is to go online at www.socialsecurity.gov/ applyforbenefits. If you do not have access to the Internet, you can call 1-800-772-1213 (TTY number, 1-800-325-0778) between 7 a.m. and 7 p.m., Monday through Friday, to apply by phone. You also can apply at any Social Security office. To avoid having to wait, call first to make an appointment. 


\section{Receiving benefits while you work}

When you reach your full retirement age, you can work and earn as much as you want and still receive your full Social Security benefit payment. If you are younger than full retirement age and if your earnings exceed certain dollar amounts, some of your benefit payments during the year will be withheld.

This does not mean you must try to limit your earnings. If we withhold some of your benefits because you continue to work, we will pay you a higher monthly benefit amount when you reach your full retirement age. In other words, if you would like to work and earn more than the exempt amount, you should know that it will not, on average, reduce the total value of lifetime benefits you receive from Social Security — and may actually increase them.
Here is how this works: after you reach full retirement age, we will recalculate your benefit amount to give you credit for any months in which you did not receive some benefit because of your earnings. In addition, as long as you continue to work, we will check your record every year to see whether the additional earnings will increase your monthly benefit.

Many people can continue to work and still receive retirement benefits. If you want more information on how earnings affect your retirement benefits, ask for How Work Affects Your Benefits (Publication No. 05-10069), which has current annual and monthly earnings limits, and is available on our website.

\section{Retirement age considerations}

\section{Full retirement age}

For persons born during the years 1943-1954, the full retirement age is 66. If you were not born in this period, you can find your full retirement age on page 2 of your Social Security Statement.

\section{Retiring early}

If you've earned 40 credits (credits are explained on page 2 of your Statement), you can start receiving Social Security benefits at 62 or at any month between 62 and full retirement age. However, your benefits will be reduced based on the number of months you receive benefits before you reach full retirement age.

If your full retirement age is 66, benefits will be reduced:

25 percent at age 62;

20 percent at age 63;

$13 \frac{1}{3}$ percent at age 64 ; or

$62 / 3$ percent at age 65 .

\section{Delaying retirement}

You may decide to wait beyond your full retirement age before choosing to receive benefits. If so, your benefit will be increased by a certain percentage for each month you don't receive benefits between your full retirement age and age 70 . This table shows the rate your benefits increase if you delay retiring.

\begin{tabular}{cc}
\hline Year of birth & Yearly increase rate \\
\hline $1941-1942$ & $7.5 \%$ \\
1943 or later & $8.0 \%$ \\
\hline
\end{tabular}

\section{Rules that may affect your survivor}

If you are married and die before your spouse, he or she may be eligible for a benefit based on your work record. If you start benefits before your full retirement age, we cannot pay your surviving spouse a full benefit from your record. Also, if you wait until after your full retirement age to begin benefits, the surviving spouse benefits based on your record will be higher.
Need more

\section{information?}

You can find answers to frequently asked questions about Social Security, learn about factors that could affect your benefits, and much more by visiting Social Security online at $\boldsymbol{w} w \mathbf{w}$. socialsecurity.gov.

If you do not have access to the Internet, you can get information about Social Security by calling 1-800-772-1213 (1-800-325-0778 for the deaf or hard of hearing) or by visiting a local Social Security office.

\section{Other useful websites}

www.mymoney.gov

This website contains calculators

for financial planning and information on money-related matters, such as retirement planning and starting a small business.

\section{www.dol.gov/ebsa/pdf/ nearretirement.pdf}

Have you determined how much money you will need in retirement? There are many tools available to help you, such as the Taking the Mystery Out of Retirement Planning Workbook available at this link.

\section{www.sec.gov/investor/ seniors.shtml}

Are you looking for information about the investment options available to you as you enter retirement? The Securities and Exchange Commission has a wealth of information on different investment products and topics available at this website.

\section{www.usa.gov/topics/ seniors.shtml}

This website has a variety of resources for seniors on topics including retirement planning, housing, and health.

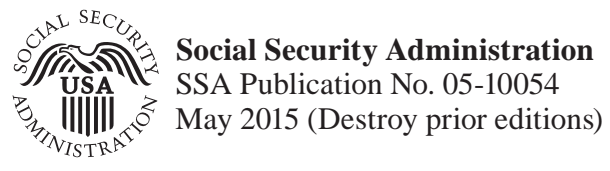




\section{RECENT WORKING PAPERS FROM THE CENTER FOR RETIREMENT RESEARCH AT BOSTON COLLEGE}

Actuarial Inputs and the Valuation of Public Pension Liabilities and Contribution Requirements: A Simulation Approach Gang Chen and David S. T. Matkin, May 2017

Why Are U.S. Households Claiming Social Security Later? Wenliang Hou, Alicia H. Munnell, Geoffrey T. Sanzenbacher, and Yinji Li, April 2017

Rising Inequality in Life Expectancy by Socioeconomic Status Geoffrey T. Sanzenbacher, Anthony Webb, Candace M. Cosgrove, and Natalia S. Orlova, April 2017

The Effect of Job Mobility on Retirement Timing by Education Geoffrey T. Sanzenbacher, Steven A. Sass, and Christopher M. Gillis, February 2017

Would Reducing the Price of Employing an Older Worker Improve Labor Market Outcomes by Socioeconomic Status? Evidence from Health Insurance Premium Restrictions Matthew S. Rutledge and Caroline V. Crawford, December 2016

The Impact of Massachusetts Health Insurance Reform on Labor Mobility Norma B. Coe, Wenliang Hou, Alicia H. Munnell, Patrick J. Purcell, and Matthew S. Rutledge, December 2016

Work, Retirement, and Social Networks at Older Ages Eleonora Patacchini and Gary V. Engelhardt, November 2016

Calculating Expected Social Security Benefits by Race, Education, and Claiming Age Geoffrey T. Sanzenbacher and Jorge D. Ramos-Mercado, November 2016

Do Late-Career Wages Boost Social Security More for Women than Men? Matthew S. Rutledge and John E. Lindner, November 2016

Cognitive Impairment and Social Security's Representative Payee Program Anek Belbase and Geoffrey T. Sanzenbacher, November 2016

How Would Reducing the Price of Older Workers Improve Labor Market Outcomes by Socioeconomic Status? Evidence from Health Insurance Premium Restrictions Matthew S. Rutledge and Caroline V. Crawford, October 2016

All working papers are available on the Center for Retirement Research website (http://crr.bc.edu) and can be requested by e-mail (crr@bc.edu) or phone (617-552-1762). 